

\author{
UNIVERSIDADE DE BRASÍLIA \\ FACULDADE DE TECNOLOGIA \\ DEPARTAMENTO DE ENGENHARIA ELETRICA
}

\title{
INSTRUMENTAÇÃO E CONTROLE EM CICLISMO ASSISTIDO POR ESTIMULAÇÃO ELÉTRICA PARA INDIVÍDUOS COM LESÃO MEDULAR
}

\section{LUCAS OLIVEIRA DA FONSECA}

DISSERTAÇÃO DE MESTRADO SUBMETIDA AO DEPARTAMENTO DE ENGENHARIA ELÉTRICA DA FACULDADE DE TECNOLOGIA DA UNIVERSIDADE DE BRASÍLIA COMO PARTE DOS REQUISITOS NECESSÁRIOS PARA A OBTENÇÃO DO GRAU DE MESTRE EM ENGENHARIA DE SISTEMAS ELETRÔNICOS E AUTOMAÇÃO.

APROVADA POR:

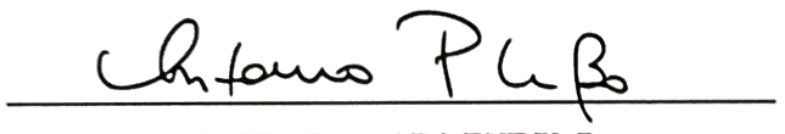

Prof. Antônio Padilha Lanari Bó, ENE/UnB

(Orientador)

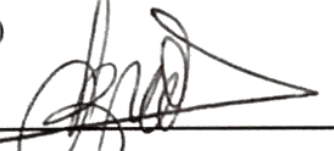

Dra. Christine Azevedo-Coste, INRIA Sophia Antipolis Examinador Ex́xterno

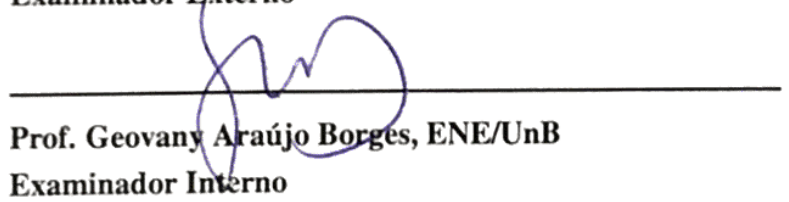

BRASÍLIA, 14 DE DEZEMBRO DE 2015. 


\section{FICHA CATALOGRÁFICA}

\section{FONSECA, LUCAS OLIVEIRA DA}

Instrumentação e controle em ciclismo assistido por estimulação elétrica para indivíduos com lesão medular [Distrito Federal] 2015.

xi, 84p., 210 x 297 mm (ENE/FT/UnB, Mestre, Engenharia Elétrica, 2015).

DISSERTAÇÃO DE MESTRADO - Universidade de Brasília, Faculdade de Tecnologia.

Departamento de Engenharia Elétrica

1. Estimulação Elétrica Funcional

2. Neuroengenharia

3. Esporte adaptado

4. Reabilitação

I. ENE/FT/UnB

II. Título (série)

\section{REFERÊNCIA BIBLIOGRÁFICA}

FONSECA, L.O. (2015). Instrumentação e controle em ciclismo assistido por estimulação elétrica para indivíduos com lesão medular, DISSERTAÇÃO DE MESTRADO em Engenharia Elétrica, Publicação PPGENE.TD-612/15, Departamento de Engenharia Elétrica, Universidade de Brasília, Brasília, DF, 84p.

\section{CESSÃO DE DIREITOS}

AUTOR: Lucas Oliveira da Fonseca

TÍTULO: Instrumentação e controle em ciclismo assistido por estimulação elétrica para indivíduos com lesão medular.

GRAU: Mestre $\quad$ ANO: 2015

É concedida à Universidade de Brasília permissão para reproduzir cópias desta dissertação de mestrado e para emprestar ou vender tais cópias somente para propósitos acadêmicos e científicos. O autor reserva outros direitos de publicação e nenhuma parte dessa dissertação de mestrado pode ser reproduzida sem autorização por escrito do autor.

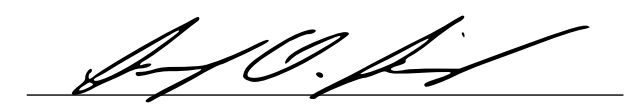

Lucas Oliveira da Fonseca

Departamento de Eng. Elétrica (ENE) - FT

Universidade de Brasília (UnB)

Campus Darcy Ribeiro

CEP 70919-970 - Brasília - DF - Brasil 
à minha família 


\section{AGRADECIMENTOS}

Quando me formei engenheiro, estava ansioso para começar a trabalhar em alguma grande empresa, fazer carreira, me tornar um grande executivo. Juntei minhas coisas, me despedi da minha família e amigos, e iniciei a busca pelos meus sonhos. Passei dois anos morando em outra cidade, convivendo com outras pessoas, enfim, vivendo uma vida bem diferente daquela que conhecia. Foi um tempo de desenvolvimento intenso, tanto profissional quanto pessoal. Apesar de ter trabalhado muito e crescido muito como engenheiro, acredito que o maior aprendizado tenha sido sobre mim mesmo. Minhas prioridades ficaram mais claras e meus objetivos e sonhos pareciam ter mudado. Percebi que, mais do que uma empresa, ou uma carreira, eu queria ter um propósito. Depois de muita reflexão, muitas conversas, e muitas dúvidas decidi seguir um caminho ligado à saúde e bem estar das pessoas, sem contudo me distanciar da engenharia. Depois de pesquisar sobre o assunto, decidi que precisava expandir meus conhecimentos, e resolvi iniciar o mestrado ligado à engenharia biomédica. Largar a minha vida de engenheiro empregado e independente foi muito difícil, mas o apoio dos meus familiares e amigos foi total e fundamental. Hoje me sinto plenamente realizado e motivado para fazer pesquisa e desenvolvimento de tecnologias para a saúde e qualidade de vida das pessoas.

Por isso eu quero agradecer profundamente aos meus pais pois, mais do que apoio financeiro para despesas diárias ou acadêmicas, sempre me incentivaram a seguir meu coração e meus sonhos, $e$ sempre me falaram "se você estiver feliz, nós também estaremos" e "faça o que você ama, e você receberá tudo que precisa”.

Agradeço também à minha noiva, Carol, pois passamos por momentos difíceis de saudade e solidão, mas mesmo assim ela sempre me apoiou em todas as decisões. Eu a tenho no coração com muito amor.

Quando voltei para a universidade depois de anos no mercado de trabalho, tive dificuldades na readaptação. A orientação e amizade do professor Antônio foram primordiais para que eu conseguisse sucesso nos meus trabalhos e, acima de tudo, desenvolvesse um grande interesse pela carreira acadêmica. Ele é um professor que admiro, e um pesquisador com quem pretendo trabalhar muito ainda.

Eu gostaria de agradecer pessoalmente a todos que me ajudaram na trajetória desse mestrado. Aos irmão, primos, avós, e todos os familiares por providenciarem momentos de alegria e conforto, sempre trazendo a segurança da família. Aos amigos, muito obrigado por perguntarem como o trabalho está indo, se eu preciso de ajuda, ou até mesmo por tentarem entender o que eu faço. Aos colegas de laboratório (e amigos também!), obrigado por dividirem suas angústias comigo, e minhas angústias com vocês. Obrigado por me ajudar quando precisei, e obrigado por me deixar ajudar em trabalhos tão interessantes. Aos colegas de disciplinas, obrigado pelos grupos de estudos e trabalhos. Aos professores, obrigado por me acatarem em suas turmas e projetos. Aos "guerreiros" que me ajudaram na revisão deste texto, muito obrigado!

Enfim, a todos que participam ou participaram da minha vida até agora, tem um pouco de cada um neste trabalho. $O$ certo era colocar o nome de todos na capa, mas espero fazer justiça à toda ajuda que recebi e pela qual sou eternamente grato. 


\title{
RESUMO
}

\section{INSTRUMENTAÇÃO E CONTROLE EM CICLISMO ASSISTIDO POR ESTIMULAÇÃO ELÉTRICA PARA INDIVÍDUOS COM LESÃO MEDULAR}

\author{
Autor: Lucas Oliveira da Fonseca \\ Orientador: Prof. Antônio Padilha Lanari Bó, ENE/UnB \\ Programa de Pós-graduação em Engenharia Elétrica
}

Brasília, 14 de dezembro de 2015

Palavras chave: Estimulação Elétrica Funcional; Neuroengenharia; Esporte adaptado; Reabilitação.

O sistema nervoso é responsável por grande parte das funções do corpo humano. Ele pode ser dividido em sistema nervoso central e sistema nervoso periférico. O sistema nervoso central compreende o encéfalo e a medula espinhal. Uma lesão na medula espinhal, seja ela traumática ou não, pode causar rompimento dos nervos e interrupção dos caminhos neurais. Se isso acontecer, todas as funções abaixo do nível da lesão serão parcial ou totalmente comprometidas. Uma das consequências mais evidentes de lesão medular é a perda da função motora. Uma lesão de nível torácica ou mais baixa torna a pessoa paraplégica, e uma lesão de nível cervical torna a pessoa tetraplégica. Além disso, essa condição pode acarretar incontinência urinária, perda de densidade óssea, disfunções sexuais e depressão. Além de fisioterapia tradicional, existem outras técnicas utilizadas na reabilitação. Entre elas, estimulação elétrica funcional possui a vantagem de potencializar a plasticidade do sistema nervoso ao estimular, simultaneamente, fibras nervosas aferentes e eferentes. Este trabalho estuda o uso dessa técnica para estimular membros inferiores de indivíduos para ciclismo em um contexto de reabilitação e esporte. São realizado testes com diferentes estratégias de controle e seus resultados são comparados entre si e com a literatura. Os resultados dos testes mostram que o controle em malha fechada com um controlador PI e uma segunda malha de controle que se adequa à cadência da pedalada proporciona um exercício que pode demorar mais de 5 minutos. Conclui-se que a estimulação elétrica, aliada à estratégias de controle em malha fechada, é uma tecnologia promissora para a reabilitação e prática de ciclismo em indivíduos com lesão medular. 


\section{ABSTRACT}

\section{Author: Lucas Oliveira da Fonseca}

Supervisor: Prof. Antônio Padilha Lanari Bó, ENE/UnB

\section{Electrical Engineering Graduation Program}

Brasília, 14th December 2015

Keywords: Funtctional Electrical Stimulation; Neuroengineering; Disabled sports; Rehabilitation.

The nervous system is responsible for many of the human body functions. It can be divided in central nervous system and peripheral nervous system. The central nervous system is the the brain and the spinal cord. A spinal cord injury, traumatic or not, can cause nerve's ruptures and neural pathway's disruptions. Were it to happen, all body functions below the injury level would be partially or completely compromised. One of the most apparent consequence is the loss of motor function. A thoracic or lower level injury will make the person paraplegic, and a cervical level injury will make the person quadriplegic. Furthermore, this condition can cause urinary incontinence, loss of bone density, sexual dysfunction and depression. Besides traditional physiotherapy, there are other techniques used in rehabilitation. Among them, functional electrical stimulation has the advantage of induce the nervous system's plasticity as it stimulates, at the same time, efferent and afferent neural fibers. This work investigates this technique to stimulate individual's lower limbs for cycling in the context of rehabilitation and sport. Test with different control strategies are performed and the results are compared to each other and to the literature. The test's results show that closed loop control with a PI controller and a second loop that adapts to the cadence provides a longer than 5 minutes exercise session. It is concluded that electrical stimulation, along closed loop strategies, is a promising technology for rehabilitation and cycling for spinal cord injury individuals. 


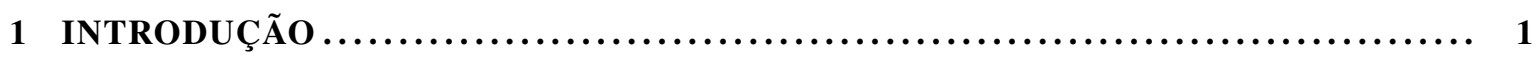

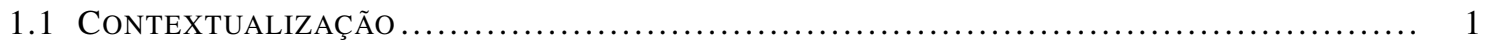

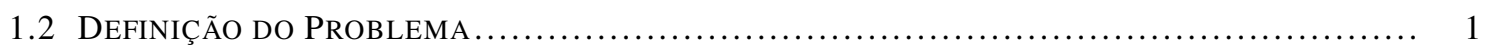

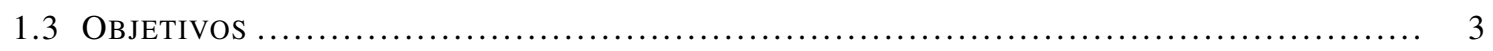

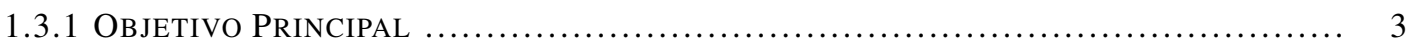

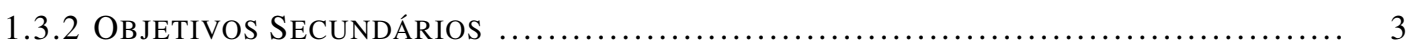

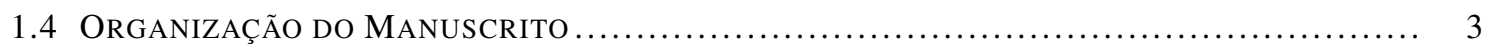

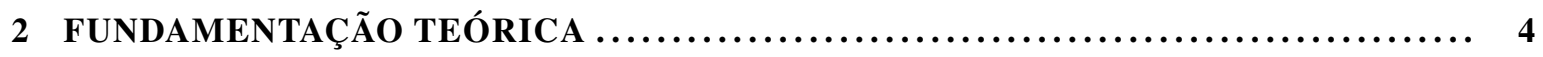

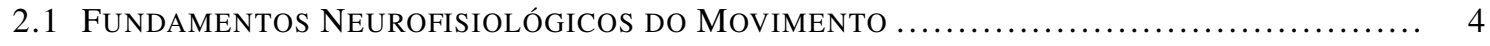

2.1.1 Sistema Nervoso, Neurônios E Nervos ................................... 4

2.1.2 Fisiologia, Contração Muscular e conexões entre Sistema Nervoso E

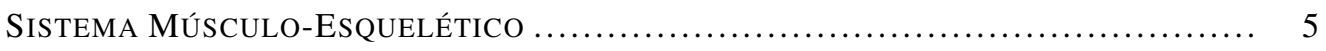

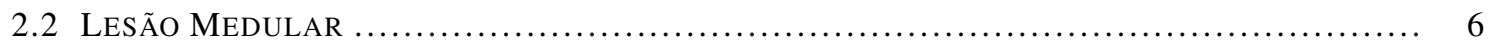

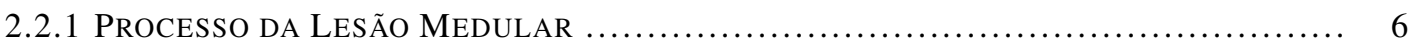

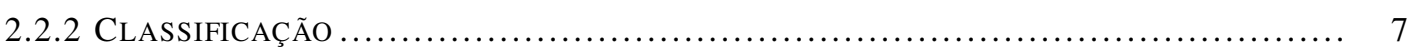

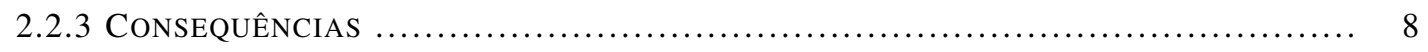

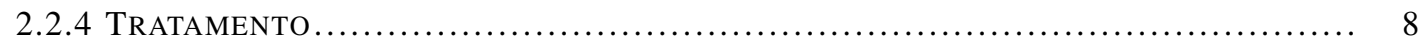

2.2.4.1 NEURORREGENERAÇÃO .............................................. 8

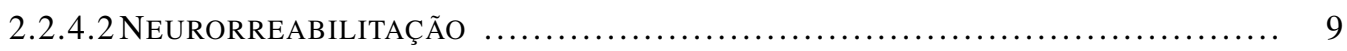

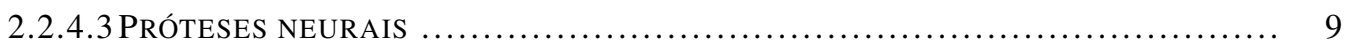

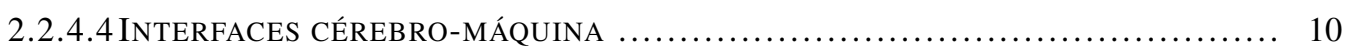

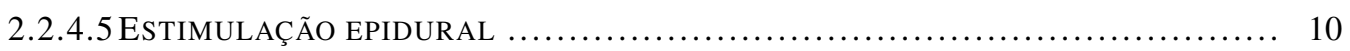

2.2.4.6 ESTIMULAÇÃo ElÉTRICA FUnCIONAL .................................. 11

2.2.4.7 MiCROESTIMULAÇÃO INTRAESPINHAL ................................. 11

2.2.4.8 MiCROESTIMULAÇÃO INTRACORTICAL ..................................... 11

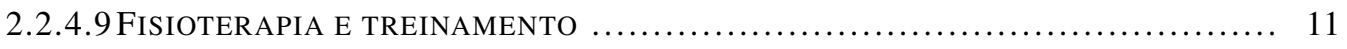

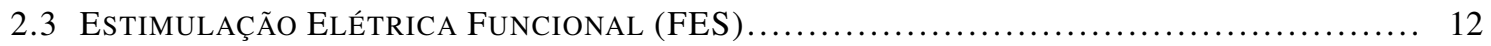

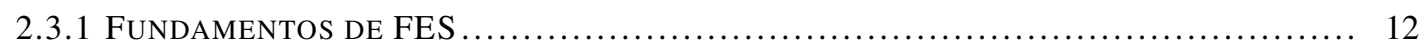

2.3.2 EletroestimulaÇão de SUPERfície E IMPlantes, E OS ELETROdos ENVOLVIDOS. 13

2.3.3 Parâmetros de Estimulação Elétrica e suas FunÇões ...................... 15

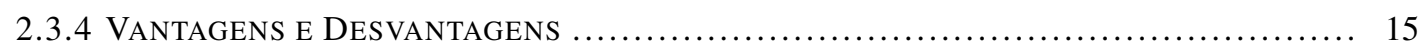

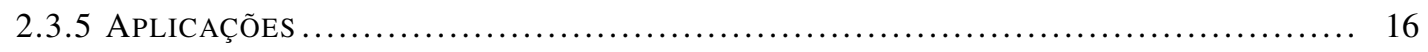

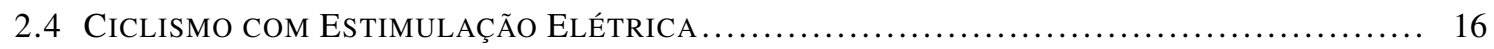

2.4.1 BENEFÍ́CIOS E LIMITAÇÕES ................................................ 16

2.4.2 Plataformas experimentais ............................................... 17

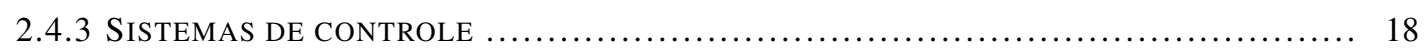

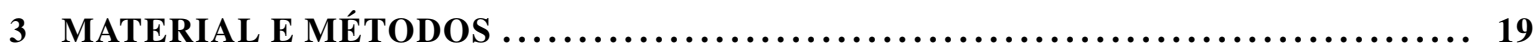

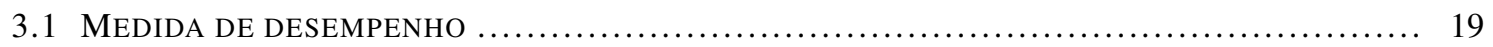

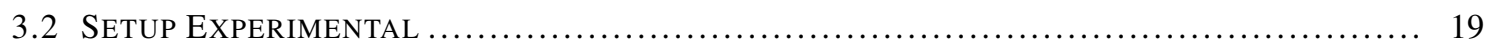




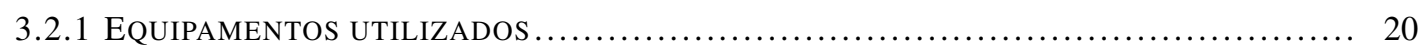

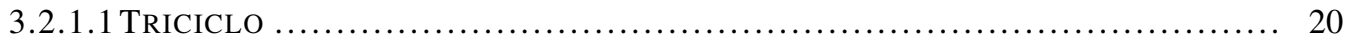

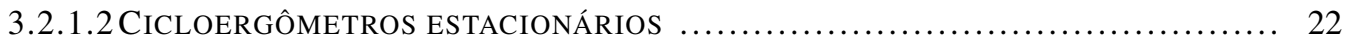

3.2.1.3 ROLO DE TREINAMENTO ........................................... 22

3.2.1.4 ESTIMULADOR ELÉTRICO ......................................... 24

3.2.1.5 UNIDADE DE MEDIDA INERCIAL ....................................... 24

3.2.1.6 SISTEMA EMBARCADO DE CONTROLE .................................... 24

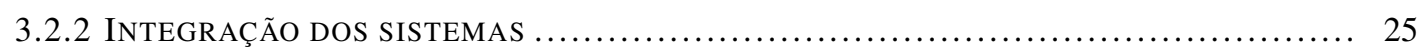

3.2.2.1 Unidade DE MEdiÇão INERCIAL ..................................... 26

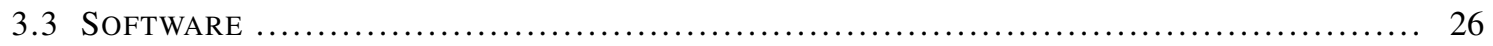

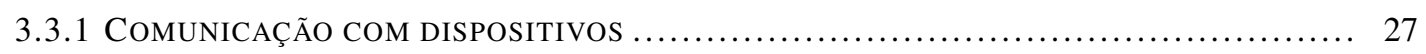

3.3.1.1 COMUNICAÇÃO COM AS IMUS ....................................... 27

3.3.1.2 COMUNICAÇÃO COM O ESTIMULADOR ................................. 28

3.3.2 Algoritmo de Controle em Tempo Real ................................ 29

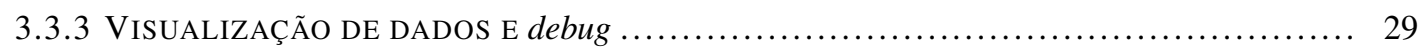

3.3 .4 APLICATIVOS DE APOIO ................................................... 30

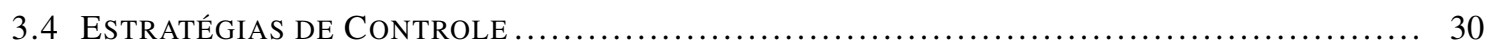

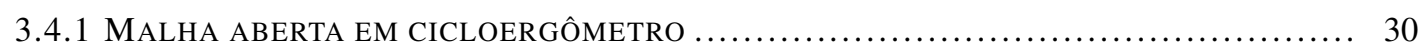

3.4.2 PI COM PERFIL DE ESTIMULAÇÃo ADAPTATIVO COM A VELOCIDAdE DA PEDIVELA ... 32

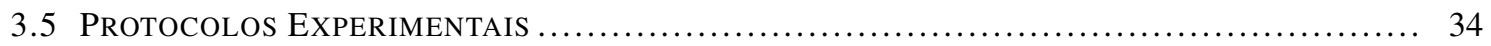

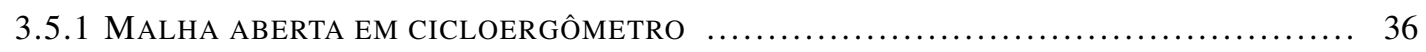

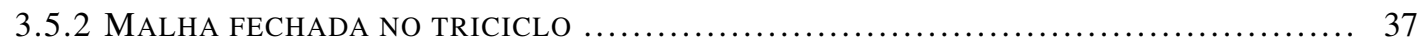

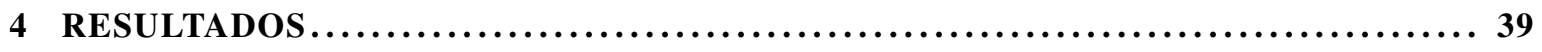

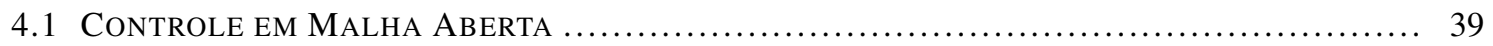

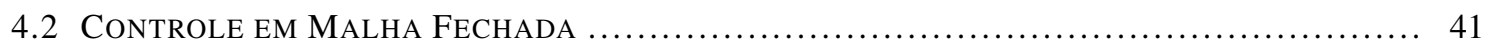

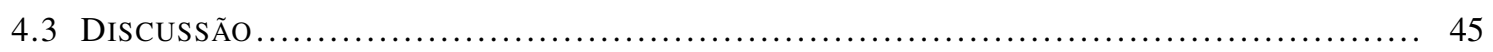

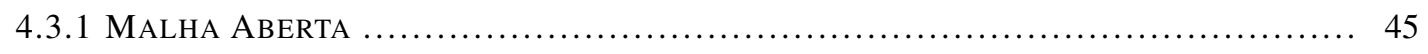

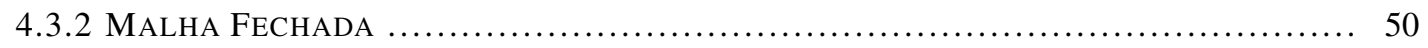

4.3 .2 .1 ANÁLISE DE FADIGA ............................................. 50

4.3.2.2 AnÁlise do Controle de CadÊnCIA ................................. 52

4.3.2.3 AnÁlise do Perfil Adaptativo e Atrasos envolvidos ................. 53

4.3 .3 Aspectos Gerais ........................................................ 53

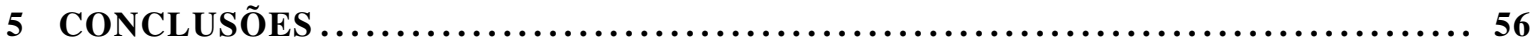

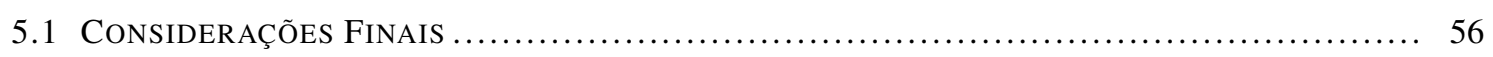

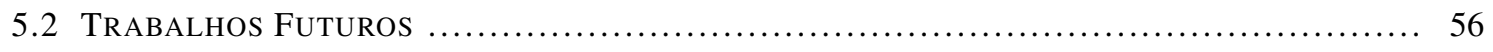

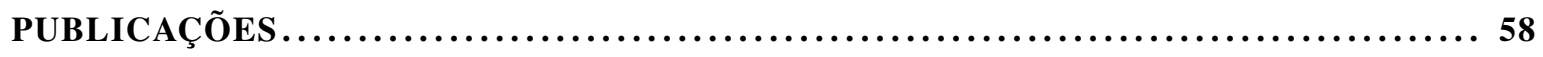

REFERÊNCIAS BIBLIOGRÁFICAS..................................... 61

$\begin{array}{llr}\text { I APENDICES } & 67\end{array}$

$\begin{array}{llr}\text { II AnEXOS } & 81\end{array}$ 
1.1 Fluxograma para indicação de tratamentos para lesão medular[1] ................................... 2

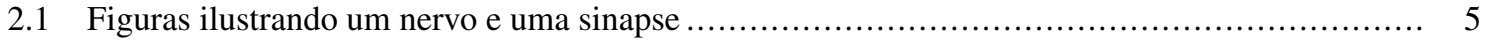

2.2 Divisão da medula espinhal em segmentos. Fonte: https://commons.wikimedia.org/wiki/File:Diagram_of_the_spinal_cord_CRUK_046.svg. 7

2.3 Exemplos de equipamentos utilizados em neurorreabilitação. ..................................... 10

2.4 Ativação muscular em função da frequência de potenciais de ação. Em vermelho os potenciais de ação. Em azul o nível de contração muscular. Fonte: http://humanphysiology.academy/ ....... 13

2.5 Comparação entre estimulação regulada por corrente (A) e regulada por tensão (B). Os sinais superiores são sinais de saída do estimulador e os sinais inferiores são a carga efetivamente sendo entregue ao músculo. Figura adaptada de [2]

2.6 Diversos formatos de onda para estimulação elétrica e seus efeitos em diferentes fatores. O símbolo usado para quantificar o efeito é uma representação simples de um potencial de ação. Quanto mais potenciais de ação, melhor o efeito. Em outras palavras, quanto mais potenciais de ação, menor o limiar de ativação, menor o nível de corrosão dos eletrodos, e menor o dano ao tecido biológico.

2.7 Eletrodos utilizados em FES. A escala fornece uma noção do tamanho. ............................ 15

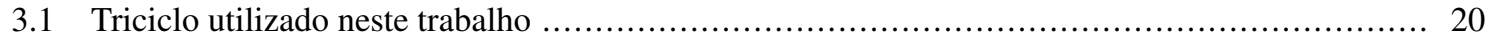

3.2 Diagrama do triciclo indicando equipamentos utilizados na instrumentação. ...................... 22

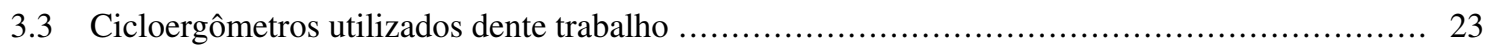

3.4 Rolo de treinamento para realizar testes com o triciclo estacionário............................... 23

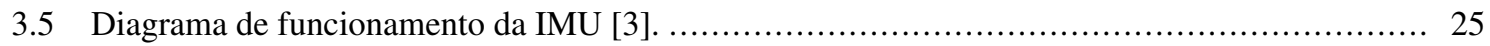

3.6 Aplicativo desenvolvido em Matlab para testes rápidos do estimulador. ............................. 27

3.7 Posicionamento de eletrodos para os experimentos em malha aberta.[4] ........................ 31

3.8 Perfil de estimulação em diferentes cadências. Os ângulos são referentes à posição angular do pedal esquerdo, onde a posição superior é a posição inicial. A fase azul é a fase de estimulação do quadríceps esquerdo (do inglês, quadríceps: left, QL), e a fase verde é a fase de estimulação do quadríceps direito (do inglês, quadríceps: right, QR). A pedivela gira no sentido horário, crescente com o valor dos ângulos [5].

3.9 Diagrama de blocos do controlador em malha fechada. O Controle PI recebe o erro entre a velocidade angular medida e a referência. Após calcular o sinal de controle, esse é enviado ao Perfil, que avalia, baseado na velocidade angular e posição angular da pedivela, se a estimulação deve ocorrer naquele momento. Se sim, o sinal de controle é passado adiante, desnormalizado e enviado ao estimulador. Esse causa a contração muscular que atua na pedivela.

3.10 Diagrama de bloco do sistema completo. A unidade de controle recebe os ângulos da IMU, calcula o sinal de estimulação e envia para o estimulador. O estimulador envia pulsos elétricos que ativam os nervos, causando contração muscular. Essa contração gera força nos membros inferiores, que é transferida para o pedal e causa o gira da pedivela. Esse giro é captado pela IMU e o laço de controle se fecha. Há, ainda, uma interface de usuário conectada à Unidade de Controle que o indivíduo pode usar para ligar ou desligar o sistema. 


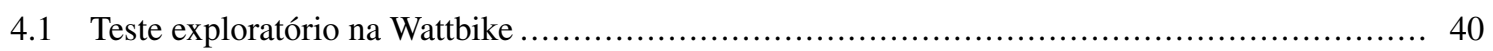

4.2 Gráficos polares de força em ciclismo.................................................. 40

4.3 Experimento em malha aberta em andamento .............................................. 41

4.4 Resultados obtidos nos experimentos em malha fechada. Nos gráficos, o eixo vertical representa, simultaneamente, a cadência em $\% / s$ e a potência em $W / K g$ desenvolvidas durante o teste. A curva é a mesma pois o sistema calcula a potência a partir da cadência e do peso do indivíduo. O eixo horizontal representa o tempo do teste em $s$.

4.5 Posicionamento de eletrodos para experimentos em malha fechada ............................ 43

4.6 Indivíduo B preparado para iniciar experimento em malha fechada .............................. 44

4.7 Gráfico em tempo real exibido durante o experimento. De cima para baixo, o primeiro gráfico apresenta o sinal de posição angular da pedivela, o segundo os sinais de controle normalizado enviados para cada canal do estimulador (azul é quadríceps esquerdo e verde é quadríceps direito), o terceiro a velocidade angular da pedivela (em verde a velocidade não filtrada, em azul a velocidade filtrada, e em vermelho a referência), e o quarto o sinal de erro. O eixo horizontal representa iterações do software, e não tem significado físico. ........................ 44

4.8 Resultados do experimento com controlador em malha fechada ............................... 46

4.9 Voluntário testando o triciclo funcionando em malha fechada durante a primeira etapada Copa Brasil de Paraciclismo, em Brasília. Abril/2015............................................ 47

4.10 Pontos de fadiga identificáveis de acordo com a definição na seção 3.1 ........................ 47

4.11 Todas as revoluções realizadas pelo indivíduo com estimulação elétrica sobrepostas .............. 48

4.12 Comparação entre os tempos totais de experimentos em malha aberta e fechada. MA(n) significa o teste número " $n$ " do experimento em malha aberta, e $\mathrm{MF}(\mathrm{X})$ é o teste em malha fechada com o indivíduo $\mathrm{X}$.

4.13 Período e frequência de amostragem do sistema durante o experimento em malha fechada. Os dados em vermelho representam os dados em azul com um filtro de média de tamanho 100. 


\section{Lista de Tabelas}

2.1 Valores típicos para frequência, intensidade de corrente e largura de pulso em FES de superfície[2]. 15

3.1 Valores nominais e parâmetros utilizados no experimento em malha fechada

3.2 Lista dos experimentos realizados com controlador em malha aberta. * Método de calibração diferenciado, onde a calibração da corrente é feita em movimento.[4] ............................ 37

4.1 Valor da corrente calibrada para os indivíduos A e B no experimento de malha fechada............ 43

4.2 Tempo total do primeiro e último teste com os indivíduos de nível de atividade física alto e moderado no experimento em malha aberta.

4.3 Corrente calibrada para os indivíduos com diferente níveis de atividade física no experimento em malha aberta

4.4 Pontos de fadiga dos indivíduos A e B, conforme definidos na seção 3.1, no experimento em malha fechada. 
NOTAÇÃO

Neste trabalho valores nominais são representados com uma barra sobre a variável. 


\section{LISTA DE SÍMBOLOS}

\section{Símbolos Latinos}

$K_{P} \quad$ Ganho do canal proporcional

$K_{I} \quad$ Ganho do canal Integral

\section{Símbolos Gregos}

$\begin{array}{ll}\theta & \text { Posição angular } \\ \omega & \text { Velocidade angular } \\ u & \text { Largura de pulso }\end{array}$




\section{INTRODUÇÃO}

\subsection{CONTEXTUALIZAÇÃO}

O sistema nervoso é responsável por comandar boa parte das funções do corpo humano. Ele é composto pelo sistema nervoso central e o sistema nervoso periférico. O sistema nervoso central é formado pelo encéfalo e medula espinhal, que fica dentro da coluna vertebral. Uma lesão na coluna pode gerar uma lesão medular, e danificar o sistema nervoso central localmente. Esse dano pode interromper os sinais enviados pelo cérebro para o resto do corpo, causando consequências sérias como perda de motricidade[6]. Essas consequências podem ser temporárias, reversíveis com tratamento adequado, ou permanentes e debilitantes, como tetraplegia, que é a perda de movimentos dos membros superiores e inferiores. É possível ainda haver incapacidade de respirar, incontinência urinária, e outras danos secundários[7].

De acordo com a Organização Mundial de Saúde (OMS), todos os anos entre 250 e 500 mil pessoas sofrem uma lesão medular em todo o mundo. A maioria dessas lesões é causada por acidentes de carro, quedas de altura ou violência, incluindo tentativas de suicídio. Pessoas com lesão medular têm de 2 a 5 vezes mais chances de morrer prematuramente que pessoas hígidas, que são aquelas sem deficiências ou patologias, e essas chances pioram em países em desenvolvimento. Lesão medular está associada à baixo desempenho escolar e participação na economia, e causa grandes custos para o indivíduo e para a sociedade ${ }^{1}$.

Existem tratamentos para lesão medular e seus sintomas, porém eles costumam ser caros e incompletos[8]. Não existe cura, atualmente, um método para restaurar totalmente os danos causados ao sistema nervoso por uma lesão medular. Os tratamentos geralmente focam em recuperar as funções mais importantes, como locomoção e comunicação; e outras condições secundárias, como úlceras de pressão, atrofia muscular, tromboses e depressão[7].

Tanto em tratamentos para restauração de funções perdidas, que se baseiam na neuroplasticidade para induzir a recuperação do tecido neural[1], quanto no trato de outras condições provindas da lesão e da falta de mobilidade, atividade física é um componente importante. Exercitar os músculos, mesmo que de formas artificiais, contribui para manter a circulação ativa, os tendões alongados, a autoestima elevada, entre outros benefícios[2, 8]. As opções de exercícios que envolvem muitos grupos musculares, particularmente os membros inferiores, são limitadas[9]. As terapias tradicionais não trabalham a musculatura, mas tecnologias assistivas modernas visam preencher essa lacuna[2]. A robótica pode ajudar a movimentar os membros e auxiliar de varias maneiras o processo de reabilitação[10,11], mas mantendo os músculos passivos. Estimulação elétrica tem o diferencial de ativar a musculatura e gerar movimento com a energia do próprio corpo, e isso tem consequências positivas[8].

\subsection{DEFINIÇÃO DO PROBLEMA}

A lesão medular pode ser traumática, originada em um acidente; ou não traumática, originada em infecções, lesões vasculares, doenças autoimunes, inflamações, entre outras causas. A lesão pode ser completa ou

\footnotetext{
${ }^{1}$ Fact sheet $\mathrm{N}^{\circ} 384$, novembro de 2013, disponível em http://www.who.int/mediacentre/factsheets/fs384/en/
} 


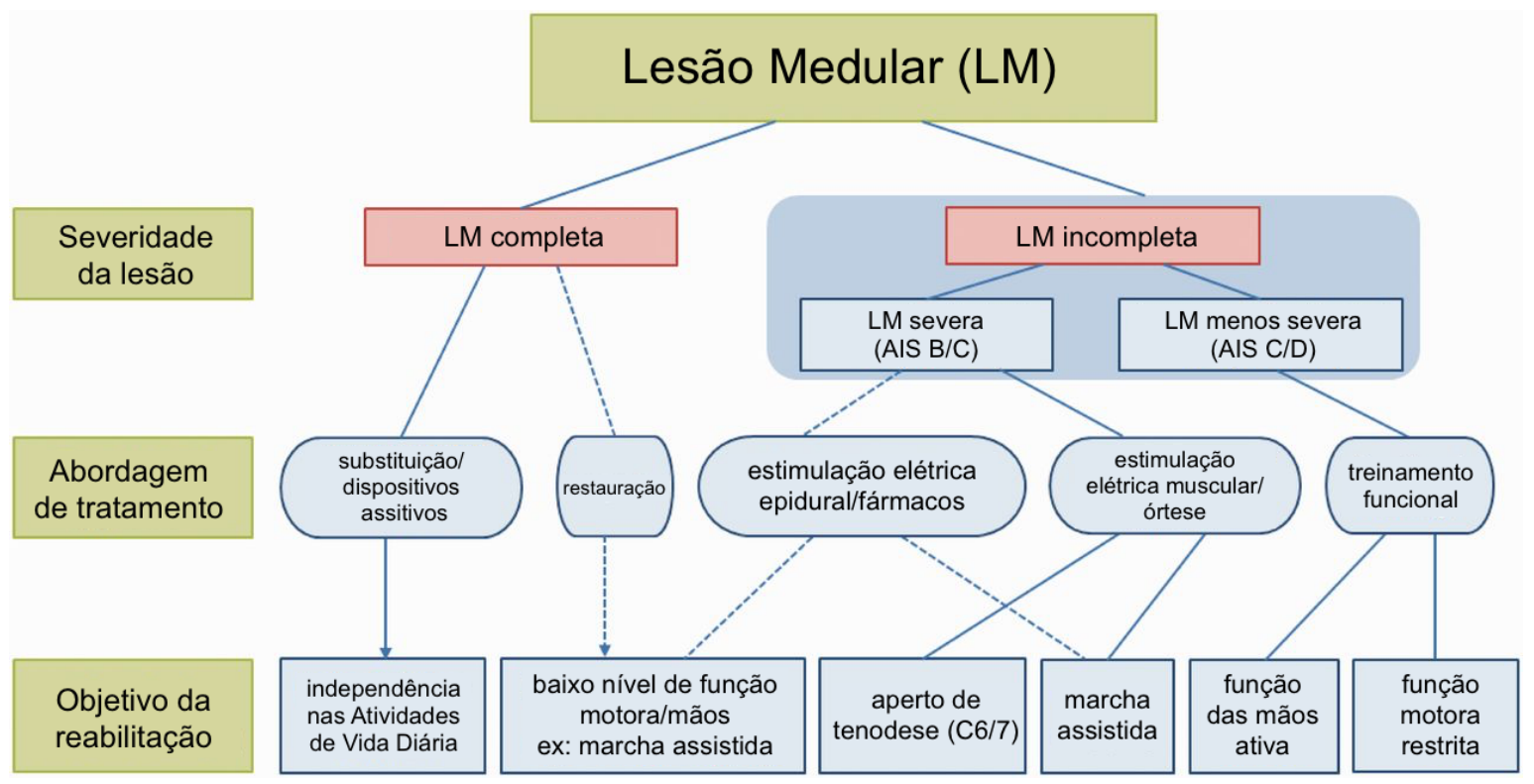

Figura 1.1: Fluxograma para indicação de tratamentos para lesão medular[1]

incompleta. Lesões completas resultam em total perda de função, sensação ou movimento abaixo do nível da lesão. Quando há lesão incompleta existem resquícios de funcionalidade, muitas vezes assimétricas. Lesões incompletas são mais comuns que lesões completas e, por isso, quando o tratamento é precoce, a maioria dos pacientes consegue recuperar um pouco das funções na fase aguda[12], ou seja, nos primeiros meses após a lesão.

O tratamento depende da classificação da lesão. Por muito tempo acreditou-se que o sistema nervoso periférico tinha capacidades regenerativas, mas o sistema nervoso central não. Entretanto pesquisas recentes em animais mostraram que mesmo o sistema nervoso central pode se regenerar sob condições específicas[2], mas muitos detalhes ainda são desconhecidos. Mesmo que esse conhecimento evolua até chegar nas clínicas em um futuro próximo, é necessário que os neurônios próximos da lesão estejam funcionais, e as técnicas atuais podem auxiliar nesse processo[13]. A figura 1.1 apresenta os tratamentos existentes, dependendo do tipo de lesão.

Fisioterapia e treinamentos funcionais são sempre empregados na reabilitação de lesão medular[1]. Além desses exemplos, existem outras formas de tratamento que podem ser utilizadas paralelamente com a função de auxiliar na recuperação das funcionalidades perdidas. Estimulação Elétrica Funcional pode potencializar a neuroplasticidade[2]. Em particular, ciclismo com estimulação elétrica de membros inferiores pode ter benefícios adicionais, como aumentar massa óssea[14] e evitar atrofia muscular[15]. Ainda assim, aplicações com estimulação elétrica apresentam desafios que impedem a popularização do tratamentos, como baixa seletividade muscular, complexidade de movimento com muitos graus de liberdade e, principalmente, recrutamento reverso das fibras musculares, que causa fadiga prematuramente[2]. Este trabalho pretende estudar essa tecnologia e superar ou contornar esses desafios, com o intuito de tornar o ciclismo com estimulação elétrica uma terapia viável e atrativa, a fim de contribuir para a reabilitação de indivíduos com lesão medular. Como forma de motivação, este trabalho está inscrito na competição Cybathlon ${ }^{2}$, que ocorrerá na Suiça em outubro de 2016. O Cybathlon contará com seis disciplinas onde os atletas terão alguma deficiência motora, mas serão auxili-

\footnotetext{
${ }^{2} \mathrm{http}: / /$ www.cybathlon.ethz.ch/
} 
ados por tecnologias avançadas para realizar tarefas e competir pelo melhor tempo. Além da categoria deste trabalho, corrida de ciclismo com estimulação Elétrica Funcional, haverá corrida com próteses ativas de membros inferiores, corrida com próteses ativas de membros superiores, corrida com cadeira de rodas motorizadas, corrida com exoesqueletos e corrida com carros virtuais controlados por interfaces cérebro-máquina.

\subsection{OBJETIVOS}

\subsubsection{Objetivo Principal}

Estudar diferentes estratégias de controle com FES para ciclismo, considerando diferente músculos, padrões de estimulação e técnicas de controle. A principal medida de desempenho será o tempo total de exercício até que a fadiga induzida pela FES impeça a continuidade, e o intuito é obter o maior tempo possível.

\subsubsection{Objetivos Secundários}

- Familiarização com técnicas e equipamentos de estimulação elétrica

- Avaliar a aplicação de FES nos membros inferiores em malha aberta para ciclismo

- Avaliar a aplicação de FES nos membros inferiores em malha fechada para ciclismo, utilizando técnicas de controle propostas no estado da arte

\subsection{ORGANIZAÇÃO DO MANUSCRITO}

Os demais capítulos deste trabalho apresentam todo o desenvolvimento do sistema proposto. Inicialmente, no capitulo 2 faz-se uma revisão bibliográfica de neurociências, lesão medular e possíveis técnicas e tecnologias para tratamentos, incluindo estimulação elétrica. Em seguida, o capítulo 3 descreve os materiais utilizados, os controladores desenvolvidos, e os protocolos experimentais seguidos nos testes. No capítulo 4 os resultados obtidos são apresentados, e esses resultados são analisados. Finalmente, o capítulo 5 expões as considerações finais do trabalho e propões melhorias para trabalhos futuros. 


\section{FUNDAMENTAÇÃO TEÓRICA}

A lesão medular é uma condição extremamente debilitante, que exige tratamentos intensos os quais muitas vezes trazem poucos resultados. O sistema nervoso humano é de suma importância para a manutenção de diversas funções do corpo, incluindo funções motoras. Muitos grupos de pesquisa trabalham em diferentes aspectos dessa condição em prol da qualidade de vida dos pacientes. Esses aspectos variam desde regeneração do tecido que foi lesionado, com o objetivo de recuperar completamente a mesma condição de antes da lesão; passando por técnicas onde o indivíduo reaprende a utilizar algumas funções perdidas; até a substituição completa de uma função por um equipamento externo, como uma cadeira de rodas.

As próximas seções explicam os fundamentos necessários para entender os diferentes tratamentos disponíveis, suas vantagens e desvantagens, e os desafios a serem ultrapassados por novas tecnologias. A seção 2.1 descreve o sistema nervoso, músculos esqueléticos e como eles interagem. A seção 2.2 apresenta detalhes dessa condição, suas possíveis causas e consequências, bem como os tratamentos disponíveis e em desenvolvimento. A seção 2.3 apresenta a estimulação elétrica funcional, mostra as diferentes metodologias utilizadas, como os sistemas podem ser parametrizados e quais suas aplicações. E, finalmente, a seção ?? explica os benefícios e limitações do uso de estimulação elétrica no contexto de ciclismo, bem como detalhes técnicos do funcionamento desses sistemas.

\subsection{FUNDAMENTOS NEUROFISIOLÓGICOS DO MOVIMENTO}

O sistema nervoso é um dos grandes controladores de todas as funções do corpo. Os movimentos podem ser concluídos no sistema motor, controlado pelo sistema nervoso. A seção 2.1.1 descreve os conceitos básicos do sistema nervoso e seus componentes. A seção 2.1.2 apresenta o sistema músculo esquelético e explica como o sistema nervoso se comunica com ele.

\subsubsection{Sistema Nervoso, Neurônios e Nervos}

O sistema nervoso humano pode ser dividido em duas partes: o sistema nervoso central (SNC) e o sistema nervoso periférico (SNP). O SNC é formado por todas as estruturas contidas dentro do crânio e coluna vertebral. A parte dentro do crânio é chamada encéfalo e a parte dentro da coluna é chamada medula espinhal. É no SNC onde estão a maioria dos neurônios nos animais, bem como os gliócitos. Os principais elementos do SNP são os nervos. Nervos são filetes alongados que, quando agrupados, formam fibras nervosas. Esses filetes são prolongamentos de neurônios, que podem ter seus corpos celulares em diferentes localizações. Os nervos conectam a medula espinhal (chamados de nervos espinhais) ou o encéfalo (chamados de nervos cranianos) aos órgãos. Eles transportam informações, por meio de pulsos elétricos, de um ponto à outro. Essas informações podem ser sensitivas ou motoras, somáticas ou viscerais, e podem ser eferentes, saindo do SNC em direção aos outros tecidos, ou aferentes, retornando dos tecidos em direção ao SNC.

O sistema nervoso é responsável por todas as funções do corpo humano e é composto por dois tipos celulares principais já mencionados: neurônios e gliócitos [6]. O neurônio é uma célula capaz de transmitir e processar

sinais do sistema nervoso. Ele é composto por corpo celular, onde fica o núcleo; dentritos, prolongamentos 


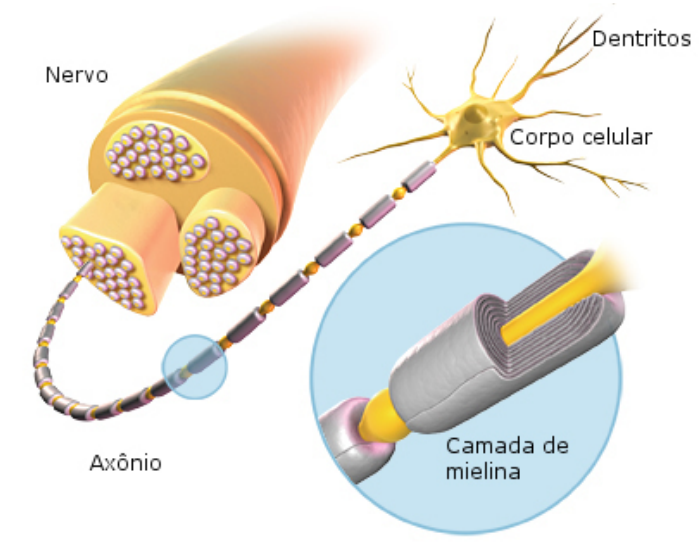

(a) Ilustração de um neurônio, com corpo celular, dentritos e axônio. O axônio está envolto por uma camada de mielina e integra um nervo. Figura adaptada de www.nlm.nih.gov

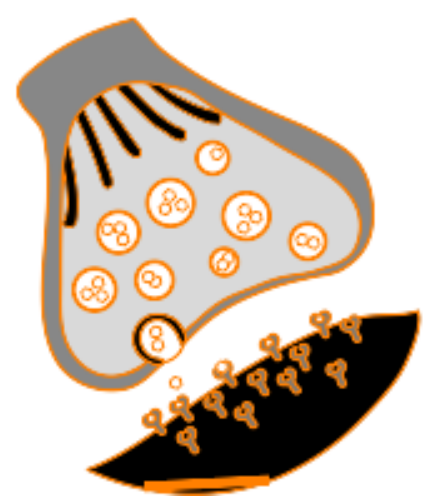

(b) Ilustração de uma sinapse. Os hexágonos são os neurotransmissores, que transportam a informação. Fonte: https://pixabay.com

Figura 2.1: Figuras ilustrando um nervo e uma sinapse

próximos ao corpo celular; e um axônio, um grande prolongamento que pode se estender por mais de um metro. Os neurônios se comunicam entre si e com células musculares através de sinapses. Sinapses são capazes de transmitir, bloquear ou modificar mensagens. Dentro do neurônio, as informações são transmitidas por meio de impulsos nervosos, que são pulsos elétricos gerados pela membrana e que viajam pelo axônio. Muitos neurônios possuem um axônio mielinado, ou seja, envolto em uma camada de mielina, cuja função é aceleração a transmissão dos impulsos nervosos. A figura 2.1a apresenta um neurônio, com corpo celular, dentritos e axônio. Este último é integrante de um nervo. Ainda na figura, pode-se ver, no detalha, a camada de mielina envolvendo o axônio. No final do axônio, o impulso nervoso desencadeia uma sinapse, que consiste na emissão de elementos químicos, os neurotransmissores, para outra(s) célula(s)2.1b. Esse impulso nervoso é a unidade de informação do sistema nervoso. Ele é de natureza elétrica e pode ser captado por eletromiografia (EMG) ou eletroencefalografia (EEG), que são técnicas de captura de sinais elétricos de músculos e do crânio, respectivamente[6]. O fluxo de informação que leva um comando até um músculo ou órgão pode ser muito complexo, passando por muitos neurônios e impulsos nervosos. Já os gliócitos são células com funções de infraestrutura e suporte, como nutrição e imunidade, além de também realizarem processamento de informações de natureza química.

\subsubsection{Fisiologia, Contração Muscular e conexões entre Sistema Nervoso e Sistema Músculo-Esquelético}

Os músculos são estruturas que geram força e promovem movimento. Para isso, eles se contraem e diminuem de comprimento. Ao relaxarem, aumentam de comprimento. Os músculos chamados esqueléticos estão conectados aos ossos por tendões e formam o sistema músculo-esquelético. Quando um músculo contrai e diminui de tamanho, ele puxa um tendão e, assim, um osso. Dessa forma, o sistema músculo-esquelético movimenta o corpo. A capacidade de um músculo se contrair é chamada contratilidade. O músculo é um tecido com a segunda maior habilidade de responder a estímulos, ficando atrás apenas do tecido nervoso. Essa habilidade chama-se excitabilidade. Além da contratilidade e da excitabilidade, músculos são também distensíveis e elásticos, que significa, respectivamente, que podem ser alongados ou esticados por uma força externa, como outro músculo ou a gravidade, e que, depois de estendidos, retornam ao seu comprimento natural sem danos (exceto se o alongamento tenha sido exagerado)[2]. 
Músculos esqueléticos são formados por partes ativas e passivas. As partes ativas são formadas por fibras musculares. Um músculo pode conter mais de um milhão de fibras musculares, que podem variar de poucos $\mathrm{mm}$ a até mais de $40 \mathrm{~cm}$, e terem espessuras entre $1 \mu \mathrm{m}$ e $150 \mu \mathrm{m}$. As fibras compõem cerca de $85 \%$ da massa de um músculo e tem propriedades ativas e passivas. O restante é composto por tecido conectivo, como colágeno e fibras elásticas, que são estruturas puramente passivas. Essas estruturas, juntamente com estruturas semelhantes nos tendões, atuam como transmissores de energia entre músculos e ossos e fornecem proteção contra forças desenvolvidas de formas muito rápidas.

Para que haja a contração muscular, é necessário que ocorra a ativação do músculo por um nervo ligado a ele. Essa ligação é chamada de enervação. O nervo entra no músculo junto com a artéria principal e se bifurca sucessivamente até alcançar todas as fibras musculares. O neurônio que se liga às fibras musculares é chamado de motoneurônio, ou neurônio motor. Um motoneurônio e as fibras às quais ele se conecta formam uma unidade motora. Algumas unidades motoras possuem muitas fibras musculares e outras possuem poucas, dependendo do tamanho do músculo e da sua função. Músculos responsáveis por movimentos finos, como os dos movimentos oculares, podem ter unidades motoras de cinco fibras musculares, enquanto músculos maiores, responsáveis por movimentos mais simples, como o gastrocnêmio, podem ter unidade motoras com mais de 2000 fibras. Cada fibra muscular é formada por cerca de 1000 miofibrilas, que são as unidades contráteis musculares. As miofibrilas são formadas por filamentos de miosina e filamentos de actina, que são proteínas. Esses filamentos formam grupos alinhados que, quando vistos ao microscópio, parecem seções claras e escuras. As seções claras são chamadas de Banda I e as seções escuras de Banda A. Cada banda I possui uma fina linha escura em seu centro, chamada de linha Z. A região entre duas linhas Z é chamada de sarcômero. Em um sarcômero existem vários filamentos completos de miosina, que é grossa e curta. Os filamentos de actina são finos e longos, e iniciam e terminam em sarcômeros adjacentes. Durante a contração, essas proteínas se combinam e deslizam umas sobre as outras, encolhendo o tamanho dos sarcômeros e, consequentemente, diminuindo o comprimento total do músculo.

Todos os movimentos do corpo humano gerados por músculos são planejados, executados e controlados por uma série de estruturas que compõem o sistema motor. Essas estruturas podem ser divididas em executores, os músculos; ordenadores, as estruturas que enviam comandos aos músculos; controladores, que monitoram os resultados dos comandos executados; planejadores, as estruturas que programam todo o movimento antes de ele ocorrer; e os receptores e aferentes, as estruturas que captam informações físicas e enviam para o sistema nervoso[6].

\subsection{LESÃO MEDULAR}

Lesão medular é frequentemente causada por um trauma que atinge os nervos da medula espinhal. Suas consequências costumam ser muito debilitantes em vários aspectos da vida do indivíduo[2]. Esta seção define lesão medular, apresenta uma forma de classificação, expõe as consequências que ela causa e explica os possíveis tratamentos.

\subsubsection{Processo da Lesão Medular}

O SNC consiste, como foi explicado na seção 2.1.1, no encéfalo e na medula espinhal. A medula espinhal está inserida no interior da coluna vertebral, protegida de impactos mecânicos. Quando a medula é danificada, 


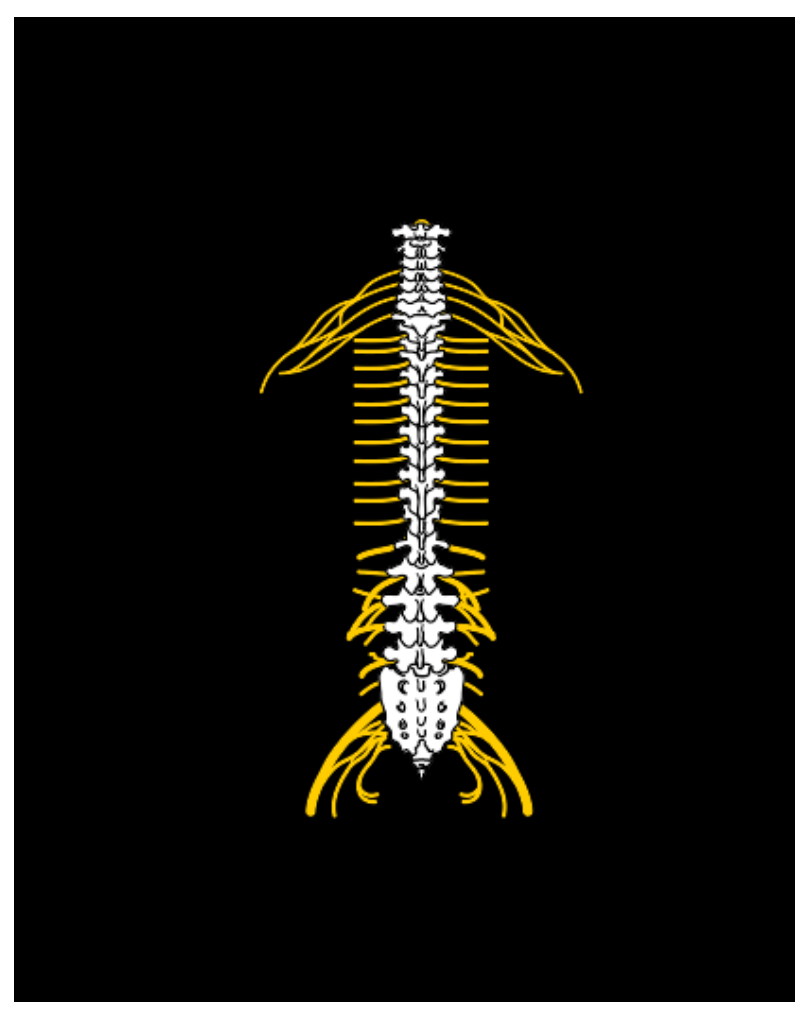

Figura 2.2: Divisão da medula espinhal em segmentos.

Fonte: https://commons.wikimedia.org/wiki/File:Diagram_of_the_spinal_cord_CRUK_046.svg

algumas funções do sistema nervoso podem ser afetadas. A medula transmite sinais do SNC superior, ou encéfalo, para os membros superiores e inferiores, além dos órgãos. Os nervos do SNP que levam os sinais neurais até esses destinos, se ramificam da medula em diferentes pontos. Se a medula for interrompida em um dado ponto, os sinais neurais eferentes não chegarão aos destinos que se ramificam naquele ponto ou além. Essa interrupção pode ser causada por diversas causas, como um impacto mecânico direto, um deslocamento entre vértebras ou um coágulo que pressiona a medula. Há ainda os casos chamados de lesão vascular, onde há uma insuficiência de oxigênio causada por privação sanguínea, causando a morte das células naquela região.

\subsubsection{Classificação}

Quando a lesão causa uma interrupção total de todo o tecido neural, de forma que todo o canal de informação superior e inferior àquele ponto fica comprometido, ela é chamada lesão completa. Todos os outros casos são chamados de lesão incompleta. A altura em que a lesão ocorre também é importante e é comumente associada com a vértebra da mesma altura, que são estruturas ósseas que compõem a coluna vertebral. Os níveis da medula óssea são nomeados de acordo com as localizações das vértebras. Então, na mesma altura da vértebra C1 está localizado o nível C1 da medula espinhal. Os níveis estão agrupados em 4 grandes grupos: cervical; torácico; lomba; e sacral e coccígeo. A nomenclatura de cada nível da medula é formada por uma letra que representa o grupo e um número que representa a altura, contada em níveis, de cima para baixo. Por exemplo, o terceiro nível lombar, de cima para baixo, chama-se L3. A figura 2.2 indica todos os níveis medulares. Uma pessoa com lesão nos níveis $\mathrm{T}$ é chamada de paraplégica. Uma pessoa com lesão na região cervical é chamada de tetraplégica. 
A Associação Americana de Lesão Medular (ASIA, do inglês) classifica uma lesão medular em 5 níveis, de acordo com a escala ASIA Impairment Score (Pontuação de dano ASIA, ou AIS). Esses níveis variam de A, lesão completa, a E, capacidades motoras e sensitivas normais. Uma pessoa é avaliada em sensibilidade com uma metodologia que se baseia em aplicar estímulos mecânicos em várias regiões do corpo com os olhos vendados e pedir para que ela indique o tipo de estímulo, sendo esse leve ou pontiagudo, e o local. A avaliação motora baseia-se na capacidade da pessoa obedecer comandos de movimentar os membros e avaliar a força de acordo com uma escala de 0 a 5 , onde 0 significa paralisia total e 5 significa força normal.

\subsubsection{Consequências}

A lesão medular está associada a outras condições médicas que podem surgir da falta de mobilidade, como trombose, osteoporose, atrofia muscular ou úlceras de pressão[2]. Algumas lesões também afetam outros sistemas que não o motor, podendo resultar em, por exemplo, incontinência urinária ou dificuldades respiratórias. Outros problemas ligados à lesões medulares são espasmos musculares e dor crônica[2].

O déficit de mobilidade que geralmente acompanha uma lesão medular pode tornar uma pessoa dependente de outras para atividades diárias. Os pacientes podem necessitar de cuidadores ou dispositivos para locomoção, comunicação, higiene pessoal, etc. É estimado de 20 a 30\% das pessoas com lesão medular apresentam sinais clínicos significativos de depressão, que pode afetar os cuidados gerais com a saúde. Essas dificuldades geram distanciamento social. Crianças com lesão medular tem maior tendência a largar a escola. E adultos a saírem do mercado de trabalho, com uma taxa global de desemprego de $60 \%$.

\subsubsection{Tratamento}

\subsubsection{Neurorregeneração}

Neurorregeneração é a técnica de restaurar o tecido nervoso depois dele ter sido lesionado[2]. Por muito tempo cirurgias de nervos periféricos têm ajudado na reabilitação de funções motoras perdidas. Essas cirurgias reconectam extremidades de nervos que foram rompidos, mas muitos neurônios se reconectam com outros neurônios, causando dificuldades no controle dos movimentos e sensibilidade. Entretanto, com fisioterapia e treinamento, o sistema nervoso é capaz de reorganizar os caminhos neurais e reaprender a controlar aquelas funções perdidas. Essa habilidade do sistema nervoso é chamada de neuroplasticidade[16]. Por outro lado, neurônios do SNC parecem não apresentar a mesma característica. Ainda assim, diversos estudos indicam ser possível a regeneração de células do SNC, desde trabalhos percursores como em [17], que apontou para a possibilidade de alguns neurônios terem uma estrutura que possibilita o crescimento, enquanto outros não; ou [18], que mostrou a viabilidade crescimento quando células especiais, chamadas células de Shwann estão presentes, fornecendo um ambiente propício; até trabalhos mais recentes, como [19], que identificou elementos inibidores do crescimento de neurônios presentes no SNC, ou [20], que inseriu nervos periféricos na medula espinhal de ratos e mostrou que nervos espinhais danificados cresceram através do enxerto e provaram, conclusivamente, que a regeneração do SNC é possível em mamíferos adultos. [21, 22, 23] afirmam ter recuperado parte das funções motoras em ratos com lesão medular completa após utilização de complexas combinações de células de Shwann, células fetais, cirurgias estabilizantes e outros fatores, porém seus resultados não foram reproduzidos. O trabalho desenvolvido em [13] demonstrou a possibilidade de regeneração do tecido neural no sistema nervoso central com condições específicas e [24] demonstrou que a aplicação de campos elétricos pode afetar diretamente a orientação e regeneração de axônios. 
Neurorregeneração é considerada a cura para lesão medular e trabalhos recentes tem obtido resultados promissores. Em [25], três indivíduos com lesão medular tiveram células do trato olfativo implantadas na região da lesão e depois passaram pela terapia tradicional. Após um tempo da terapia, os pacientes que passaram pelo transplante obtiveram resultados positivos de atividade nos músculo das extremidades inferiores, enquanto o grupo controle não. Resultados assim ainda precisam ser reproduzidos em populações maiores e a esperança é que auxiliem no tratamento de muitas pessoas no futuro.

Todos esses fatores indicam caminhos para pesquisas em neurorregeneração em humanos, mas confrontam barreiras relacionadas à segurança e ética dos procedimentos. A transferência desses conhecimentos para a prática médica deve passar por extensivos testes e revisões, mas é consenso que um conjunto de fatores deve ser combinado para a reabilitação do paciente, incluindo técnicas de neurorregeneração, cirurgias e fisioterapia[2].

\subsubsection{Neurorreabilitação}

Neurorreabilitação consiste nos métodos para utilizar as estruturas remanescentes para recuperar as funções perdidas [26]. Em [27], o assunto neurorreabilitação é dividido em três aspectos: restauração, substituição e neuromodulação.

Restauração é quando algum processo ou tecnologia é utilizado para restaurar uma função perdida, tal e qual ela seria sem a lesão. Uma restauração funciona enquanto é utilizada e não tem efeito quando o uso é interrompido. Um exemplo são órteses de pé caído, como a da figura 2.3a, utilizadas para ajustar o ângulo do tornozelo, facilitando a marcha de indivíduos que perderam o controle funcional sobre essa articulação.

Substituição é quando algum equipamento ou processo substitui uma função. Próteses são substituições, assim como cadeiras de rodas. Evidentemente, elas também apenas restauram a funções enquanto são utilizadas.

Neuromodulação ocorre quando algum método ou tecnologia proporciona ou potencializa a neuroplasticidade com o objetivo de recuperar funções perdidas. Uma terapia baseada em neuromodulação busca uma recuperação duradoura, onde o indivíduo conclui um tratamento e, então, consegue realizar as funções treinadas sem nenhum equipamento. Como exemplos existem robôs desenvolvidos para reabilitação motora, como o Lokomat (Hocoma $)^{1}$, apresentado na figura 2.3b.

Neuromodulação exige do indivíduo engajamento em atividades que demandem esforço e atenção. É preciso que ele tenha a intenção de realizar uma tarefa. Tecnologias assistivas disponíveis atualmente visam auxiliálo na tarefa. O conjunto de intenção e feedback do sucesso, aliado ao esforço, propicia a neuroplasticidade, fazendo com que o sistema nervoso crie novos caminhos neurais para realizar aquela função específica[27].

\subsubsection{Próteses neurais}

Próteses neurais, ou neuropróteses, são dispositivos desenvolvidos para auxiliar uma pessoa a executar uma função perdida e que possuem uma interface com o sistema nervoso. Essa interface com o sistema nervoso possibilita que o indivíduo envie comandos para o equipamento, como direcionar uma cadeira de rodas, ou controlar um sistema de comunicação. Essas próteses se comunicam com o sistema nervoso explorando a

${ }^{1}$ https://www.hocoma.com/world/en/products/lokomat/ 


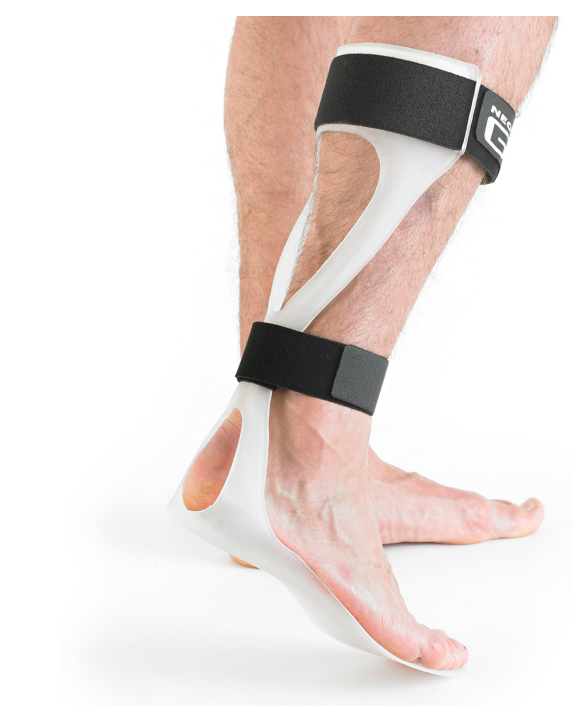

(a) Órtese tornozelo-pé para pé caído. http://www.physioroom.com/

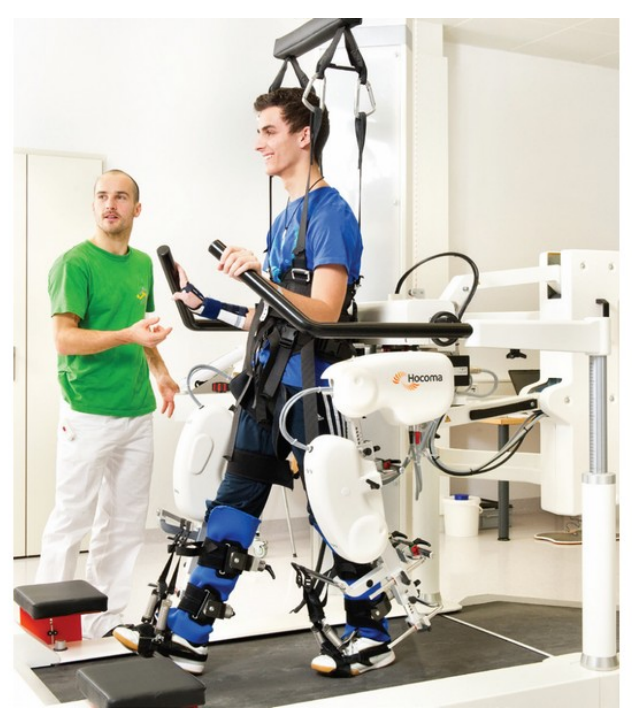

Fonte:(b) Lokomat. Robô para neurorreabilitação de membros inferiores. http://airindo.com/product/lokomat/

Figura 2.3: Exemplos de equipamentos utilizados em neurorreabilitação.

natureza elétrica de seu funcionamento. Dessa forma, utiliza-se eletrodos capazes de captar esses sinais, como é feito em eletromiografia, ou eletroculografia. Além de próteses com atuadores, como o exemplo da cadeira de rodas, ou exoesqueletos, elas podem atuar diretamente nos músculos do indivíduo aplicando estimulação elétrica funcional, gerando torque no membro e auxiliando na execução de tarefas, além de contribuir para neurorreabilitação[24]. Um exemplo que chegou ao mercado foi o FreeHand System (NeuroControl, Estados Unidos da América), um sistema implantado que foi utilizado por mais de 250 pessoas [28]. Era um dispositivo com eletrodos e sistemas de controle implantados para membro superior que permitia movimentos complexos de mão[29]. Apesar de ter tido bons resultados com vítimas de lesão medular, o produto foi descontinuado por razões mercadológicas.

\subsubsection{Interfaces cérebro-máquina}

Outra possível interface com o sistema nervoso é a captação de sinais elétricos direto do cérebro com eletrodos superficiais ou implantados. Conhecendo-se a região do córtex relacionada a movimento, essa técnica visa capturar esses sinais elétricos e decodificá-los em intenção de movimento. Estudos mostram que interfaces cérebro-máquina podem ser usados para controle de dispositivos assistivos[30, 31] e também em terapias de reabilitação[30, 32].

\subsubsection{Estimulação epidural}

Estimulação epidural consiste em estimular diretamente a medula espinhal com pulsos elétricos ou fármacos. Essa estimulação é mais semelhante à natural, gerando menos fadiga que estimulação superficial[1]. Entretanto, há a inconveniência de envolver um procedimento invasivo e os benefícios são principalmente voltados para membros inferiores. 


\subsubsection{Estimulação Elétrica Funcional}

Estimulação elétrica funcional, ou FES (do inglês, functional electrical stimulation) consiste na estimulação elétrica de nervos motores com eletrodos superficiais[2, 13], com o objetivo de restaurar funções perdidas com a lesão[1,33]. Estimulação superficial proporciona a conveniência de não necessitar de cirurgia, entretanto acarreta problemas como falta de seletividade dos músculos. Além disso, pacientes com lesão medular frequentemente sofrem de atrofia muscular ou úlceras de pressão, que dificultam a aplicação bem sucedida de FES. Essa tecnologia já é estudada a décadas e existem equipamentos no mercado, como a órtese de membro superior NESS H200 (Bioness Inc., Estados Unidos da América) ${ }^{2}$, ou o sistema de marcha com eletrodos de superfície Parastep (Sigmedics Inc., Estados Unidos da América) ${ }^{3}$. Mas esses equipamentos nem sempre conseguem restaurar a funcionalidade perdida, ou exigem outras terapias ou procedimentos cirúrgicos para utilização. Avanços continuam sendo feitos em pesquisa e desenvolvimento de tecnologias com FES, como órteses híbridas[34, 35]. Mais detalhes sobre FES são apresentados na seção 2.3.

\subsubsection{Microestimulação intraespinhal}

A microestimulação intraespinhal, ou ISMS (do inglês, intraspinal microstimulation) é semelhante à estimulação peridural, no que diz respeito ao ponto de estimulação. Entretanto, essa técnica explora os circuitos neurais responsáveis por movimentos rítmicos para locomoção[24, 36, 37, 38].

\subsubsection{Microestimulação intracortical}

Microestimulação intracortical, ou ICMS (do inglês, intracortical stimulation), utiliza microeletrodos implantados em regiões do cérebros relacionadas com funções motoras e sensitivas perdidas pelo indivíduo. $\mathrm{O}$ objetivo é estimular essas regiões com sinais artificiais em sincronia com estímulos visuais para recriar caminhos neurais[12]. Essa técnica pode ser usada no contexto de reabilitação, mas também no controle de equipamentos assistivos, como uma interface cérebro-máquina.

\subsubsection{Fisioterapia e treinamento}

Fisioterapia tradicional, baseada em treinamento de tarefas específicas, é o tratamento mais bem sucedido e menos invasivo disponível para recuperação de funções motoras[1]. Todos os tratamentos citados acima são aplicados em paralelo às sessões de fisioterapia tradicional. Nessas sessões, fisioterapeutas auxiliam o indivíduo a executar tarefas, como, por exemplo, marcha. Isso pode ser feito com a ajuda de equipamentos como andadores, barras paralelas ou dispositivos de suporte de peso. Nesses casos, são necessários dois fisioterapeutas, um para movimentar cada perna do paciente. Isso demanda muito esforço do profissional e tira a sua atenção do processo de reabilitação.

Algumas tecnologias vêm sendo desenvolvidas para tentar minimizar esses problemas, como o Lokomat (Hocoma, Suíça $)^{4}$, um sistema de suspensão de peso com esteira, e robôs que são acoplados aos membros inferiores e executam o movimento de marcha. Com o progresso do tratamento, pode-se aumentar o grau de dificuldade da tarefa e/ou diminuir a magnitude do auxilio exercido pelo equipamento. Outros sistemas

\footnotetext{
${ }^{2}$ http://www.bioness.com/Home.php

${ }^{3}$ http://www.sigmedics.com/

${ }^{4}$ https://www.hocoma.com
} 
visam a locomoção durante a utilização, como exoesqueletos. Alguns exemplos disponíveis no mercado são o WalkTrainer[39], o HYBRID[40], o Hybrid Assistive Limb (HAL)[41] e o RehabREX (REX Bionics) ${ }^{5}$, que é o único exoesqueleto capaz de se equilibrar sozinho, sem a necessidade de suportes, como bengalas ou muletas, liberando os membros superiores para outras tarefas. A possibilidade de locomoção utilizando movimento de marcha pode ter um impacto significativo na reabilitação, tanto do ponto de vista de plasticidade, quanto aspectos circulatórios e psicológicos[42].

\subsection{ESTIMULAÇÃO ELÉTRICA FUNCIONAL (FES)}

Estimulação elétrica funcional consiste em utilizar pulsos elétricos no contexto de alguma funcionalidade do corpo. Além de FES, essa técnica também é conhecida por Estimulação Elétrica Neuromuscular (do inglês, Neuromuscular Electrical Stimulation, NMES) ou Estimulação Neuromuscular Funcional (do inglês, Functional Neuromuscular Stimulation, FNS)[2]. Esta seção apresenta os fundamentos de FES, diferentes metodologias e parâmetros de utilização, bem como vantagens e desvantagens em possíveis aplicações.

\subsubsection{Fundamentos de FES}

Como descrito na seção 2.1, os sinais transmitidos pelo sistema nervoso possuem natureza elétrica. pulsos elétricos viajam pelos nervos levando informação para diferentes locais do corpo. Esse pulso pode ser induzido artificialmente, se for aplicado um estímulo elétrico acima do limiar daquele nervo. Atingindo-se esse limiar, o impulso nervoso é desencadeado na forma tudo-ou-nada. Isso significa que um estímulo abaixo do limiar não gera um impulso menor, e um estímulo acima do limiar não gera um impulso maior. Se esse estímulo for aplicado em um nervo motor, esse impulso pode viajar até o músculo correspondente e ativar fibras musculares daquela unidade motora. Essas fibras também são ativadas na forma tudo-ou-nada. Novamente, um maior estímulo nessa unidade motora não gera uma maior ativação[2].

Quando um impulso nervoso, também chamado de potencial de ação, ativa uma unidade motora, o músculo responde com uma rápida e fraca contração chamada de twitch. O twitch é a resposta tudo-ou-nada do músculo e possui um tempo entre seu início e final da ordem de até $100 \mathrm{~ms}$. Se um segundo potencial de ação ativar as fibras antes do twitch terminar, a segunda ativação será mais forte. Por isso, esse fenômeno chama-se soma. Se vários potenciais de ação chegarem em sequência, ocorre uma contração tetânica, onde a resposta do músculo cresce gradativamente com cada novo potencial de ação. Se a frequência de potenciais de ação for alta, acima de $20 \mathrm{~Hz}$ para a maioria dos músculos do corpo humano[2], a contração tetânica será completa, representada por uma curva suave que pode subir até a força máxima do músculo, conforme pode ser visto na figura 2.4.

A aplicação de FES é feito com eletrodos em duas possíveis configurações: monopolar ou bipolar. Na configuração monopolar, há um eletrodo comum e mais um eletrodo para cada canal. Todos os canais fecham o circuito entre o eletrodo correspondente e o eletrodo comum. Na configuração bipolar, cada canal é formado por dois eletrodos, e fecha o circuito entre esses eles. A estimulação é transmitida entre os eletrodos em pulsos elétricos, imitando a forma como o sistema nervoso trabalha naturalmente[2]. O estimulador pode fornecer uma estimulação regulada em corrente ou em tensão. Os tecidos estimulados, incluindo tecido muscular, adiposo e epitelial, possuem naturezas capacitivas. Portanto, uma estimulação com regulagem de tensão pode resultar em correntes sem controle atravessando esses tecidos. Estimulação regulada por corrente, ao contrário, sempre

\footnotetext{
${ }^{5}$ http://www.rexbionics.com/
} 


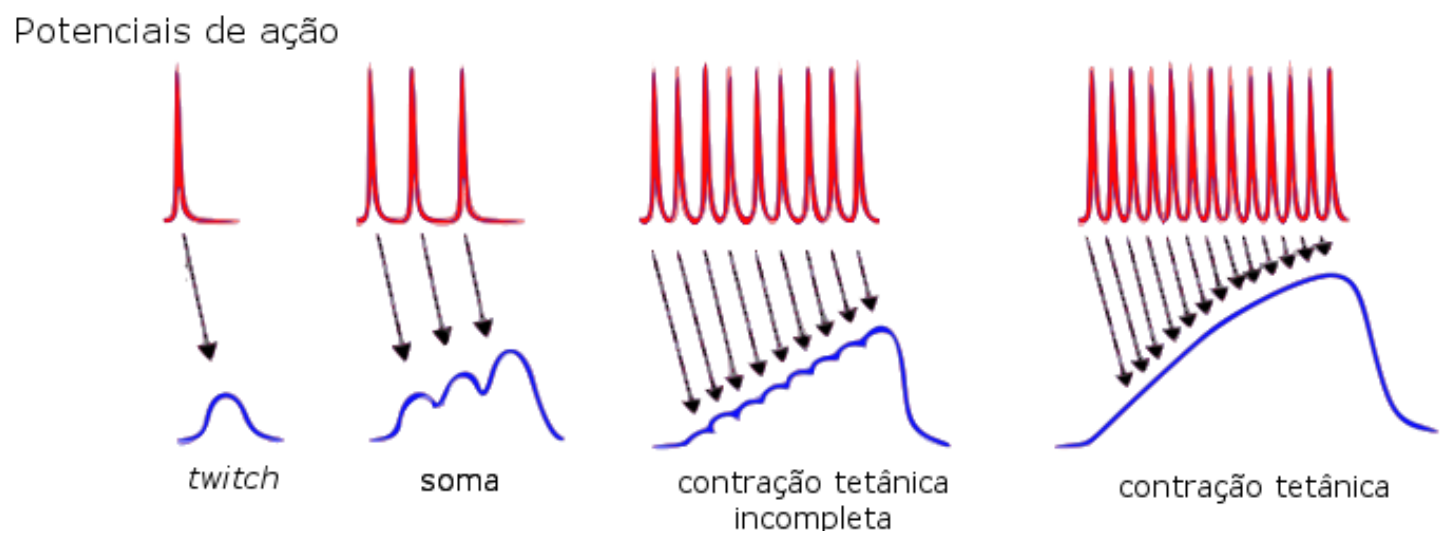

Figura 2.4: Ativação muscular em função da frequência de potenciais de ação. Em vermelho os potenciais de ação. Em azul o nível de contração muscular. Fonte: http://humanphysiology.academy/

entrega a corrente apropriada. A figura 2.5 ilustra os dois casos.

O formato da onda na estimulação pode causar diferentes efeitos [43]. Os três principais fatores a serem considerados para a escolha do formato de onda são o limiar de ativação neuro-muscular, o nível de corrosão dos eletrodos, e possíveis danos ao tecido biológico. [44] estuda algumas possíveis formas de ondas e seus efeitos nos fatores citados. Um resumo de suas conclusões pode ser visto na figura 2.6. Pode-se ver que a onda quadrada bifásica, em particular com um breve intervalo entre os pulsos positivo e negativo, representa um bom compromisso entre os três fatores analisados, e é o formato de onda fornecido pelo estimulador utilizado neste trabalho.

\subsubsection{Eletroestimulação de superfície e implantes, e os eletrodos envolvidos}

A estimulação elétrica pode ser aplicada à superfície da pele; ou internamente ao tecido neuromuscular. Cada uma dessas estratégias exige um eletrodo diferente.

Para estimulação de superfície, utiliza-se eletrodos autoadesivos, com filamentos de metais, que podem ser prata ou aço, desenhados para distribuir a corrente uniformemente por toda a sua área. Nesse contexto, o tamanho do eletrodo está diretamente relacionado à corrente aplicada pelo estimulador. Quanto maior o eletrodo, mais a corrente será espalhada pela sua área, portanto maior a intensidade de corrente que pode ser aplicada pelo estimulador. A intensidade de corrente dividido pela área do eletrodo chama-se densidade de corrente. Quando menor a densidade de corrente, mais confortável é o estímulo para o indivíduo. Além disso, o tamanho do eletrodo também está relacionado à área muscular que se deseja estimular. Músculos grandes exigem eletrodos grandes e músculos pequenos precisam de pequenos eletrodos[2]. A figura 2.7a apresenta alguns formatos e tamanhos de eletrodos.

Para estimulação direta no tecido neuromuscular, usa-se eletrodos implantados. Esses eletrodos deve ser instalados por meio de procedimento cirúrgico ou, em alguns casos, podem ser injetados no músculo. A figura 2.7b apresenta um eletrodo do tipo algema (do inglês, cuff), exemplo de eletrodo implantado que envolve um nervo antes mesmo da enervação do músculo[45]. 


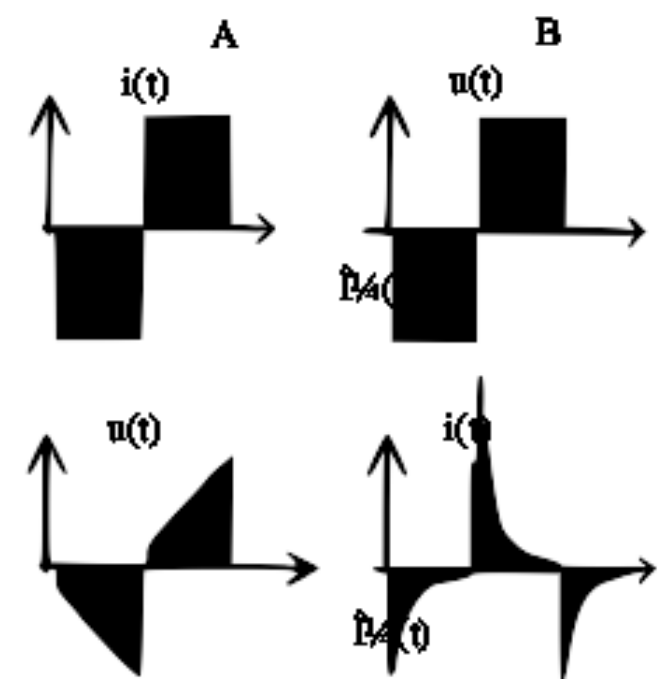

Figura 2.5: Comparação entre estimulação regulada por corrente (A) e regulada por tensão (B). Os sinais superiores são sinais de saída do estimulador e os sinais inferiores são a carga efetivamente sendo entregue ao músculo. Figura adaptada de [2]

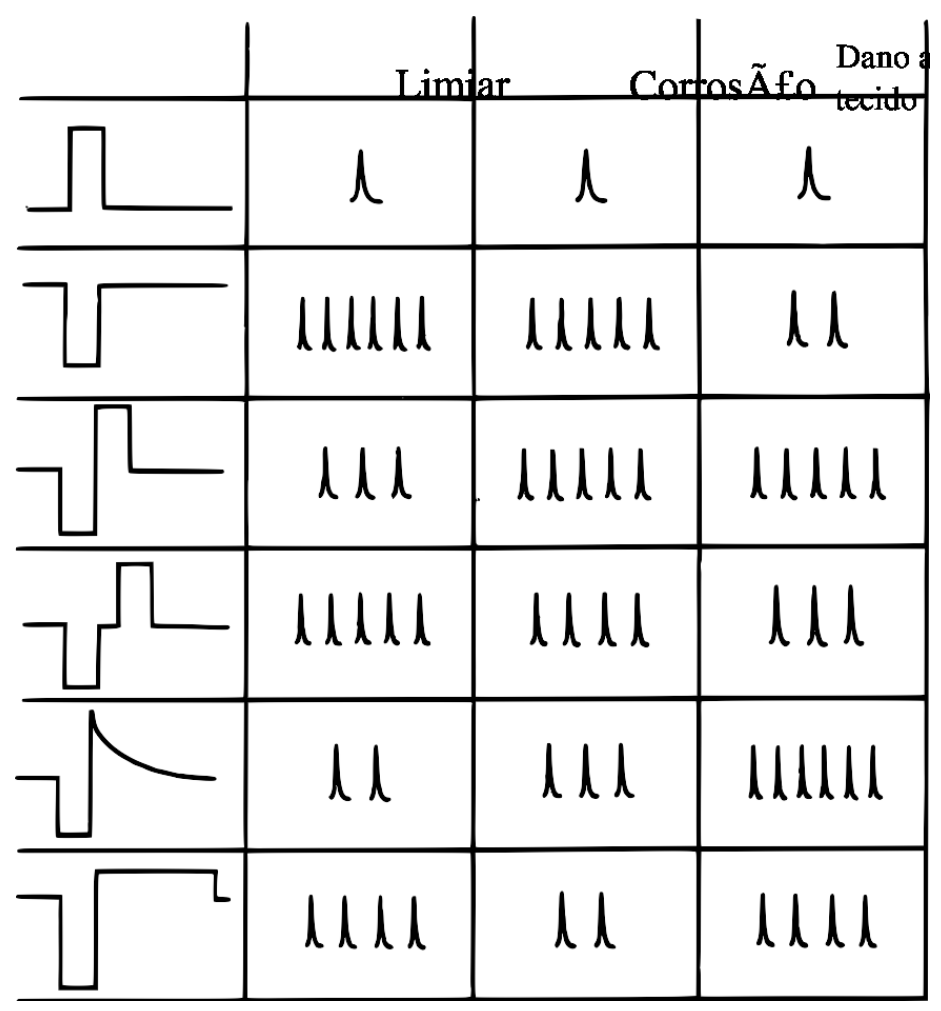

Figura 2.6: Diversos formatos de onda para estimulação elétrica e seus efeitos em diferentes fatores. O símbolo usado para quantificar o efeito é uma representação simples de um potencial de ação. Quanto mais potenciais de ação, melhor o efeito. Em outras palavras, quanto mais potenciais de ação, menor o limiar de ativação, menor o nível de corrosão dos eletrodos, e menor o dano ao tecido biológico. 


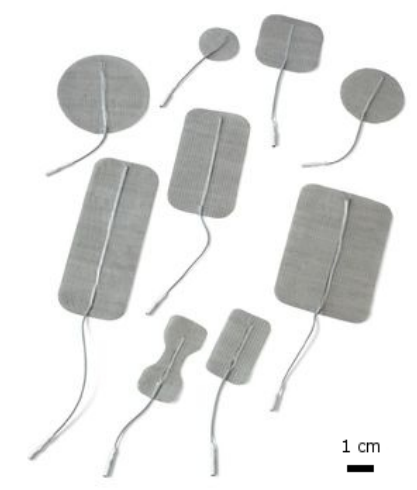

(a) Eletrodos para estimulação superficial. Fonte: http://www.berktree.com/

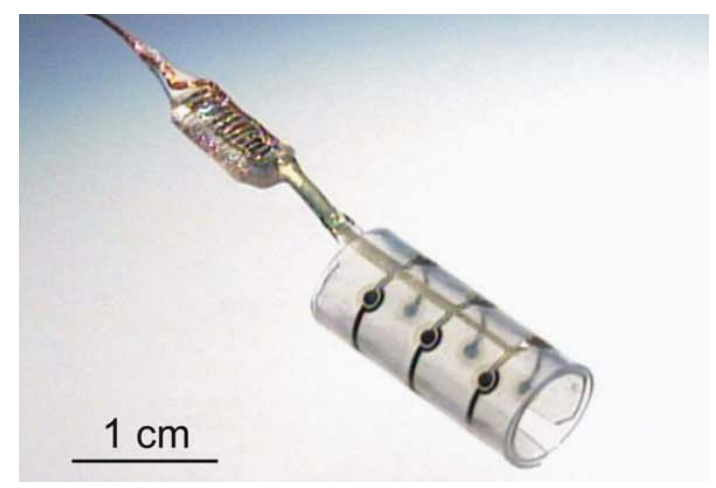

(b) Eletrodo algema, para estimulação direta do nervo. Fonte: http://storiesbywilliams.com/

Figura 2.7: Eletrodos utilizados em FES. A escala fornece uma noção do tamanho.

Tabela 2.1: Valores típicos para frequência, intensidade de corrente e largura de pulso em FES de superfície[2].

\begin{tabular}{|c|c|c|}
\hline & Mínimo & Máximo \\
\hline \hline Frequência $[\mathrm{Hz}]$ & 20 & 50 \\
\hline Intensidade de corrente $[\mathrm{mA}]$ & 0 & 70 \\
\hline Largura de pulso $[\mu s]$ & 50 & 500 \\
\hline
\end{tabular}

\subsubsection{Parâmetros de Estimulação Elétrica e suas Funções}

Além do formato de onda, explicado anteriormente, os principais parâmetros de FES são frequência de estimulação, largura de pulso e intensidade de corrente. Parâmetros típicos de FES superficial são descritos na tabela 2.1. Todos esses parâmetros são proporcionais à resposta muscular[46, 47]. Com relação à conforto, maiores frequências resultam em estimulação mais confortável, porém induz a fadiga mais rapidamente[2]. Já com respeito à intensidade de corrente e largura de pulso, ambos parâmetros podem ser usados para modulação de um controle de contração muscular. [46] demonstrou que modulação por largura de pulso exige um pouco menos de corrente para obter a mesma resposta que a modulação por intensidade de corrente.

\subsubsection{Vantagens e Desvantagens}

A estimulação elétrica funcional como tratamento para lesão medular possui a vantagem de estimular, simultaneamente, fibras nervosas eferentes e aferentes, potencializando a plasticidade do sistema nervoso. Estimulação de superfície é o método mais prático de aplicação da FES, pois não exige nenhum procedimento cirúrgico e a preparação é simples. Por outro lado, eletrodos de superfície oferecem baixa seletividade neuromuscular, tornando difícil a ativação de músculos pequenos, responsáveis por movimentos finos.

$\mathrm{Na}$ estimulação com eletrodos implantados, como a corrente é aplicada diretamente ou muito próxima ao ponto motor, sua intensidade é bem mais baixa que a usada em estimulação de superfície. Outra vantagem é a alta seletividade, pois o implante é feito diretamente no local a ser estimulado. Além disso, estimulação com eletrodos implantados costuma ser mais confortável para o indivíduo pois a corrente elétrica não passa por sensores de dor presentes na pele. Por outro lado, a invasividade dessa técnica pode ser uma inconveniência, tanto na instalação como na manutenção em caso de mal funcionamento. 
Os músculos são formados por fibras muscular rápidas, responsáveis por movimentos de explosão, envolvendo alta potência; e fibras lentas, responsáveis por movimentos lentos e finos. As fibras rápidas são facilmente fadigadas, e rapidamente se recuperam. As fibras lentas demoram mais a fadigar, e também demoram mais a se recuperar. As fibras rápidas, são mais sensíveis à estimulação elétrica e, por isso, são mais facilmente recrutadas. Por esse motivo a FES costuma resultar em fadiga prematura dos músculos alvos, diminuindo o tempo de terapia. Esse fenômeno chama-se recrutamento reverso[2].

\subsubsection{Aplicações}

FES pode ser usada em diversos contextos. Além de reabilitação motora pós lesão neural, como lesão medular, acidente vascular encefálico, ou paralisia cerebral, há outras deficiências relacionadas ao sistema nervoso que podem ser tratadas com estimulação elétrica. Os dois sistemas mais difundidos de FES são marcapasso e implante coclear. O primeiro é um sistema de estimulação elétrica implantado no peito do indivíduo que controla seu batimento cardíaco. O segundo é um sistema parcialmente implantado que transforma sinais sonoros em sinais elétricos e os aplica na cóclea, uma das partes do ouvido interno.

Especificamente em tratamento de lesão medular, as duas aplicações mais completas de FES são ciclismo e remo auxiliado por estimulação elétrica. No primeiro caso, os membros inferiores são estimulados para gerar as pedaladas de forma alternada. No segundo caso, os membros inferiores são estimulados na extensão em sincronia com a flexão dos membros superiores e movimento posterior do tronco. Ambas aplicações possuem benefícios comprovados para a saúde dos indivíduos com lesão medular [48, 49, 50, 51]. Apesar de o remo apresentar um exercício mais completo por envolver tronco e membros superiores, este trabalho foi desenvolvido sobre uma plataforma de ciclismo pela maior facilidade e viabilidade da utilização de um veículo não estacionário. Em outras palavras, o objetivo envolve uma atividade ao ar livre para, além de terapia e exercício, também lazer ou locomoção.

\subsection{CICLISMO COM ESTIMULAÇÃO ELÉTRICA}

Com base nos aspectos discutidos nas seções anteriores, a FES aplicada em conjunto com cicloergometria ou outras plataformas ciclísticas (em inglês, FES-cycling) pode representar tanto uma opção para uso terapêutico em ambientes de reabilitação como uma opção de adequação tecnológica em dispositivos de locomoção como bicicletas ou triciclos [49].

\subsubsection{Benefícios e limitações}

A literatura descreve variados benefícios que o ciclismo assistido por FES pode produzir ao usuário, em especial aos sistemas cardiorrespiratório, neuromuscular e esquelético [48, 49], como aumento da massa muscular, melhora da circulação sanguínea, redução de úlceras de pressão, melhora da auto estima e redução da perda de massa óssea.

De forma ilustrativa, é notável o declínio da massa óssea em indivíduos com lesão medular. O estudo de [52] realizou um protocolo de FES Cycling com 11 indivíduos com frequência de treinamento de 3 a 7 vezes por semana, cada sessão durou 1 hora na máxima intensidade tolerada pelo indivíduo. Após um ano observou-se que houve aumento da massa óssea nos membros inferiores paralisados. 
O declínio da massa muscular ocorre de forma ainda mais rápida que o da massa óssea devido ao desuso imposto pela lesão neurológica. Vários estudos indicaram claramente que várias semanas de prática de ciclismo com FES não apenas induziu a hipertrofia, mas também aprimorou força e resistência dos músculos estimulados $[53,54]$.

A eletroestimulação com FES também modifica a composição das fibras musculares. A proporção entre fibras tipo 2 (rápida glicolítica) e tipo 1 (lenta oxidativa) aumenta em decorrência da lesão medular. No entanto, após um ano de treinamento foi observada uma mudança com aumento das fibras lentas com consequente aumento da resistência à fadiga [53].

O treino cardiovascular satisfatório com base em uma maior quantidade de grupos musculares (e maior gasto energético) permite obtenção de condicionamento físico para execução de atividades de vida diária de forma independente e para contextos esportivos de competição [9]. Dessa forma, a eletroestimulação neuromuscular é capaz de melhorar as propriedades musculares relacionadas ao treinamento como o fluxo sanguíneo intramuscular, geração máxima de força e resistência muscular através de repetitivas contrações.

No entanto, devido a ausência de controle voluntário e presença de movimentos involuntários, o controle da estimulação para produção de movimentos cíclicos coordenados é essencial para o sucesso da terapia. Além disso, diferente do que ocorre durante as contrações voluntárias, conforme discutido na Seção 2.3 as contrações desencadeadas pelos estímulos elétricos ativam de forma sincrônica todas as unidades motoras e recrutam inicialmente as fibras rápidas glicolíticas (tipo II), podendo resultar em fadiga muscular precoce[55]. Por estas razões, é necessário o desenvolvimento de novos equipamentos e sistemas de controle para garantir e expandir as consequências positivas do uso de FES-cycling por indivíduos com lesão medular.

\subsubsection{Plataformas experimentais}

Em termos de uso terapêutico, FES-cycling é geralmente realizada em paciente utilizando cicloergômetro, no qual o pedalar é realizado com movimentos sinérgicos desencadeados por estímulos elétricos transmitidos aos músculos por meio de eletrodos de superfície colocados nos membros inferiores para gerar um padrão de movimento em pedalada. Entretanto, essa terapia também pode ser utilizada em plataformas móveis em contextos lúdicos ou competições esportivas, como em corridas com triciclos adaptados.[3, 56]

Quando comparados a outros equipamentos de suporte, sistemas ciclísticos possuem alta eficiência entre o movimento gerado e a força aplicada ao pedal. Além disso, a restrição mecânica provocada pela estrutura (os pés estão presos ao pedal) e o movimento executado apenas no plano sagital, tornam as bicicletas com FES uma ótima opção de equipamento de suporte para fornecer treinamento muscular a indivíduos com lesão medular. Entretanto, uma das desvantagens reside no fato de que a atividade do usuário paraplégico em uma bicicleta estacionária pode tornar-se excessivamente passiva e, assim, reduzir o engajamento e a efetividade da terapia. De forma a minimizar tal problema e possibilitar a utilização como meio de transporte e lazer é uma vantagem, uma alternativa é usar triciclos adaptados para uso por paraplégicos. A escolha do triciclo ao invés de uma simples bicicleta para possibilitar o ciclismo móvel se dá pela dificuldade que o usuário teria para manter o equilíbrio lateral de uma bicicleta, sobretudo quando comparada à estabilidade oferecida por um triciclo. Em relação à configurações de triciclos, os dois principais tipos são delta (duas rodas atrás) e tadpole (duas rodas na frente). Em geral é escolhido o modelo tadpole, por suas características de reduzido peso, agilidade e simplicidade mecânica.

Em relação aos equipamentos necessários para adaptação de plataforma ciclística para propulsão via FES, são necessários (além do estimulador, naturalmente), sensores que fornecem informações em tempo real acerca 
do estado do sistema. Em especial, é fundamental a leitura da posição da pedivela, uma vez que a partir do conhecimento da posição do pedal se define os músculos que serão ativados de maneira coordenada. Entretanto, a implementação de controladores mais robustos em geral requer a instalação de sensores adicionais, como velocidade da bicicleta e força aplicada ao pedal $[9,57]$.

\subsubsection{Sistemas de controle}

Acerca dos sistemas de controles utilizados para ativar coordenadamente os músculos dos membros inferiores para transferir potência ao pedal, a maioria das estratégias de controle possuem origem em estudos da biomecânica do ciclismo. Os precursores dessa tecnologia [49] desenvolveram controladores nos quais os períodos de estimulação são definidos unicamente por meio da fase do ciclo da pedalada. Em tais trabalhos, não existe medição da força aplicada no pedal ou da cadência produzida, mas é necessária a medição da posição da pedivela para que os músculos sejam ativados na fase correta. Dessa forma, caso se considere em sistemas FES-cycling se deseje controlar a cadência da pedalada ou a potência transferida, podemos inferir que em tais métodos ocorre controle em malha aberta.[58]

Apesar da relativa simplicidade, tais métodos foram capazes de demonstrar o potencial da tecnologia. Entretanto, o desempenho obtido é consideravelmente degradado em situações em que há alterações inerentes ao sistema, tais como fadiga muscular, que irá alterar o perfil de força produzida no pedal, e diferentes condições de operação, como diferentes cargas aplicadas ao sistema (subidas, por exemplo). Dessa forma, diferentes técnicas de controle foram aplicadas ao problema, em geral baseadas no uso de sensores adicionais [9, 59, 60, 61, 62, 57, 63] ou mesmo uma quantidade maior de canais de estimulação por músculo [64].

As estratégias de controle descritas até o momento consideram que o indivíduo não é capaz de contrair os músculos correspondentes ao movimento de pedalar e, adicionalmente, que apenas o sistema FES é disponível para fornecer energia ao sistema. Entretanto, como comentado na Seção 2.4.2 uma alternativa de alto potencial benéfico para a população de interesse envolve a integração de outros mecanismos de atuação que atuam em paralelo à estimulação, tais como motores elétricos $[9,62]$ ou a propulsão cíclica gerada pelos membros superior do piloto $[49,65]$. 


\section{MATERIAL E MÉTODOS}

Este capitulo destina-se a descrever todas estratégias de controle, equipamentos e protocolos experimentais realizados neste trabalho. Para avaliar e comparar os diferentes métodos aplicados com a finalidade de atingir maior tempo de exercício antes da fadiga, uma medida de desempenho é proposta na sessão 3.1. A sessão 3.2 descreve os equipamentos utilizados, e como eles foram integrados. A sessão 3.3.4 apresenta o software desenvolvido para controlar o sistema. Na sessão 3.4, são explicadas as estratégias de controle aplicadas no sistema. A sessão 3.5 descreve como cada experimento foi realizado.

\subsection{MEDIDA DE DESEMPENHO}

Chama-se fadiga neuromuscular a incapacidade de produzir repetidamente um nível de força ou potência, que pode durar minutos, dias ou semanas[66]. Neste estudo, o termo fadiga é utilizado quando o músculo estimulado eletricamente apresenta resposta inferior ao mesmo estímulo a que respondia anteriormente. Se um indivíduo hígido atingir a fadiga durante algum dos experimentos, ele normalmente poderá continuar o movimento voluntariamente, se desejar. Isso ocorre porque a fadiga em questão afeta apenas um dos tipos de fibra muscular, conforme descrito na seção 2.3 .

A principal métrica de desempenho adotada, então, foi o tempo total do exercício até quando a fadiga neuromuscular é alcançada e o músculo não responde mais à estimulação. Essa medida de desempenho é utilizada por $[9,58]$ e pode ser usada para comparação com esse trabalho e outros. Além desse tempo, é possível identificar três momentos relevantes, no que diz respeito ao desempenho do controlador empregado em relação à fadiga: o momento em que o controlador começa a reagir à fadiga, o momento em que o controlador não consegue mais compensar o efeito da fadiga, e o momento em que a fadiga impede a continuidade do movimento:

1. O primeiro ocorre quando o sinal de controle começa uma rampa ascendente, sem que a referência seja alterada.

2. O segundo ocorre quando, simultaneamente, o sinal de controle satura e a cadência inicia uma rampa descendente e constante.

3. O terceiro ocorre quando a cadência chega à zero.

\subsection{SETUP EXPERIMENTAL}

Nesse trabalho, foram desenvolvidos diferentes setups experimentais para avaliação dos sistema de controle com FES aplicados ao ciclismo. Cada plataforma foi utilizada em uma determinada fase do projeto e serviu para fornecer resultados distintos, descrevendo assim de forma indireta a própria evolução do trabalho. Inicialmente, foram realizados testes em cicloergômetros. Na sequência, foi adquirido um triciclo e este foi adaptado para que permitisse a realização de testes nos quais o veículo estivesse em movimento. 


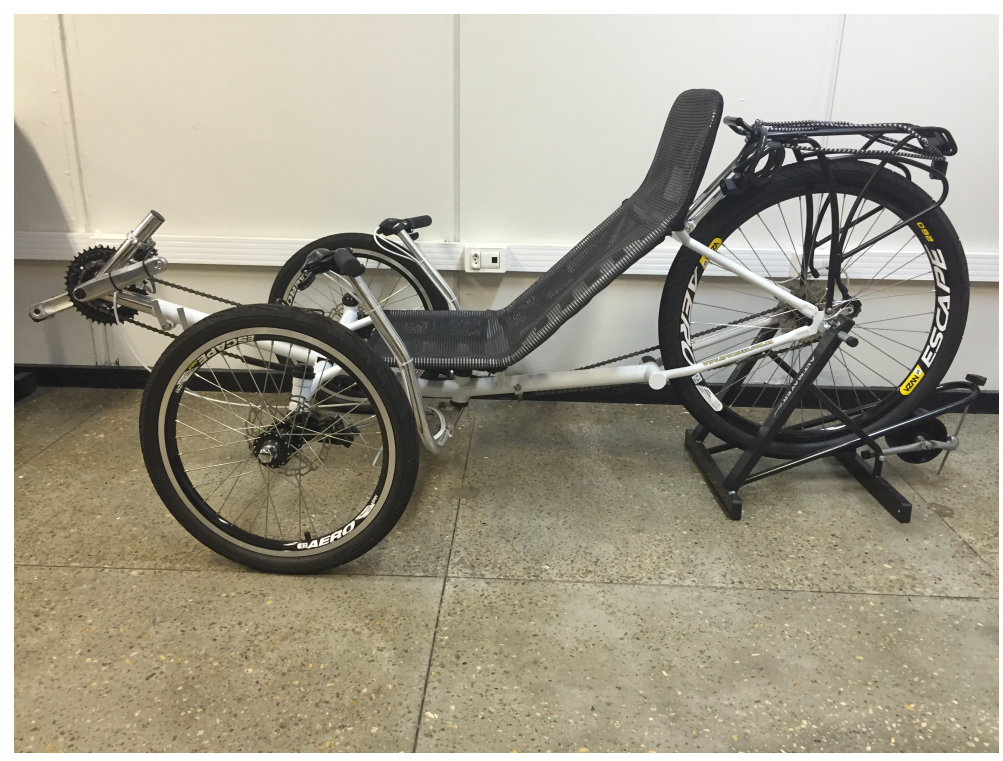

Figura 3.1: Triciclo utilizado neste trabalho

Após os experimentos iniciais com cicloergômetros, ficou claro que essa plataforma de testes não era apropriada para a população alvo, indivíduos com lesão medular. Esses indivíduos, além de não terem a capacidade de movimentar os membros inferiores, geralmente possuem pouco ou nenhum controle postural de tronco. Isso significa que não conseguem se equilibrar sobre um banco sem encosto para as costas ou boa sustentação, como são os bancos tradicionais de bicicletas. Foi preciso então uma plataforma capaz de oferecer sustentação para o tronco, além de exigir que apenas os membros inferiores sejam estimulados durante o exercícios, e não a musculatura do tronco. Um triciclo adaptado, por suprir de maneira satisfatória tais aspectos, foi adotado neste trabalho. Esse triciclo foi instrumentado com equipamentos necessários para realizar a estimulação elétrica com controle em malha aberta ou fechada, medição da posição e velocidade angular da pedivela, velocidade da roda e distância percorrida. As próximas subseções descrevem todos esses equipamentos.

\subsubsection{Equipamentos utilizados}

\subsubsection{Triciclo}

Um modelo comercial de triciclo foi encomendado da empresa HP3 (Rio de Janeiro, Brasil), e é apresentado na figura 3.1. O modelo base é chamado tadpole, e possui duas rodas na frente e uma atrás.

As principais caraterísticas técnicas do triciclo são apresentadas a seguir:

- Estrutura principal

O quadro é formado por tubos de aço carbono unidos por solda TIG. Os aros, pedivela e cubos são de alumínio. O veículo possui dimensões totais de 1980 x 900 x 750 mm, distância entre eixos de 1040 mm e distância entre as duas rodas dianteiras de $800 \mathrm{~mm}$. O guidão é ajustável na altura e na inclinação, e existe, ainda, um ajuste da distância do pedal para pessoas de diferentes alturas. As rodas dianteiras possuem aro 20 e a roda traseira aro 26 . O arco mínimo para curva é de $2,3 \mathrm{~m}$. O peso aproximado é de $18 \mathrm{~kg}$, e o peso máximo do piloto é de 100kg. O sistema de direção é formado por barras cruzadas em uma geometria de Ackerman modificada. Isso permite que o centro de rotação do guidão não seja 
único, fazendo com que o movimento dos membros superiores para fazer uma curva seja de menor amplitude[67].

- Assento

O assento foi projetado na posição recumbente (i.e. inclinada) para dar mais conforto e estabilidade para o piloto, principalmente se ele não possuir controle postural necessário para equilibrar-se em assentos característicos de ciclismo vertical. É construído com um perímetro de aço, e fechado por um tecido macio. De fato, é importante que a superfície de contato com o piloto seja macia para minimizar o risco de úlceras de pressão. Apesar da atual estrutura apresentar desempenho satisfatório para a maioria da população de potenciais usuários, caso o piloto tenha quadris largos, é recomendada a utilização de uma almofada ou travesseiro, de forma que o perímetro de aço, que é rígido, não fique em contato direto com o indivíduo.

- Freios

São utilizados freios dianteiros mecânicos a disco de $160 \mathrm{~mm}$. Uma das características do sistema de freio é que é possível, tal como em uma bicicleta tradicional, freiar de maneira independente duas rodas, no caso as dianteiras. Entretanto, no triciclo, a possibilidade de freiar as rodas dianteiras individualmente pode provocar comportamentos perigosos ao usuário iniciante (ou mesmo possibilitar a realização de movimentos acrobáticos pelo usuário avançado). Dessa forma, sempre que o triciclo for utilizado para deslocamento por indivíduos iniciantes, deve-se explicar que frear com apenas uma roda pode acarretar em acidentes.

- Sistema de marchas

O sistema de marchas possui 24 combinações com base em sistema de 8 catracas e 3 coroas. Essa relação é importante para possibilitar a transferência de potência em diversas intensidades de carga, como subidas, altas velocidades, ou momentos em que a fadiga está afetando os músculos.

- Ajuste de distância dos pedais ao assento

Existe um sistema telescópio de montagem da pedivela, que permite aumentar e diminuir a distância entre o quadril do piloto e os pedais. Isso é importante para possibilitar que pessoas de diferentes medidas antropométricas, em especial a altura, possam utilizar o sistema.

- Corrente

Corrente comum de bicicleta. Caso as medidas antropométricas do indivíduo exijam uma modificação na distância dos pedais de mais de $150 \mathrm{~mm}$, faz-se necessário remover ou adicionar elos na corrente, de acordo com os parâmetros de folga determinados pelo fabricante.

\section{- Guidão}

Visando atender a pacientes com lesões neurais afetando também os membros superiores, optou-se por um guidão horizontal com regulagem de altura e distância do tronco, em contraste ao tradicional guidão vertical adotado em triciclos.

A figura 3.2 apresenta um diagrama do triciclo instrumentado. 


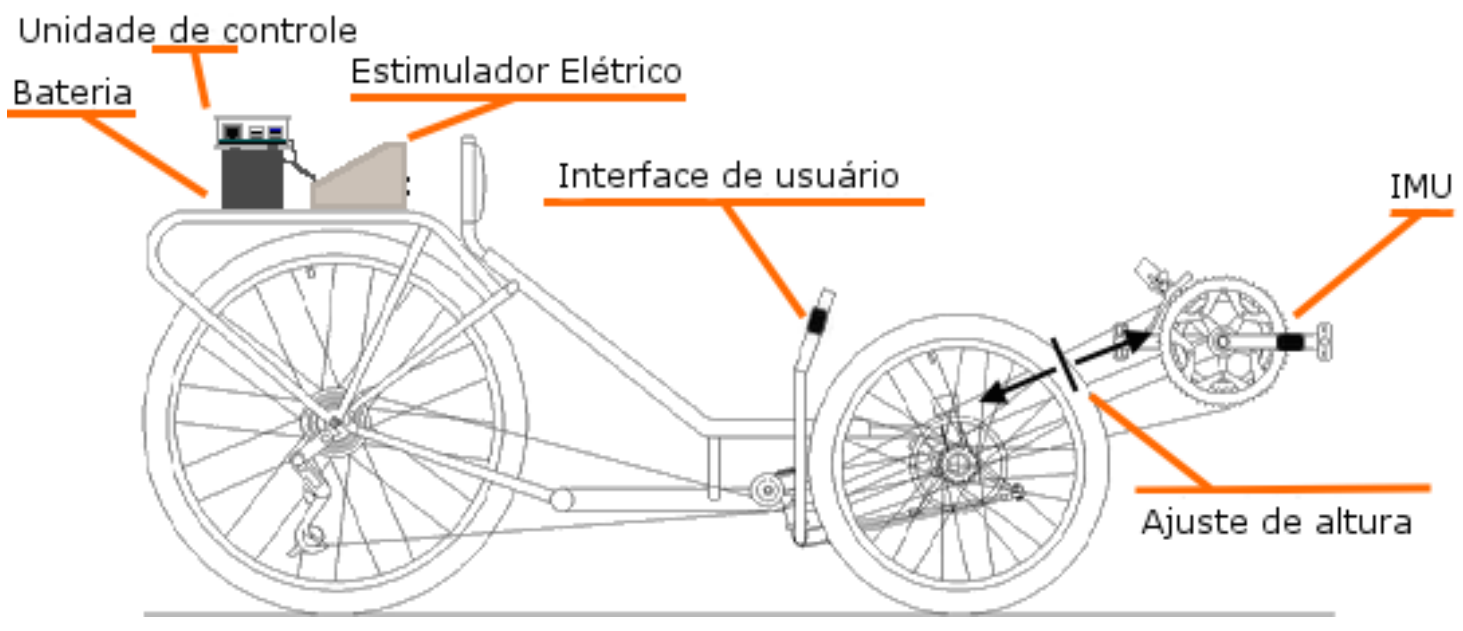

Figura 3.2: Diagrama do triciclo indicando equipamentos utilizados na instrumentação.

\subsubsection{Cicloergômetros estacionários}

Cicloergômetros são equipamentos desenvolvidos para exercício ou terapia realizando-se movimentos cíclicos. Neste trabalho, foram utilizados cicloergômetros de membro inferior, também chamados de bicicletas ergométricas. Nos testes iniciais e em malha aberta foram utilizados dois cicloergômetros:

- Cicloergômetro Wattbike

A Wattbike (Wattbike Ltd., Reino Unido) ${ }^{1}$, figura 3.3a, é um cicloergômetro desenvolvido para avaliação biomecânica de ciclistas de alto desempenho. Ela possui sensores que registram o torque desenvolvido em cada pedal durante todo o percurso do ciclo. A Wattbike utilizada neste trabalho pertence ao hospital HOME, em Brasília.

- Cicloergômetro Biotec 2100 .

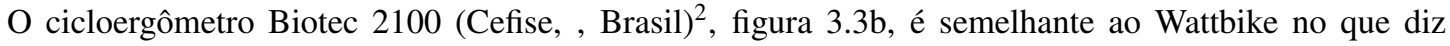
respeito à sua função, com exceção que sua taxa de amostragem é menor. O Biotec 2100 utilizado neste trabalho pertence à Faculdade de Educação Física da Universidade de Brasília.

\subsubsection{Rolo de treinamento}

De maneira a possibilitar testes estacionários com o triciclo em ambiente controlado, foi utilizado um rolo de treinamento (figura 3.4). O rolo mantém o triciclo estacionário durante a atividade de pedalar. Ele é instalado sob a roda de tração que é, em geral, a traseira. O rolo possui dispositivos mecânicos que possibilitam adicionar resistência ao seu rolamento. Essa resistência é transferida diretamente por meio da transmissão, e implica em um aumento proporcional do esforço mecânico exercido pelo piloto. Porém, no modelo utilizado nesse trabalho não há indicação ou medição dessa carga. Vale mencionar que nos experimentos realizados nesse projeto foi utilizada uma carga suficientemente grande para impedir o giro livre da roda.

\footnotetext{
${ }^{1}$ http://wattbike.com

${ }^{2}$ http://www.cefise.com.br/
} 


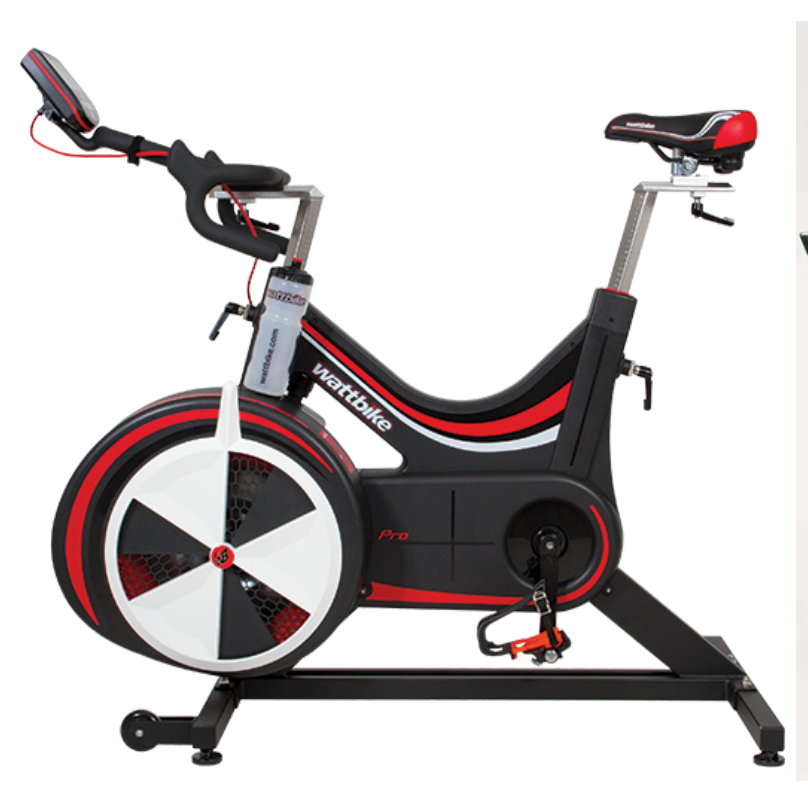

(a) Cicloergômetro Wattbike. Fonte: http://wattbike.com/

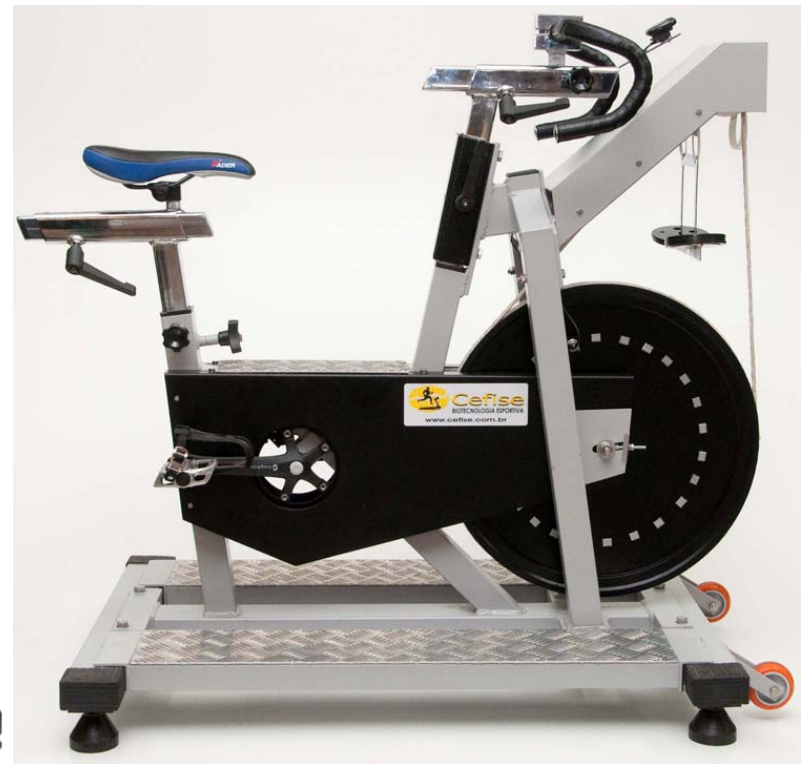

(b) Cicloergômetro Biotec 2100

Figura 3.3: Cicloergômetros utilizados dente trabalho

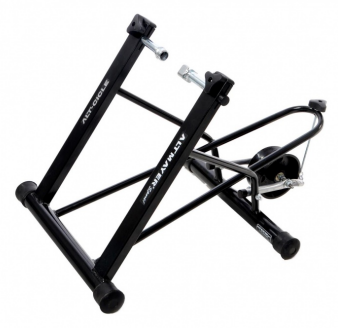

Figura 3.4: Rolo de treinamento para realizar testes com o triciclo estacionário. 


\subsubsection{Estimulador Elétrico}

O estimulador elétrico utilizado é o modelo Rehastim(Hasomed, Alemanha). Ele foi desenvolvido especificamente para FES em aplicações clínicas e científicas ou experimentais. Ele pode ser operado por uma tela touchscreen, sendo possível programação de sequência de estimulação. Em aplicações científicas ou experimentais, é possível conectá-lo à um computador por uma porta USB e controlá-lo em tempo real. O dispositivo é capaz de gerar ondas quadradas bifásicas em frequências até $50 \mathrm{~Hz}$, largura de pulso de até $500 \mu \mathrm{s}$ e intensidade de corrente de até $130 \mathrm{~mA}$. Pode-se ainda gerar pulsos em diferentes frequências ao mesmo tempo[68].

O estimulador possui 8 canais independentes, que são energizados 4 a 4 por duas baterias separadas. As baterias possibilitam que o aparelho seja portátil e possa ser utilizado em ambientes externos, ou onde não há acesso à rede elétrica. O estimulador possui, também, dois sistemas de segurança: um botão de emergência, que desconecta mecanicamente a parte elétrica; e um sistema automático que detecta mal funcionamento nos eletrodos, como descolamento da pele, reduzindo riscos de queimaduras no paciente.

São utilizados eletrodos auto adesivos de $10 \mathrm{~cm}$ x $5 \mathrm{~cm}$ para estimulação elétrica de superfície. Eles são feitos com filamentos de prata que foram desenvolvidos para distribuir a corrente uniformemente ao longo da superfície do eletrodo.

\subsubsection{Unidade de medida inercial}

Para medição de variáveis cinemáticas envolvidas, foi utilizada uma unidade de medida inercial, ou, do inglês, inertial measurement unit (IMU), que integra acelerômetro, giroscópio e magnetômetro, cada um com 3 eixos ortogonais, além de dois botões, um led colorido, e processador embarcado. O dispositivo utilizado funciona com ou sem fio, utilizando um receptor USB e comunicação proprietária em 2.4 GHz. Possui taxa de amostragem de até $1 \mathrm{kHz}$, dependendo do pré-processamento dos dados. São capazes de fornecer os dados dos sensores com ou sem pré-processamento. O equipamento pode fornecer os dados sob diversas formas, como ângulos de Euler, quatérnios, ou matriz de rotação, e permite utilizar tara e diferentes formas de referências

magnéticas e gravitacionais[69]. É possível solicitar dados da IMU sob demanda, um pacote por vez, ou configurá-la para enviar dados continuamente, ou seja, em modo streaming. No último caso, pode-se configurar parâmetros como intervalo entre pacotes, e quais informações estão inclusas no pacote. A figura 3.5 é um diagrama de blocos mostrando o funcionamento da IMU Yei.

\subsubsection{Sistema embarcado de controle}

O sistema embarcado de controle é o sistema responsável por adquirir os sinais dos sensores, processálos, e enviar os comandos ao estimulador elétrico. É nesse sistema que o software de controle desenvolvido é instalado. Sua função é fundamental para que todos os elementos do sistema se comuniquem, gerando o sinal de controle apropriado. É composto por um Raspberry Pi, uma interface de controle do usuário, e uma bateria. Esses elementos são detalhados abaixo.

\section{Raspberry Pi}

Corresponde à principal unidade de processamento do sistema. É onde os sensores e o estimulador são conectados, e onde é instalado o software de controle. A versão utilizada é o Raspberry Pi modelo B+ V 1.2. É um computador completo, compacto ( $85.60 \mathrm{~mm}$ x $56 \mathrm{~mm}$ x $21 \mathrm{~mm}, 45 \mathrm{~g}$ ), com saída de áudio e vídeo HDMI, processador de 700MHz, 512 MB de RAM, leitor de cartão de memória (Micro SD), porta 


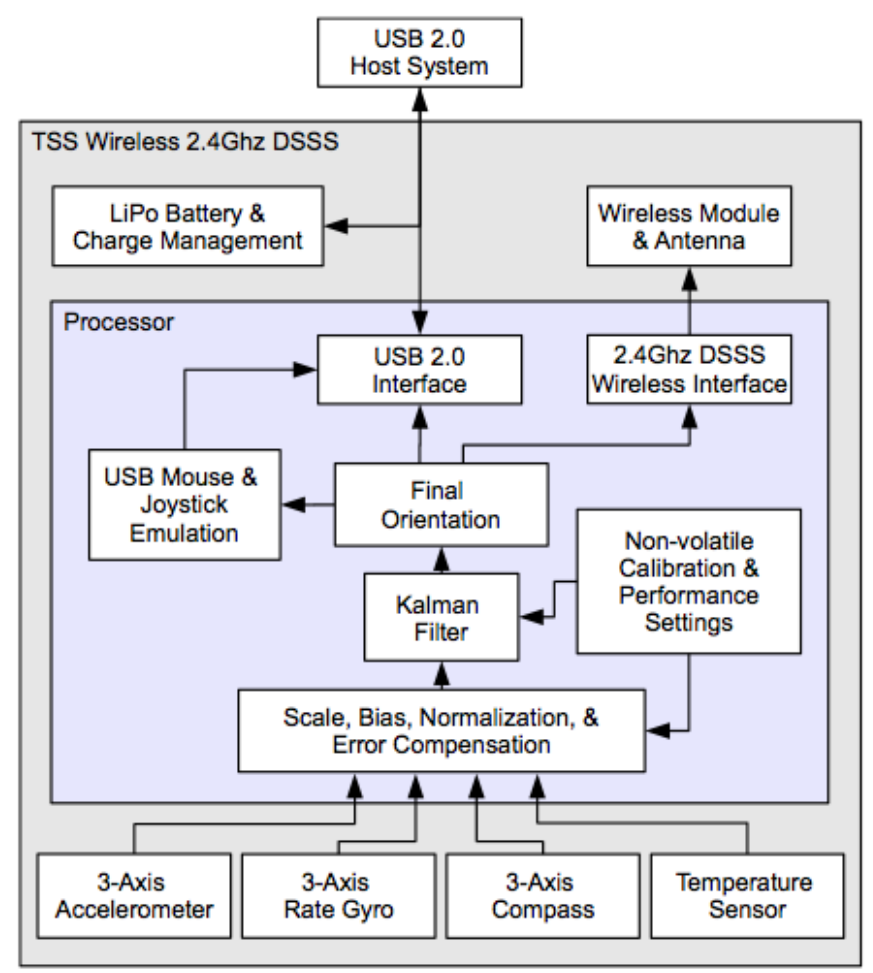

Figura 3.5: Diagrama de funcionamento da IMU [3].

Ethernet 10/100, e portas USB, além de 26 portas de entradas e saídas de propósito genérico[70]

2. Interface de controle do usuário

Para que o usuário do sistema possa iniciar e interromper a estimulação, lhe é fornecido uma IMU que serve como controle remoto. Dos dois botões presentes, um deles inicia a estimulação, enquanto o outro interrompe. A IMU pode ser colocada, com uma pulseira, no punho do indivíduo, mantendo-a segura e acessível.

\section{Bateria}

Para energizar a unidade de controle, foi utilizada uma bateria de lítio de 1450 mAh, 11,1 V. Para conexão à unidade de controle, utiliza-se um regulador de tensão LM2596s e um cabo USB. Todo o conjunto foi enclausurado em uma caixa de plástico e fixado ao bagageiro na parte posterior do triciclo.

\subsubsection{Integração dos sistemas}

Todos os equipamentos foram integrados conforme o diagrama ilustrado na Figura 3.2. O estimulador, unidade de controle, e bateria foram instalados no bagageiro traseiro. A unidade inercial foi instalada na pedivela, e uma segunda unidade inercial foi instalada no guidão. Essa última é utilizada apenas como controle liga/desliga do sistema pelo piloto, através dos seus botões. O botão de emergência foi instalado, também, no guidão, para fácil acesso do piloto. 


\subsubsection{Unidade de Medição Inercial}

A IMU foi instalada na pedivela para que fosse possível a aquisição de informações de velocidade e posição angulares de cada pedal. Por estarem rigidamente acoplados em uma configuração conhecida, a posição e velocidade do segundo pedal podem ser calculadas a partir das respectivas informações do primeiro, dispensando-se o uso de uma segunda IMU. Com as informações de posição e velocidade angular, é possível projetar um sistema que controle essas variáveis por meio da estimulação elétrica, conforme descrito na seção 3.4.2.

Devido ao movimento circular da pedivela durante o uso do triciclo, optou-se por utilizar uma IMU sem fios, com o intuito de evitar enrolamento dos fios. Portanto ela foi utilizada na função wireless. Para isso, é utilizado um receptor USB do mesmo fabricante para a comunicação.

Dentre os dados que as IMUs utilizadas são capazes de fornecer, neste trabalho foram utilizados ângulos de Euler com tara. Dessa forma o sistema de referência do sensor é relativo ao triciclo, e não à referências magnéticas ou gravitacionais. Não houve problemas com Gimbal lock pois, como todos os experimentos foram realizados com o triciclo estacionário, a IMU sempre gira em um mesmo plano. .

\subsection{SOFTWARE}

O desenvolvimento de um software foi necessário para permitir a captura de dados fornecidos pelas IMUs, processar esses dados, calcular o sinal de estimulação apropriado e envio desse sinal para o eletroestimulador em tempo real. Mesmo sendo possível conectar um monitor ao Raspberry Pi, a versão 1.2 utilizada não demonstrou capacidade de reproduzir os gráficos desejados em tempo real. Para facilitar o monitoramento dos dados experimentais, utilizaram-se computadores de maior potência durante os experimentos. Por isso, para que o sistema fosse compatível com múltiplas plataformas, tanto para testes quanto para aplicações com o usuário final, foi realizado um estudo envolvendo diferentes linguagens de programação a fim de escolher a mais apropriada. Python, Java e C foram avaliadas quanto à:

- portabilidade entre Windows, Linux, e OSX

- viabilidade de portabilidade para plataformas mobile, como Android e iOS

- taxa de transmissão e processamento de dados da IMU com e sem fio

- facilidade de programação e familiaridade dos membros da equipe com a linguagem

Para essas avaliações, foram feitos três programas, um em cada linguagem, que coletavam dados da IMU, extraiam os três ângulos de Euler e imprimiam na tela. O software desenvolvido na linguagem Python atendeu a todos os quesitos e foi escolhido como linguagem de programação. Além disso, a unidade de controle utilizada possui um sistema Linux embarcado, e o interpretador Python é instalado por padrão nesse sistema, representando mais uma vantagem na utilização dessa linguagem.

A arquitetura do software pode ser dividida em comunicação com dispositivos; controle; e visualização e debug. As subseções a seguir apresentam os detalhes de cada parte. Todo o código está disponível abertamente no GitHub ${ }^{3}$.

\footnotetext{
${ }^{3}$ https://github.com/lara-unb/ema-trike.git
} 


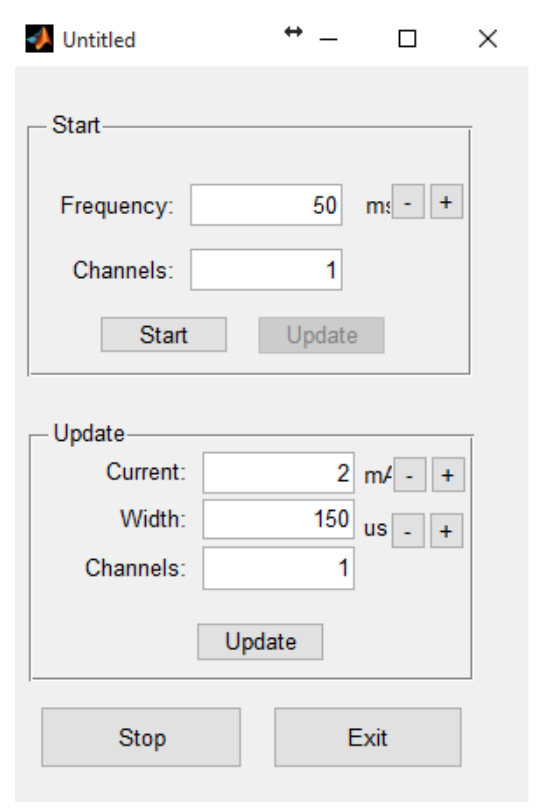

Figura 3.6: Aplicativo desenvolvido em Matlab para testes rápidos do estimulador.

\subsubsection{Comunicação com dispositivos}

\subsubsection{Comunicação com as IMUs}

A comunicação com as IMUs pode ser direta, quando a conexão for com fio, ou por meio do receptor, quando for sem fio. Na conexão sem fio, um receptor pode se comunicar com até 15 IMUs. A configuração de quais IMUs se comunicam com cada receptor fica armazenada em uma tabela de endereços.

A unidade de controle se comunica com a IMU com um protocolo de comunicação por porta serial fornecido pelo fabricante. Existem, também, bibliotecas em $\mathrm{C}$ e em Python que que implementam o protocolo. Entretanto, essas bibliotecas não são compatíveis com os sistemas operacionais Linux e OSX e, por isso, não foram utilizadas. Portanto uma biblioteca de comunicação com a IMU foi desenvolvida e disponibilizada para este e outros projetos. Essa biblioteca implementa uma classe, IMU, que possui os seguintes parâmetros e funções:

- Parâmetros

- serial_por: salva as configurações de porta serial utilizado para se comunicar com o sensor ou receptor responsável pela comunicação com o sensor.

- address: salva o endereço do sensor na tabela de endereços do receptor.

- Funções

- calibrate: executa o procedimento de auto calibração da IMU.

- setEulerToYXZ: configura a orientação dos ângulos de Euler para YXZ.

- tare: tara a IMU

- sync_timestamp: sincroniza os timestamps de todas as IMUs com o timestamp do receptor. 
- reset_timestamp: reinicia o timestamp da IMU

- checkButtons: retorna o estado dos botões da IMU

- getEulerAngles: retorna os ângulos de Euler considerando a tara

- getUntaredQuaternions: retorna os quatérnios considerando a tara

- getUntaredQuaternionsAsBytes: retorna os quatérnios desconsiderando a tara

- startStreaming: inicia o streaming de dados

- stop_streaming: finaliza o streaming de dados

- getGyroData: retorna os dados de rotação da IMU

- single Command: executa um único comando

- listen_streaming: retorna os dados sendo enviados por streaming.

Além da classe $I M U$, a biblioteca também implementa as seguintes funções:

- Funções de suporte

- readData: lê os dados disponíveis na porta serial

- bytesToFloat: concatena 4 bytes em um float.

- get_port: retorna todas as portas seriais onde receptores ou a IMUs estão conectados

\subsubsection{Comunicação com o estimulador}

Assim como a IMU, o estimulador também possui um protocolo de comunicação serial fornecido pelo fabricante. Da mesma forma, uma biblioteca para esse dispositivo foi desenvolvida com a classe Stimulator:

- Parâmetros

- serial_port: salva as configurações de porta serial utilizado para se comunicar com o estimulador.

- Funções

- initialization: inicializa o processo de estimulação com corrente nula, indicando os canais a serem utilizados e a frequência de estimulação

- update: atualiza os parâmetros de estimulação, incluindo largura de pulso e intensidade de corrente

- stop: finaliza o processo de estimulação

Além da classe Stimulator, a biblioteca também implementa as seguintes funções:

- Funções de suporte:

- get_port: retorna todas as portas seriais onde há estimuladores conectados

Essa biblioteca foi desenvolvida com base nas funções em Matlab desenvolvida por [71] e de acordo com o protocolo descrito em [68]. 


\subsubsection{Algoritmo de Controle em Tempo Real}

O algoritmo de controle é responsável por coletar as informações dos sensores, processá-las e enviar comandos ao estimulador. Aqui também são gerenciadas as conexões por portas seriais, calibração da IMU, os gráficos para debug, e o registro de todas os dados do experimento para análise posterior. O algoritmo 3.1 descreve o pseudocódigo do sistema. Primeiramente as conexões com todos os dispositivos são estabelecidas. Em seguida, a IMU é calibrada e é feita a tara, e o estimulador é inicializado com informações iniciais, que contemplam os canais que serão utilizados e a frequência de estimulação. A partir desse momento, o sistema está pronto para iniciar e aguarda o indivíduo pressionar o botão apropriado na interface de usuário. Quando o botão é pressionado, o gráfico de visualização das variáveis aparece na tela e o loop de controle inicia-se. $\mathrm{O}$ loop consiste em solicitar a posição e a velocidade angular da IMU, aplicar as duas malhas de controle, calcular o sinal de estimulação, e enviar esse sinal ao estimulador. Esse loop é repetido até que o usuário pressione o botão de interrupção. Nesse momento o software armazena todas as variáveis (velocidade angular, posição angular, sinal de controle, sinal de erro, e timestamps) em memória não volátil, encerra as conexões com todos os dispositivos e termina.

Os cálculos executados pela fase de controle são descritos na seção 3.4.2.

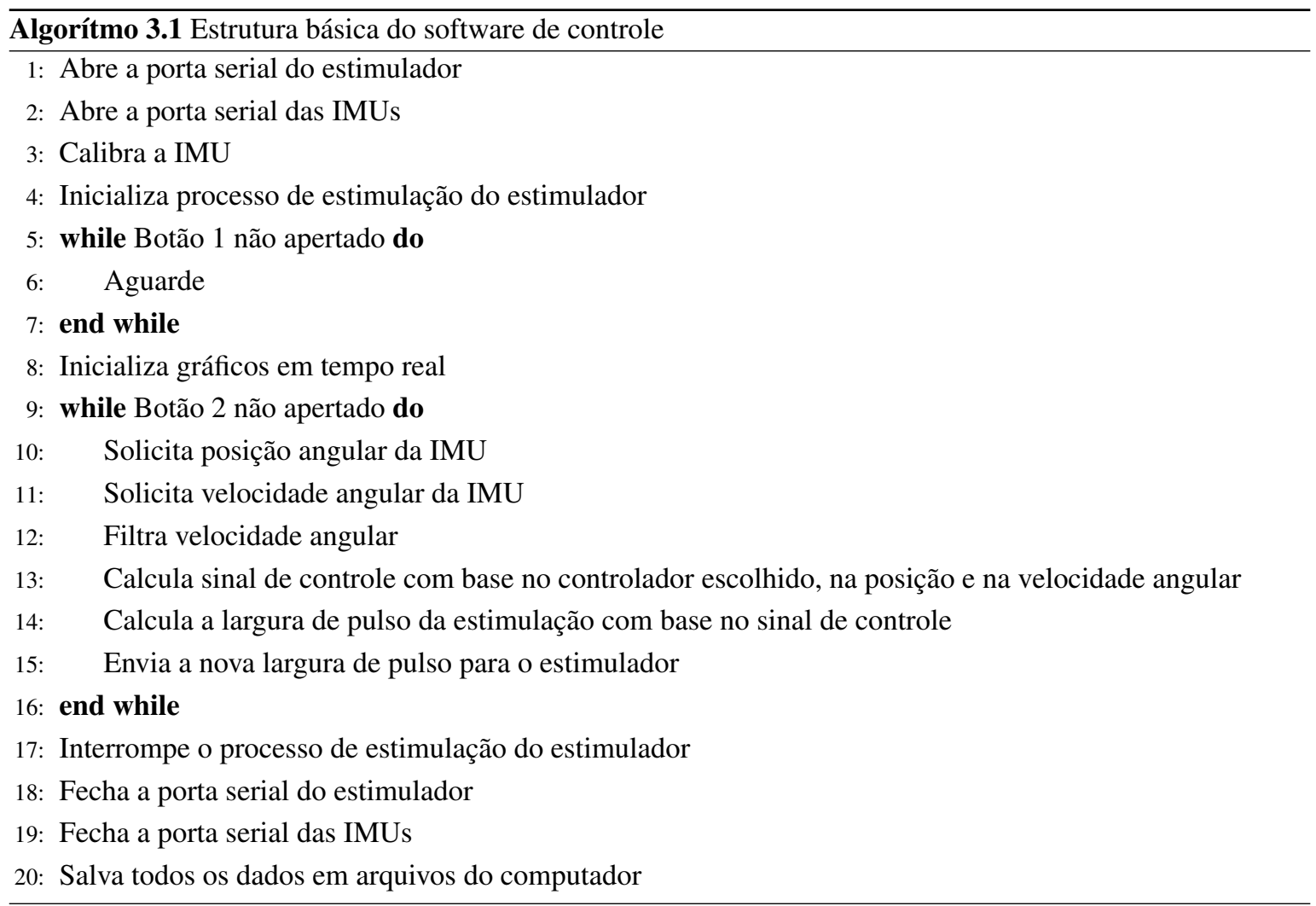

\subsubsection{Visualização de dados e debug}

A fim de facilitar a análise qualitativa do desempenho dos controladores, o sistema possibilita a visualização de representações gráficas, em tempo real, de um subconjunto de variáveis de controle e observação do sistema. A quantidade de variáveis envolvidas, bem como suas naturezas, fazem com que representações gráficas sejam 
apropriadas para a visualização. Portanto, gráficos em tempo real, como o da figura 4.7 são exibidos durante os experimentos.

\subsubsection{Aplicativos de apoio}

O conjunto de software desenvolvido nesse trabalho possui a função de garantir a conexão entre os diferentes equipamentos em tempo real, bem como a execução de algoritmos de controle. Dessa forma, além do software principal desenvolvido para o sistema embarcado de controle, foram utilizadas ferramentas para validação de elementos individuais do sistema.

Inicialmente, para familiarização e configuração das IMUs Yei, foi utilizado o software fornecido pelo fabricante, 3-Space Sensor Suite[3]. Com ele é possível testar as IMUs, ativar e desativar cada um dos sensores, configurar o receptor e conectar-se com os sensores, realizar coletas de dados, além de outros recursos.

O estimulador elétrico foi inicialmente utilizado com o software embarcado no próprio equipamento. Entretanto, esse software é muito limitado para aplicações científicas de controle, onde é necessário realizar ajustes nos parâmetros durante a estimulação, algo que o software embarcado não permite. Portanto foi desenvolvido um aplicativo em MatLab (Mathworks, Estados Unidos da América) ${ }^{4}$ que é capaz de executar a maior parte dos comandos disponíveis para o estimulador, como controlar os canais de estimulação, frequência dos pulsos, intensidade de corrente e largura de pulso; tudo durante a estimulação e com comandos simples em uma interface gráfica demonstrada na figura 3.6. Para o desenvolvimento desse aplicativo, trabalhos anteriores foram utilizados como referência[71], bem como o protocolo de comunicação descrito em [68].

\subsection{ESTRATÉGIAS DE CONTROLE}

Com o objetivo de explorar formas de parametrizar a estimulação elétrica, este trabalho investigou diferentes estratégias de controle. O objetivo do controlador é atuar para que a velocidade angular da pedivela seja a mesma que uma referência indicada. Para isso, ele deve gerar movimentos eficientes dos pontos de vista neuromuscular e biomecânico. Inicialmente, um controle em malha aberta é descrito na subseção3.4.1. Posteriormente um controlador PI adaptado para as condições de ciclismo com FES é detalhado na subseção 3.4.2. A avaliação e comparação de desempenho de diferentes controladores em testes envolvendo indivíduos hígidos são apresentados no capítulo 4. As subseções a seguir explicam o funcionamento de cada controlador.

\subsubsection{Malha aberta em cicloergômetro}

Inicialmente, uma serie de testes foi realizado em malha aberta. Com esses testes, foi possível ter uma percepção inicial dos efeitos da estimulação elétrica na fadiga muscular, além de servir como baseline para o teste com controlador em malha fechada. Também foram testadas diferentes combinações de músculos a serem estimulados e parâmetros de estimulação. Além disso, esses testes serviram para verificar a viabilidade de gerar movimentos cíclicos de pedalada com estimulação elétrica.

O padrão típico de ativação muscular de um indivíduo hígido durante a atividade de pedalar é complexo e envolve vários músculos [72]. Tal sofisticação, no entanto, não é estritamente necessária: Consegue-se pedalar

${ }^{4}$ http://www.mathworks.com/products/matlab/ 


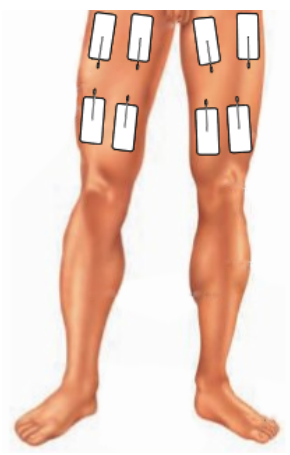

(a) Configuração 1, com dois canais em cada quadríceps

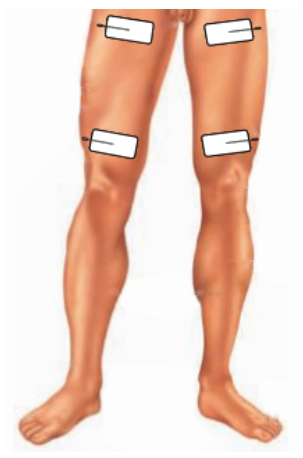

(b) Configuração 2, com um canal em cada quadríceps

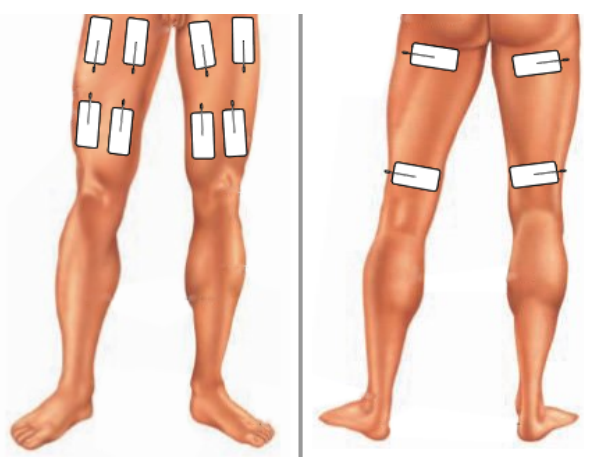

(c) Configuração 3, com dois canais em cada quadríceps e um canal em cada bíceps femoral

Figura 3.7: Posicionamento de eletrodos para os experimentos em malha aberta.[4]

de maneira efetiva apenas por meio de empurrões e puxões alternados nos pedais.. Baseando-se nesse conceito, este controlador visa estimular cada músculo envolvido no momento apropriado, ou seja, quando o membro inferior deve executar uma extensão, os quadríceps são estimulados, e, quando o membro deve executar uma flexão, os bíceps femorais são estimulados. Dessa forma, dois conjuntos de grupos musculares diferentes foram avaliados: quadríceps e bíceps femorais.

Ao todo foram testadas três configurações de eletrodos, de acordo com a figura 3.7.:

1. apenas nos quadríceps, com um canal para o vasto lateral e outro para o vasto medial[73], conforme figura 3.7a;

2. apenas quadríceps com apenas um canal para todo o grupo muscular, conforme figura 3.7b;

3. quadríceps e bíceps femoral, com um canal para o vasto lateral e outro para o vasto medial, conforme figura $3.7 \mathrm{c}$

Foram avaliados três padrões de estimulação:

1. quadríceps alternados entre si

2. quadríceps alternados entre si e bíceps femorais sincronizados com os quadríceps contralaterais

3. quadríceps alternados entre si e bíceps femorais com estimulação constante

Esses padrões foram programados no próprio estimulador, sem necessidade de uma unidade de controle. O dispositivo permite programar tempos de início e fim da estimulação em cada canal, de forma independente. Como exemplo de um teste com a configuração de eletrodos 2 e padrão de estimulação 1, em um ciclo completo de 2,4s, o algoritmo 3.2 é programado no estimulador.

Diagrama de blocos contendo:

- Inputs:

- Tempo de estimulação 


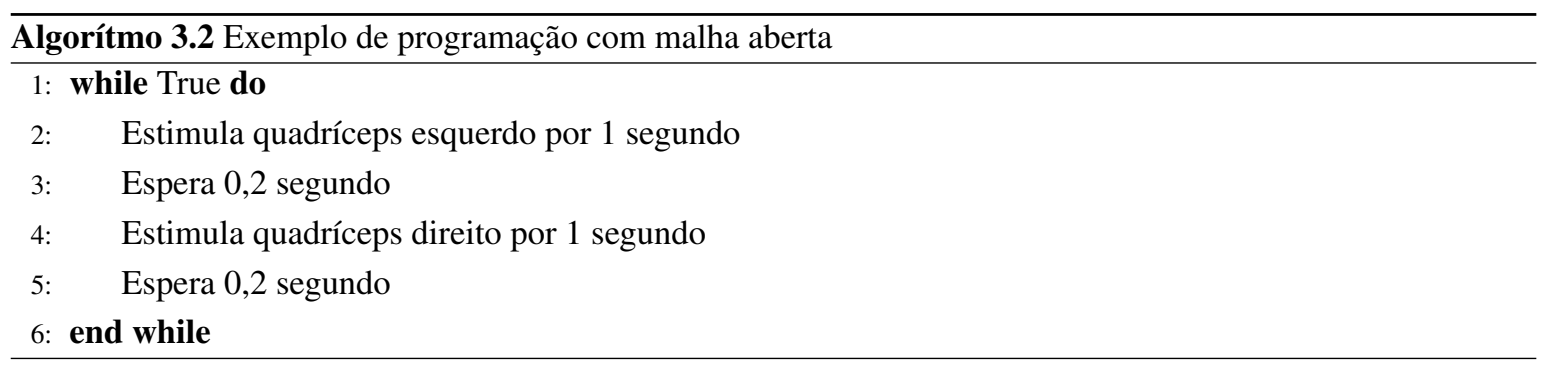

- Parâmetros de estimulação

- Estimulador

- Eletrodos

- Sistema neuromuscular

- Sensor de rotação na roda

- Sistema de medição de potência

- Output:

- Potência desenvolvida

\subsubsection{PI com perfil de estimulação adaptativo com a velocidade da pedivela}

Este controlador é composto por duas malhas. A primeira é um PI com anti wind-up que avalia a velocidade angular da pedivela e atua na estimulação alterando a largura de pulso, buscando a velocidade de referência. Uma maior largura de pulso gera uma maior contração muscular, uma extensão mais rápida da perna e, consequentemente, um aumento na velocidade. Esse controlador possui um valor nominal, $\overline{u_{x}}$, e é atualizado a cada iteração pelos parâmetros $K_{P}$ e $K_{I}$. A escolha da atuação na largura de pulso seguiu os resultados do trabalho de [46], conforme descrito em na seção 2.3.3.

Em paralelo à esse controle, existe um perfil de estimulação que define em qual momento a estimulação deve ocorrer. A figura 3.8a mostra esses momentos. A equação 3.1 define, de acordo com [9], esse perfil, onde $\theta_{x}^{\min }$ é o ângulo onde a estimulação inicia, $\theta_{x}^{\max }$ é o ângulo onde a estimulação é interrompida, e $\theta$ é o ângulo atual da pedivela.

A segunda malha de controle avalia a velocidade angular para ajustar o perfil de pedalada explicado anteriormente. Essa intervenção foi realizada de acordo com o trabalho de[9], que indica que o perfil de estimulação é alterado com o aumento da velocidade angular da pedivela. Esse shift acontece devido aos atrasos envolvidos no sistema fisiológico. Com o aumento da velocidade, é preciso enviar o comando de atuação para o estimulador com mais antecedência, e, da mesma, forma, interromper a estimulação mais cedo. A figura 3.8b mostra o shift do perfil para velocidade de $300^{\circ} / \mathrm{s}$. A equações 3.2 e 3.3, juntamente com os parâmetros nominais da tabela 3.1, descrevem o shift. Nas equações, $\theta_{e s q}^{\min }$ e $\theta_{\text {dir }}^{\min }$ são os valores iniciais para o ângulo onde a estimulação é acionada para as pernas esquerda e direita, respectivamente. O parâmetro $\theta_{x}^{s h}$ é o shift máximo do perfil, que ocorre quando a velocidade máxima, $\omega_{\max }$, é alcançada. 


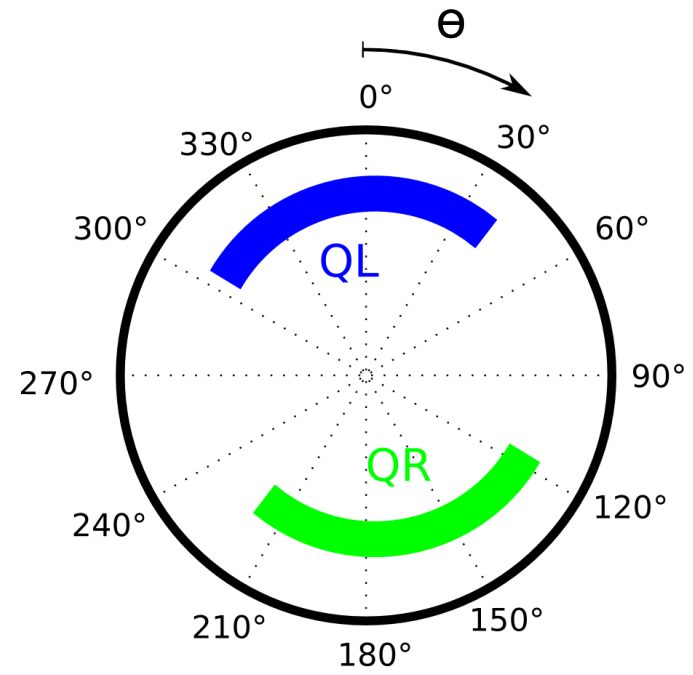

(a) Perfil de estimulação para $\omega=0^{\circ} / \mathrm{s}$

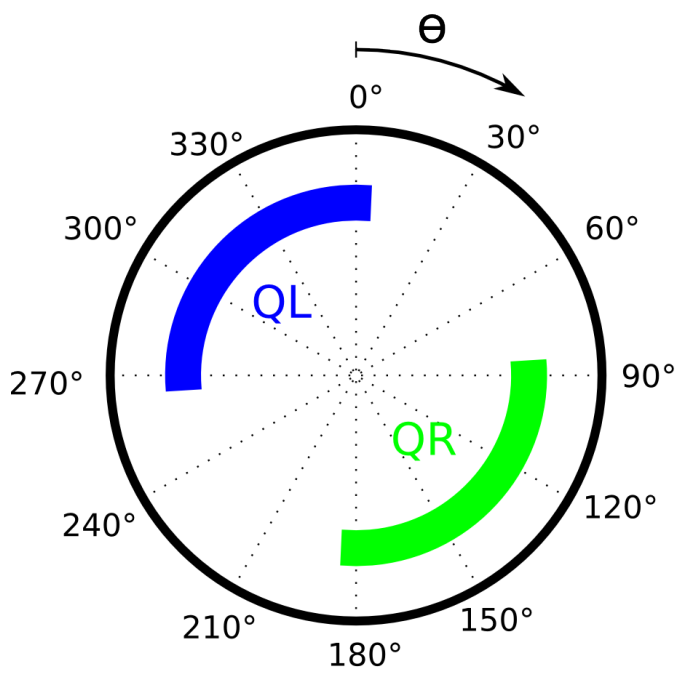

(b) Perfil de estimulação para $\omega=300^{\circ} / \mathrm{s}$

Figura 3.8: Perfil de estimulação em diferentes cadências. Os ângulos são referentes à posição angular do pedal esquerdo, onde a posição superior é a posição inicial. A fase azul é a fase de estimulação do quadríceps esquerdo (do inglês, quadríceps: left, QL), e a fase verde é a fase de estimulação do quadríceps direito (do inglês, quadríceps: right, QR). A pedivela gira no sentido horário, crescente com o valor dos ângulos [5].

A tabela 3.1 apresenta todos os valores nominais e parâmetros do controlador. Finalmente, o sinal de controle final é formado pelas duas malhas de controle, de acordo com a equação 3.4. A figura 3.9 apresenta o diagrama de blocos do controle.

$$
\begin{gathered}
f_{x}(\theta, \omega)= \begin{cases}1 & \theta_{x}^{\min }(\omega)<\theta<\theta_{x}^{\max }(\omega), \\
0 & \text { caso contrário }\end{cases} \\
\theta_{x}^{\min }(\omega)=\theta_{x}^{\min }-\left(\frac{\omega}{\omega_{\max }} \theta_{x}^{\overline{s h}}\right) \\
\theta_{x}^{\max }(\omega)=\theta_{x}^{\min }(\omega)+\theta_{x}^{\overline{r g}} \\
u_{x}=f_{x}(\theta, \omega) f(\omega)
\end{gathered}
$$

- Inputs:

- Velocidade angular de referência: $300^{\circ} / s$. Esse valor foi definido arbitrariamente por condizer com uma cadência real de ciclismo.

- Cálculo do erro.

- Controlador.

- Estimulador

- Eletrodos

- Sistema neuromuscular 
Tabela 3.1: Valores nominais e parâmetros utilizados no experimento em malha fechada

\begin{tabular}{|c|c|}
\hline Parâmetro & Valor \\
\hline \hline$\theta_{\text {esq }}^{\min }$ & $300^{\circ}$ \\
\hline$\theta_{d i r}^{\min }$ & $120^{\circ}$ \\
\hline$\theta_{x}^{\text {sh }}$ & $35^{\circ}$ \\
\hline$\theta_{x}^{\overline{r g}}$ & $100^{\circ}$ \\
\hline$\omega_{\max }$ & $300^{\circ} / s$ \\
\hline$\overline{u_{x}}$ & $250 \mu s$ \\
\hline$K_{P}$ & 0,5 \\
\hline$K_{I}$ & 0,005 \\
\hline
\end{tabular}

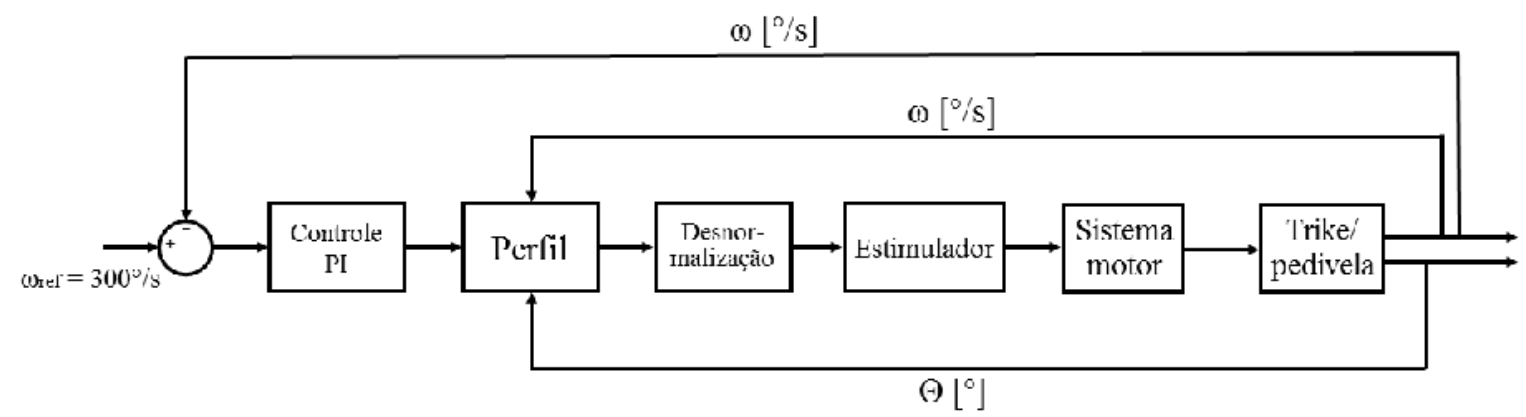

Figura 3.9: Diagrama de blocos do controlador em malha fechada. O Controle PI recebe o erro entre a velocidade angular medida e a referência. Após calcular o sinal de controle, esse é enviado ao Perfil, que avalia, baseado na velocidade angular e posição angular da pedivela, se a estimulação deve ocorrer naquele momento. Se sim, o sinal de controle é passado adiante, desnormalizado e enviado ao estimulador. Esse causa a contração muscular que atua na pedivela.

- Força nos pedais

- Output:

- Velocidade angular do pedivela pela IMU

- Posição angular do pedivela pela IMU, realimentando o controlador diretamente.

- Fecha a malha.

A figura 3.10 apresenta um diagrama de bloco do sistema completo, em malha fechada.

\subsection{PROTOCOLOS EXPERIMENTAIS}

As próximas subseções apresentam os protocolos experimentais utilizados nos experimentos. Em cada caso, diferentes equipamentos foram utilizados, e diferentes sistemas de medição. Entretanto, o principal objetivo de realizar esses testes é comparar as diferentes condições, como equipamentos e controladores, com relação ao tempo que o indivíduo consegue manter a atividade de pedalada antes que a fadiga interrompa o 


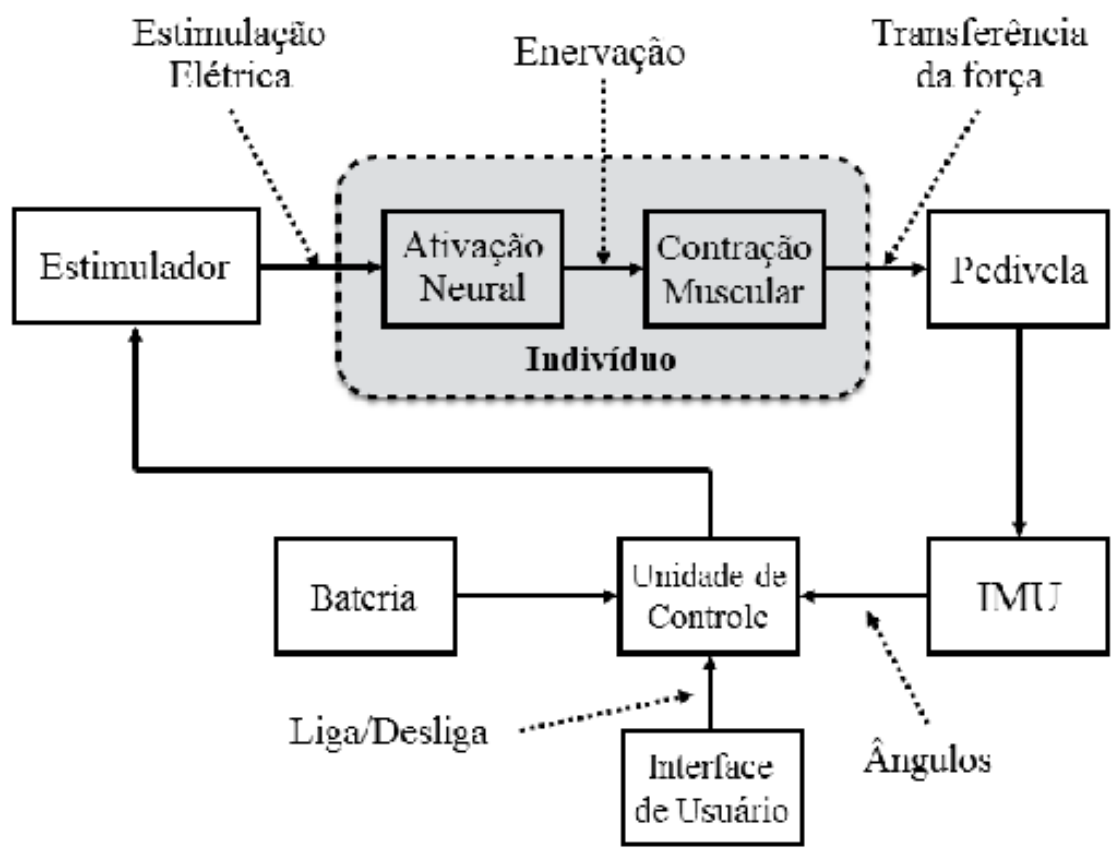

Figura 3.10: Diagrama de bloco do sistema completo. A unidade de controle recebe os ângulos da IMU, calcula o sinal de estimulação e envia para o estimulador. O estimulador envia pulsos elétricos que ativam os nervos, causando contração muscular. Essa contração gera força nos membros inferiores, que é transferida para o pedal e causa o gira da pedivela. Esse giro é captado pela IMU e o laço de controle se fecha. Há, ainda, uma interface de usuário conectada à Unidade de Controle que o indivíduo pode usar para ligar ou desligar o sistema. 
exercício. Nesse caso, todos os sistemas de medição utilizados são capazes de fornecer dados suficientes para a comparação desejada.

A subseção 3.5.1 descreve o protocolo utilizado com o controlador em malha aberta apresentado na seção 3.4.1, e a subseção 3.5.2 descreve o protocolo utilizado com o controlador apresentado na seção 3.4.2.

\subsubsection{Malha aberta em cicloergômetro}

Os primeiros testes foram realizados nos cicloergômetros apresentados na seção 3.2.1.2. Os objetivos eram os listados a seguir, sempre no contexto de estimulação elétrica para ciclismo:

- Familiarização com o estimulador elétrico, sua programação, e posicionamento de eletrodos.

- Entender as diferenças na aplicação da estimulação elétrica em músculos mais ou menos desenvolvidos

- Entender as vantagens e desvantagens nas posições recumbente e vertical

- Investigar as diferenças entre configurações de eletrodos

- Investigar diferentes padrões de estimulação

Os eletrodos foram posicionados nos quadríceps e bíceps conforme figura 3.7, com o objetivo de atingir a maior área muscular, bem como o ponto motor, que é o ponto de enervação do músculo. Foram utilizados eletrodos de $5 \times 10 \mathrm{~cm}$.

Primeiramente era realizada uma calibração da corrente com largura de pulso fixa em $400 \mu s$, em frequência em $50 \mathrm{~Hz}$, a intensidade de corrente era aumentada, de $2 \mathrm{em} 2 \mathrm{~mA}$, até o movimento total de extensão era realizado. A largura de pulso tem esse valor para que fosse utilizado um valor alto permitido pelo estimulador $\mathrm{e}$, ainda assim, permitir incrementos finos, caso necessário. A corrente ficava definida para aquele sujeito. $\mathrm{O}$ processo era repetido para a outra perna. No caso do bíceps femoral, a estimulação elétrica era incrementada até o nível máximo que o indivíduo ainda se sentia confortável. Com os parâmetros de estimulação definidos, o estimulador era programado conforme foi explicado na seção 3.4.1

O estimulador era, então, programado conforme o exemplo apresentado no algoritmo 3.2. Os tempos eram inicializados com $1 \mathrm{~s}$ para cada perna e $0,1 \mathrm{~s}$ de intervalo. Esses tempos foram definidos de tal forma que fosse gerado um movimento lento, facilitando a sincronização entre as duas pernas. A estimulação era iniciada e era pedido ao indivíduo que, ativamente, completasse revoluções de 2,2 segundos em sincronia com o sistema. Depois disso, pedia-se que ele(a) relaxasse o máximo possível. Os tempos de estimulação e intensidade de corrente de cada canal eram, então, ajustados conforme necessidade. Caso a extensão estivesse ocorrendo muito rapidamente, o tempo ou a corrente eram diminuídos, e aumentados caso contrário, sempre buscando uma atividade de pedalada suave e contínua, ou, em outras palavras, com uma velocidade angular o mais próxima possível de constante.

Esses testes foram realizados por três voluntários hígidos, com idade média de 25,3 anos e desvio padrão de 2,9 anos, peso médio de $67 \mathrm{~kg}$ e desvio padrão de $6,4 \mathrm{~kg}$, e altura média de $1,70 \mathrm{~m}$ e desvio padrão de $0,06 \mathrm{~m}$. Para o teste na posição recumbente o banco do ciclo ergômetro foi removido e foi feita uma adaptação como assento atrás do ciclo, conforme figura 4.3b. Além das configurações de eletrodos e dos padrões de estimulação apresentados na seção 3.4.1, as seguintes variáveis foram, também, avaliadas:

- Duas posturas do piloto foram testadas: 
Tabela 3.2: Lista dos experimentos realizados com controlador em malha aberta. * Método de calibração diferenciado, onde a calibração da corrente é feita em movimento.[4]

\begin{tabular}{|c|c|c|c|c|}
\hline Teste \# & Nível de atividade física & Configuração de eletrodos & Padrão de estimulação & Posição \\
\hline \hline 1 & 1 & 3 & 1 & 2 \\
\hline 2 & 1 & 3 & 2 & 2 \\
\hline 3 & 1 & 3 & 3 & 2 \\
\hline 4 & 2 & 3 & 3 & 2 \\
\hline 5 & 2 & 3 & 3 & 1 \\
\hline 6 & 2 & 3 & $3 *$ & 1 \\
\hline 7 & 3 & 1 & 1 & 1 \\
\hline 8 & 3 & 1 & 1 & 2 \\
\hline 9 & 3 & 2 & 1 & 2 \\
\hline 10 & 3 & 3 & 3 & 2 \\
\hline
\end{tabular}

1. Vertical

2. Recumbente

- Nível de atividade física exercida regularmente pelo piloto:

1. Alta (3 ou mais vezes por semana)

2. Moderada (1 a 2 vezes por semana)

3. Baixa (não pratica atividade física)

Depois de todos os testes, um protocolo diferente de calibração da corrente foi testado: era solicitado que o indivíduo mantivesse uma pedalada de cerca de $2 s$ por revolução, tempo semelhante ao utilizado no passo anterior. Durante a pedalada a corrente era ajustada com o objetivo de manter o movimento em velocidade angular constante. Era solicitado que o piloto reduzisse o esforço voluntário a medida que a corrente aumentava, de modo que chegava o momento em que não havia nenhum esforço voluntário, e todo o torque era gerado pela estimulação elétrica. Esse teste foi feito apenas na posição vertical, por um indivíduo, na configuração 3 de eletrodos, e no padrão 3 de estimulação. Na tabela 3.2, esse teste foi apresentado como o de número 6.

\subsubsection{Malha fechada no triciclo}

Estes testes foram realizados no triciclo e rolo de treinamento descritos na seção 3.2.1. A intensidade de corrente foi calibrada no limite de conforto do piloto, antes de atingir o limiar de dor, em $500 \mu \mathrm{s}$, que é a máxima largura de pulso fornecida pelo controlador. A frequência utilizada foi de $50 \mathrm{~Hz}$. Apenas um canal em cada quadríceps foi utilizado.

Era pedido que o indivíduo se preparasse para o início do experimento com o pedal esquerdo na posição superior, onde o ângulo da pedivela é definido como 0, de acordo com a figura 3.8. Era entregue ao indivíduo uma IMU e, quando o sistema estava acionado, ele poderia pressionar um de seus botões e o controlador passava a funcionar. O teste era monitorado por vídeo e todas as variáveis de controle, ângulos, parâmetros 
de estimulação e erro eram monitoradas em tempo real na tela do computador. O experimento era finalizado, e a estimulação interrompida, quando o movimento de pedalada não era mais sustentado pela estimulação ou quando o indivíduo relatava desconforto. A estimulação e o experimento poderiam ser finalizados pelo indivíduo ao pressionar o outro botão da IMU, ou por comando remoto do computador em controle.

Todos os experimentos em malha fechada foram realizados por dois voluntários hígidos, com idade média de 30 anos e desvio padrão de 5,7 anos, peso médio de $70 \mathrm{~kg}$ e desvio padrão de $7 \mathrm{~kg}$, e altura média de $1,72 \mathrm{~m}$ e desvio padrão de $0,05 \mathrm{~m}$. 


\section{RESULTADOS}

Os experimentos realizados neste trabalho demonstraram detalhes práticos da aplicação de FES, como a forma de posicionar os eletrodos, além do potencial de um controlador de malha fechada, quando comparado com um de malha aberta. Também foi possível obter dados comparativos com trabalhos recentes e estado da arte. Este capítulo apresenta os resultados dos testes e experimentos descritos no capítulo 3. Na seção 4.1 são apresentados os resultados dos experimentos realizados com o controlador de malha aberta descrito na seção 3.4.1. Na seção 4.2 são apresentados os resultados obtidos nos experimentos com o controlador em malha fechada, descrito na seção 3.4.2. A seção 4.3 discute esses resultados.

\subsection{CONTROLE EM MALHA ABERTA}

Durante as seções envolvendo controle em malha aberta foram realizados testes com diferentes combinações de grupos musculares, posicionamento de eletrodos, e posicionamento dos indivíduos no equipamento. Inicialmente, testes exploratórios foram realizados na Wattbike. A figura 4.1 mostra um indivíduo durante um desses testes. A Wattbike é capaz de medir a força aplicada nos pedais durante todo o exercício, e gera gráficos como o da figura 4.2a. Essa figura representa uma revolução realizada com estimulação elétrica alternada de quadríceps. A figura $4.2 \mathrm{~b}$ apresenta o mesmo tipo de gráfico, mas demonstrando diversas revoluções feitas por um ciclista treinado de alto desempenho, para efeitos de comparação.

Após os testes exploratórios, novos experimentos foram realizados no cicloergômetro Biotec 2100. Nesses experimentos, foi seguido o protocolo descrito em 3.5.1. A figura 4.3 mostra dois desses testes em andamento.

Conforme explicado na seção 3.5.1, os parâmetros de estimulação foram $50 \mathrm{~Hz}$ de frequência e $400 \mu$ s de largura de pulso. A intensidade da corrente era calibrada para cada indivíduo, levando-se em consideração se ele conseguia movimentar os pedais, e seu nível de conforto. As intensidade de corrente calibradas ficaram entre 14 e 20mA para o indivíduo com alto nível de atividade física, 30 e 36mA para o indivíduo com nível de atividade física moderado, e 42 e $46 \mathrm{~mA}$ para o indivíduo com baixo nível de atividade física.

As figuras 4.4a e 4.4b apresentam os resultados dos testes 1 e 3, que comparam o desempenho do indivíduo com alto nível de atividade física com estimulação alternada apenas nos quadríceps, na sua primeira sessão, e com estimulação alternada nos quadríceps e constante nos bíceps femorais, na sua terceira sessão; e as figuras 4.4c, 4.4d, e 4.4e apresentam os resultados dos testes 8, 9 e 10, que comparam as três sessões do indivíduo com baixo nível de atividade física. Todos os testes apresentados nessas figuras foram realizados na posição recumbente, e são descritos na seção 3.5.1. Nessas figuras é apresentada a cadência, em \% $/ \mathrm{s}$, desenvolvida nos testes. A cadência foi medida na roda de tração do cicloergômetro.

A figura 4.4a mostra o indivíduo A mantendo uma cadência de $150 \% \mathrm{~s}$ por cerca de $20 \mathrm{~s}$ e depois uma queda. A figura $4.4 \mathrm{~b}$ tem um comportamento semelhante, porém com a queda ocorrendo em aproximadamente $29 \mathrm{~s}$. A figura $4.4 \mathrm{c}$ mostra o indivíduo C mantendo uma cadência de aproximadamente $200 \% \mathrm{~s}$ por cerca de $20 \mathrm{~s}$, e depois a queda. A figura 4.4d mostra o mesmo indivíduo mantendo a mesma cadência por $10 \mathrm{~s}$, e, na figura $4.4 \mathrm{e}$, ele adota um comportamento instável inicialmente, atingindo um pico de $242^{\circ} / \mathrm{s}$, depois estabiliza momentaneamente em aproximadamente $175^{\circ} / \mathrm{s}$, até a queda em $11 \mathrm{~s}$. O equipamento utilizado nesses testes 


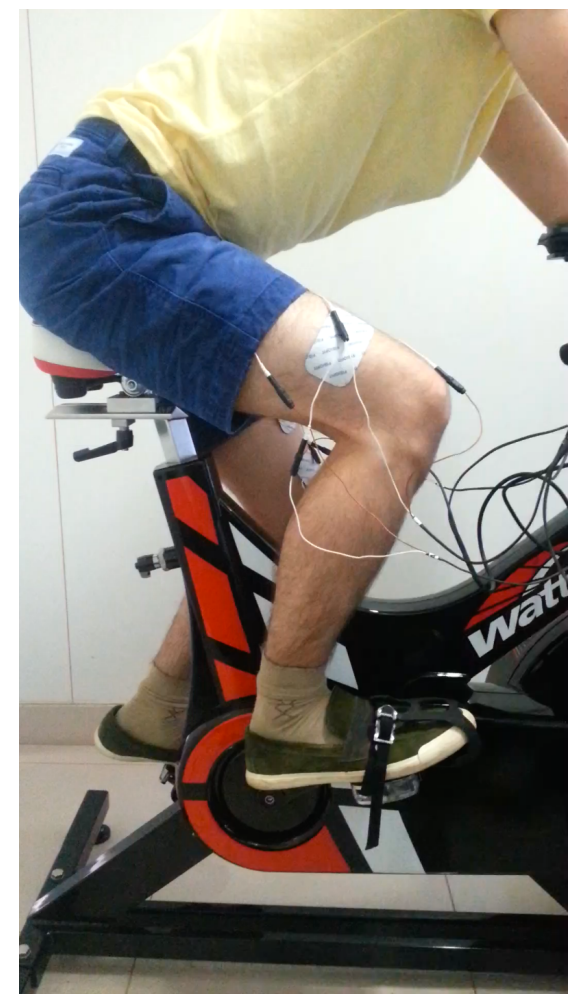

Figura 4.1: Teste exploratório na Wattbike

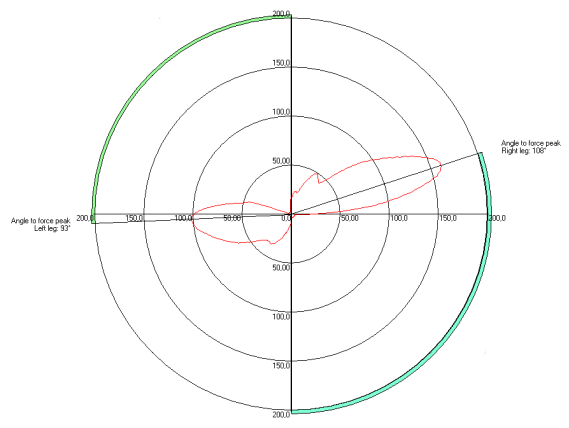

(a) Gráfico polar demonstrando uma revolução de um indivíduo pedalando com estimulação elétrica

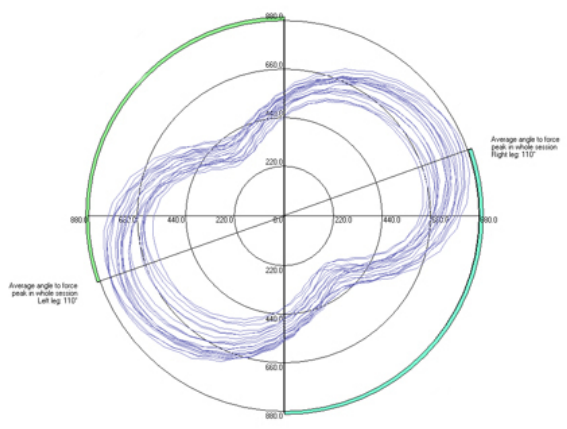

(b) Gráfico polar típico de várias revoluções de alto desempenho de um ciclista treinado. Fonte: http://www.cyclosport.org/

Figura 4.2: Gráficos polares de força em ciclismo 


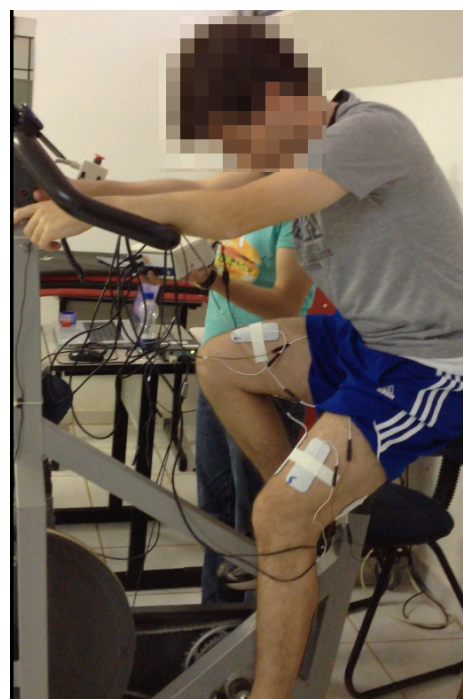

(a) Indivíduo 2 durante experimento com malha aberta, na configuração de eletrodos 3 , e posição 1 (vertical).

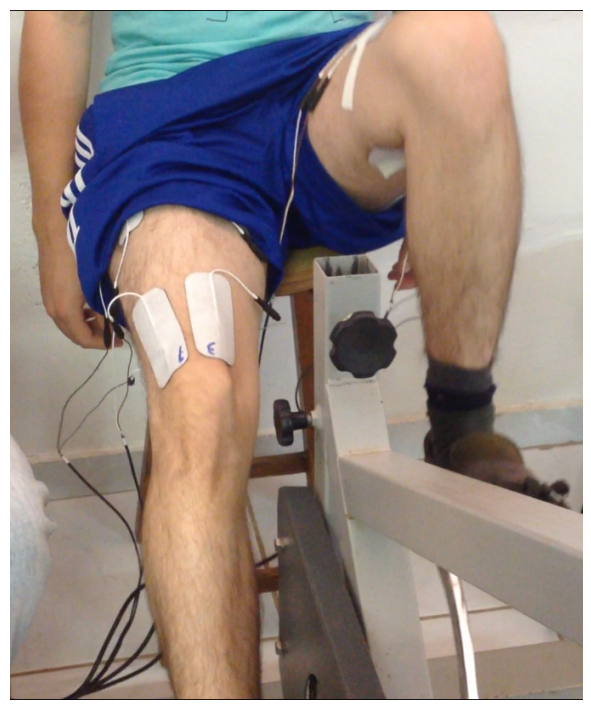

(b) Indivíduo 3 durante experimento com malha aberta, na configuração de eletrodos 3 , e posição 2 (recumbente).

Figura 4.3: Experimento em malha aberta em andamento

fornece, também, a potência desenvolvida pelo indivíduo. Essa potência é calculada a partir da cadência da pedalada, portanto as curvas das duas medidas são idênticas. Nesse contexto, as figuras apresentam os dois dados simultaneamente, com as duas unidades indicadas nos eixos dos gráficos.

Os testes 1, 2 e 3, comparando os diferentes padrões de estimulação com o indivíduo de com alto nível de atividade física, demonstraram que o padrão de estimulação 3, que estimula os quadríceps alternadamente e os bíceps femorais constantemente, é o único que conseguiu gerar ciclos de pedaladas suaves e contínuos. O padrão 1, com estimulação apenas de quadríceps, foi capaz de gerar ciclos, porém acarretava em descontinuidades evidentes no final de cada extensão. O padrão 2, com estimulação alternada de quadríceps e bíceps femorais não introduziu novos efeitos em relação ao padrão 1, pois o torque gerado pelo bíceps femoral não era suficiente para causar movimento nos pedais. Os teste 8,9 e 10, que comparam as diferentes configurações de eletrodos no indivíduo de baixo nível de atividade física, demonstraram que a configuração de eletrodos número 3, com dois canais em cada quadríceps e um canal em cada bíceps femoral, foi a única capaz de gerar movimento nos pedais com esse indivíduo. No teste 8 , onde o indivíduo com baixo nível de atividade física testou a posição recumbente, ele não foi capaz de gerar mais de uma revolução completa nos pedais, enquanto no teste 7 , na posição vertical, ele conseguiu.

Todos os indivíduos relataram sensações fortes de formigamento porém sem desconforto, durante a maioria dos testes. Uma exceção foi um indivíduo que relatou forte desconforto na região posterior da coxa quando a corrente aplicada no bíceps femoral era aumentada de 16 para $18 \mathrm{~mA}$.

\subsection{CONTROLE EM MALHA FECHADA}

Durante as sessões envolvendo experimentos em malha fechada, um controle PI com perfil de estimulação adaptativo foi testado com dois indivíduos. Conforme explicado na seção 3.5.2, a largura de pulso da estimula- 


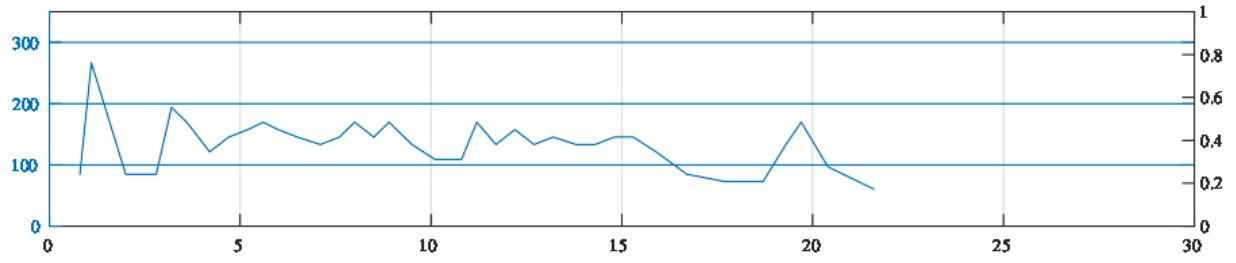

(a) Nível de atividade física alto. Primeira sessão.

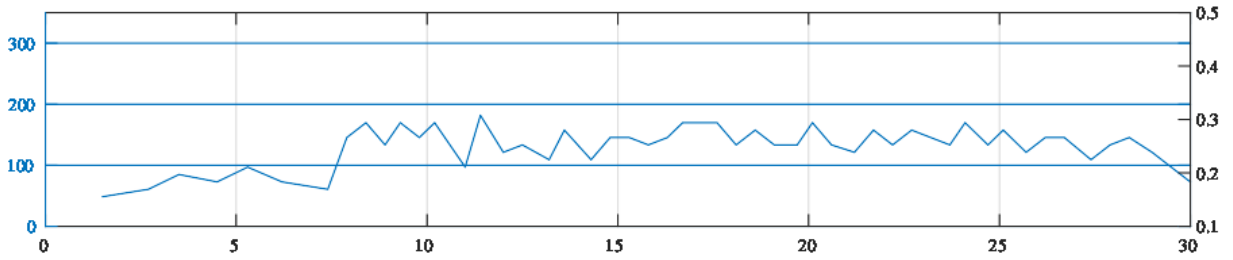

(b) Nível de atividade física alto. Terceira sessão.

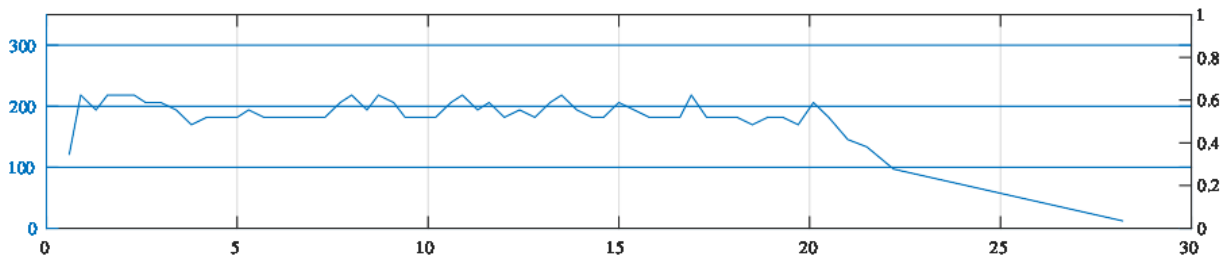

(c) Nível de atividade física moderado. Primeira sessão.

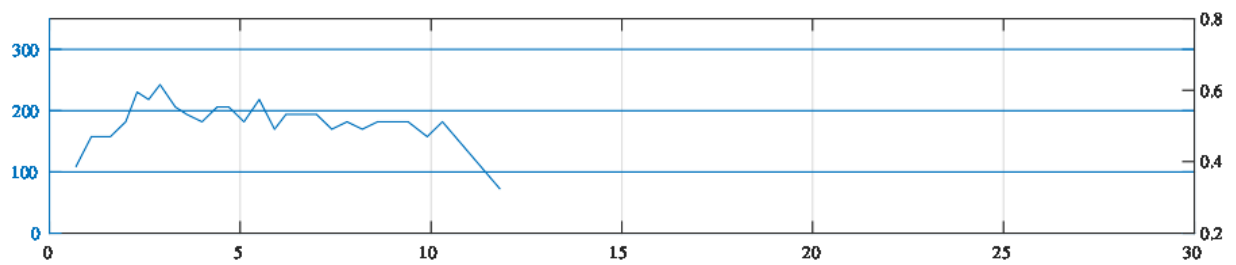

(d) Nível de atividade física moderado. Segunda sessão.

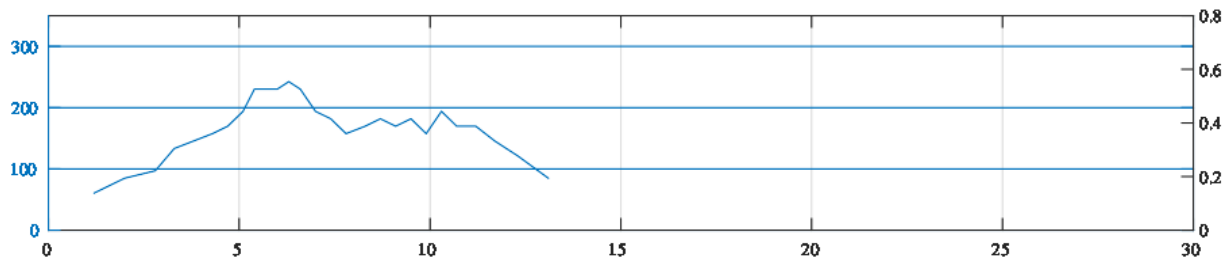

(e) Nível de atividade física moderado. Terceira sessão.

Figura 4.4: Resultados obtidos nos experimentos em malha fechada. Nos gráficos, o eixo vertical representa, simultaneamente, a cadência em $\% / \mathrm{s}$ e a potência em $W / K g$ desenvolvidas durante o teste. A curva é a mesma pois o sistema calcula a potência a partir da cadência e do peso do indivíduo. $\mathrm{O}$ eixo horizontal representa o tempo do teste em $s$. 
Tabela 4.1: Valor da corrente calibrada para os indivíduos A e B no experimento de malha fechada.

\begin{tabular}{|c|c|}
\hline Indivíduo & Valor da corrente calibrada [mA] \\
\hline \hline A & 30 \\
\hline B & 24 \\
\hline
\end{tabular}

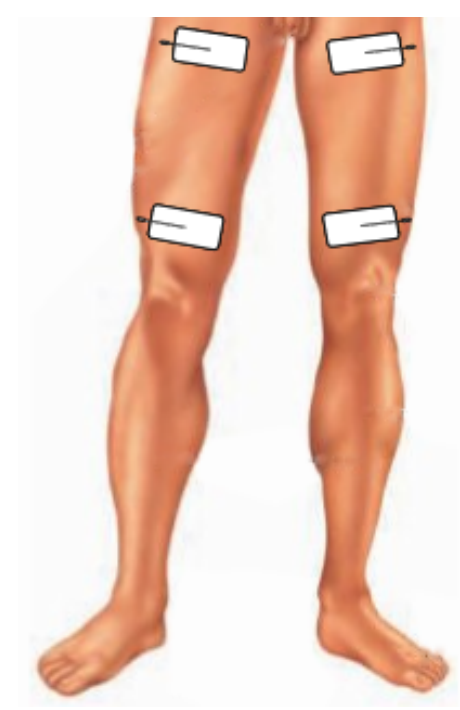

Figura 4.5: Posicionamento de eletrodos para experimentos em malha fechada

ção foi fixada em $500 \mu s$ para a calibração da intensidade de corrente, que resultou em 30mA para o indivíduo A e $24 \mathrm{~mA}$ para o indivíduo B, conforme tabela 4.1. A frequência utilizada foi de $50 \mathrm{~Hz}$. A figura 4.5 ilustra o posicionamentos dos eletrodos, com um canal em cada quadríceps. Durante o experimento, o sinal de saída do controlador indicava a largura de pulso a ser utilizada, que variou de 0 a $500 \mu s$. A figura 4.6 mostra indivíduo B preparado para iniciar o experimento. Ao fundo é possível ver o computador onde está instalado o software de controle. A figura 4.7 mostra o gráfico em tempo real utilizado durante os experimentos para acompanhar as varáveis, e é possível perceber que o sinal de controle está aumentando, pois a velocidade está caindo.

As figuras 4.8a e 4.8b apresentam os resultados do experimento com o controlador em malha fechado descrito em 3.4.2. A estimulação foi iniciada em $t=25 \mathrm{sem}$ ambos os casos. Na figura 4.8a, relativa ao teste com o indivíduo A, é possível ver um pico no sinal de controle logo no início da estimulação, seguido por uma rampa ascendente que é saturada em $t=120 \mathrm{~s}$, aproximadamente, e se mantém saturada até o final do teste, em $t=180 \mathrm{~s}$. A figura 4.8b, referente ao indivíduo $\mathrm{B}$, também apresenta o pico do sinal de controle no início do estimulação, porém há uma estabilização em torno de 0,5 até $t=240 \mathrm{~s}$, quando uma rampa ascendente é iniciada até o término do experimento, em $t=450 \mathrm{~s}$. Nas figuras, o sinal de controle é normalizado para simplificar a análise gráfica. A cadência desenvolvida pelo indivíduo A fica, na maior parte do tempo, entre 250 e $300 \%$. Antes de $t=60 \mathrm{~s}$ ela é mais baixa, e vai gradativamente subindo. Próximo ao final do teste, em $t=175 \mathrm{~s}$, há uma indicação de queda. No indivíduo B há um overshoot na cadência no início da estimulação, seguido por um período entre cerca de $275^{\circ} / \mathrm{s}$ e $325^{\circ} / \mathrm{s}$. Em $t=240 \mathrm{~s}$ é possível perceber que a cadência inicia uma rampa descendente, com baixa inclinação, até o final do teste. Nos dois indivíduos a cadência é mostrada após passar por um filtro de média de tamanho 20 para reduzir o efeito de oscilações ao longo de uma mesma revolução. Há, ainda, um vídeo disponível online onde é possível ver os testes em execução, bem como 


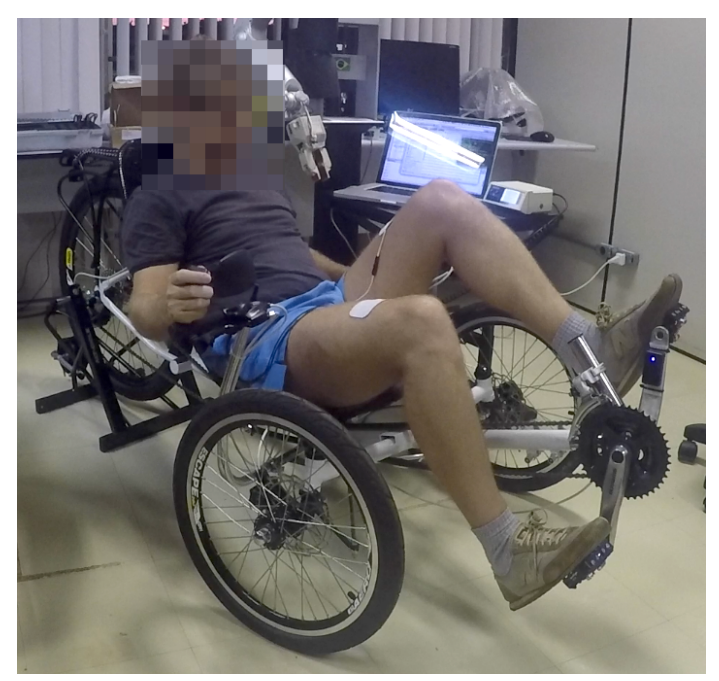

Figura 4.6: Indivíduo B preparado para iniciar experimento em malha fechada
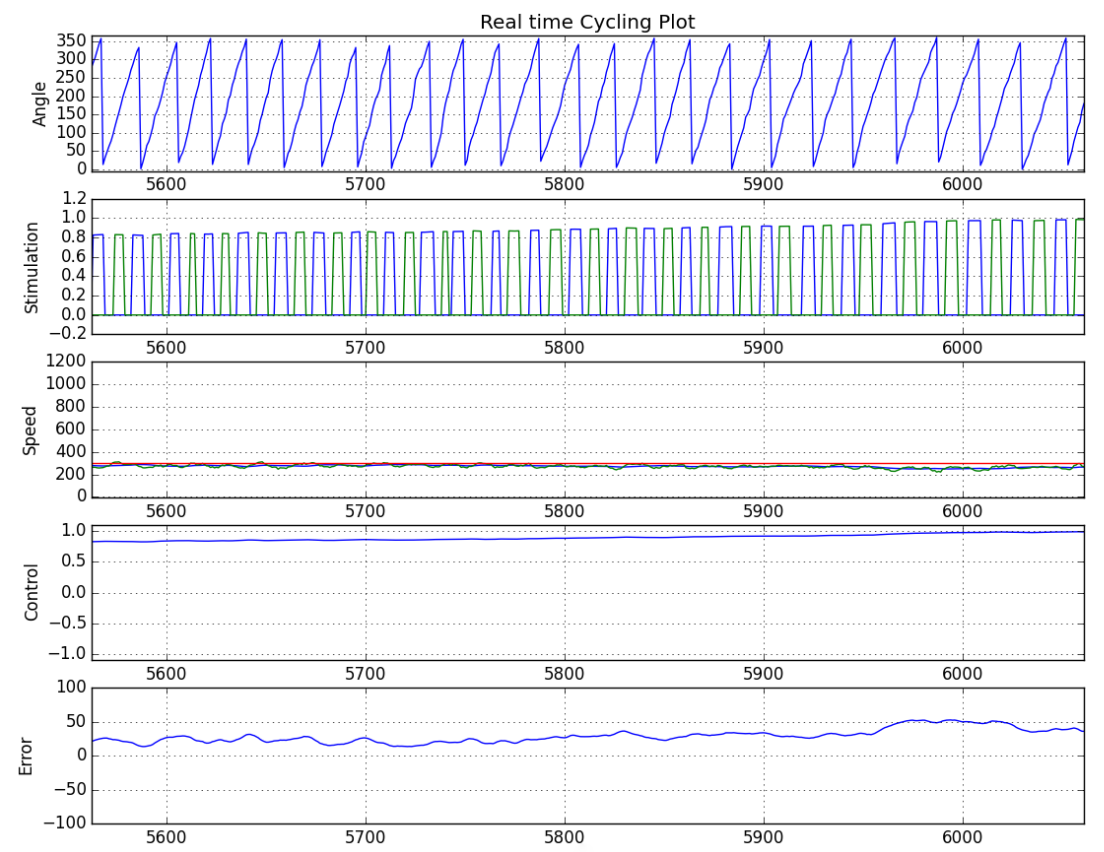

Figura 4.7: Gráfico em tempo real exibido durante o experimento. De cima para baixo, o primeiro gráfico apresenta o sinal de posição angular da pedivela, o segundo os sinais de controle normalizado enviados para cada canal do estimulador (azul é quadríceps esquerdo e verde é quadríceps direito), o terceiro a velocidade angular da pedivela (em verde a velocidade não filtrada, em azul a velocidade filtrada, e em vermelho a referência), e o quarto o sinal de erro. O eixo horizontal representa iterações do software, e não tem significado físico. 
a captura de dados e controle em tempo real ${ }^{1}$.

Em abril de 2015, houve, em Brasília, a primeira etapa da Copa Brasil 2015 de paraciclismo. Foi montado uma exposição para exibir o triciclo instrumentado utilizado neste trabalho. Nessa ocasião, foi testado o controlador em malha fechada em questão com diversos voluntários. Todos conseguiram pedalar com sucesso, e relataram experiências positivas. A figura 4.9 mostra um desses voluntários pedalando no triciclo com o controlador em malha fechada.

\subsection{DISCUSSÃO}

Os controladores utilizados nos testes podem ser comparados em desempenho analisando-se quanto tempo cada um foi capaz de manter o exercício antes que a fadiga impedisse a continuidade. Observando os resultados dos experimentos, é possível perceber a influência da fadiga em todos os casos observando-se o momento em que a resposta do sistema começa a diminuir. Nos testes em malha aberta, o controle não reage à essas diminuições, por não possuir feedback. Considerando-se os pontos de fadiga definidos na seção 3.1, dois pontos são identificáveis: o primeiro, quando a fadiga começa a afetar o sistema, e o terceiro, quando a fadiga impossibilita a continuidade do movimento, que coincide com o fim do experimento. Esses pontos são ilustrados na figura 4.10a. Nos testes em malha fechada, o controlador tenta compensar o efeito da fadiga. Por isso, nesse sistema, é possível identificar dois pontos relevantes: o primeiro, quando o controlador começa a reagir à fadiga; e o segundo, quando o controlador não consegue mais compensar o efeito da fadiga. $\mathrm{O}$ terceiro não foi identificado pois o experimento terminou antes de ele ocorrer. Esses pontos são ilustrados na figura 4.10b.

\subsubsection{Malha Aberta}

Com os primeiros testes exploratório na Wattbike, foram gerados dados como os vistos na figura 4.2a. A figura $4.2 \mathrm{~b}$ representa o mesmo tipo de gráfico, porém com dados de um ciclista treinado. Essa forma vista nesse gráfico chama-se amendoim (do inglês, peanut), e representa revoluções de alto desempenho. Observe que existe um eixo onde as maiores forças são aplicadas, e no eixo perpendicular estão as menores forças. Mesmo sendo menores, elas ainda são significativas, com o valor aproximado de pouco menos da metade do valor da força máxima. Isso significa que o ciclista aplica torque na pedivela durante todo o ciclo. O indivíduo que pedalou com estimulação elétrica, porém, realiza as forças máximas desequilibradas, e em ângulos que não pertencem ao mesmo eixo. Além disso, nos eixos perpendiculares a força aplicada é nula, o que representa uma falta de eficiência no movimento. Essa falta de eficiência é um resultado da estimulação apenas nos quadríceps, gerando apenas o movimento de extensão. Para obter um gráfico mais próximo do amendoim, seria necessário estimular corretamente todos os grupos musculares envolvidos na atividade de pedalar.

Outro fator a se considerar é a consistência entre revoluções. A figura 4.2b mostra várias revoluções realizadas por um ciclista profissional. Observa-se que todas são semelhantes, cada uma fazendo um desenho muito parecido. Ao se sobrepor todas as revoluções do indivíduo com estimulação elétrica, obtém-se a figura, onde pode-se observar a inconsistência entre revoluções.

O controlador de malha aberta foi capaz de manter o exercício por tempos entre 11 e 30s. Apesar de ser um tempo muito curto, uma série de observações foram feitas que são significativas para o uso de FES em ciclismo.

\footnotetext{
${ }^{1}$ http://youtu.be/iS6dBmGtfvM
} 

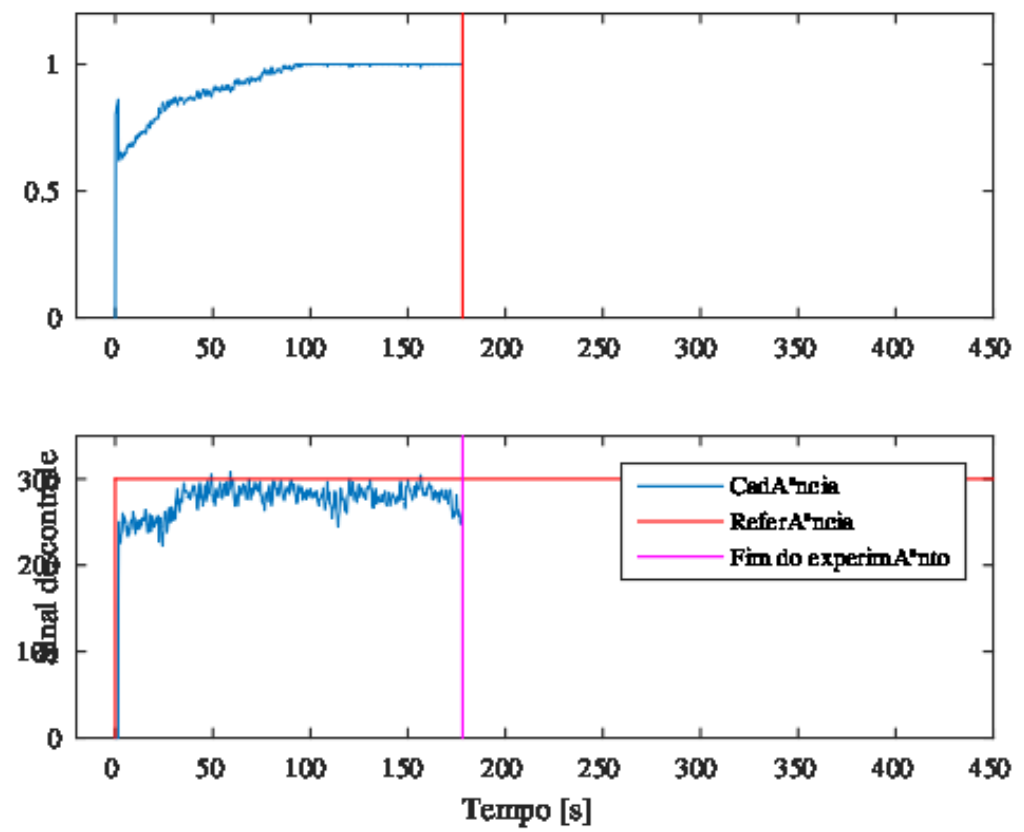

(a) Indivíduo A
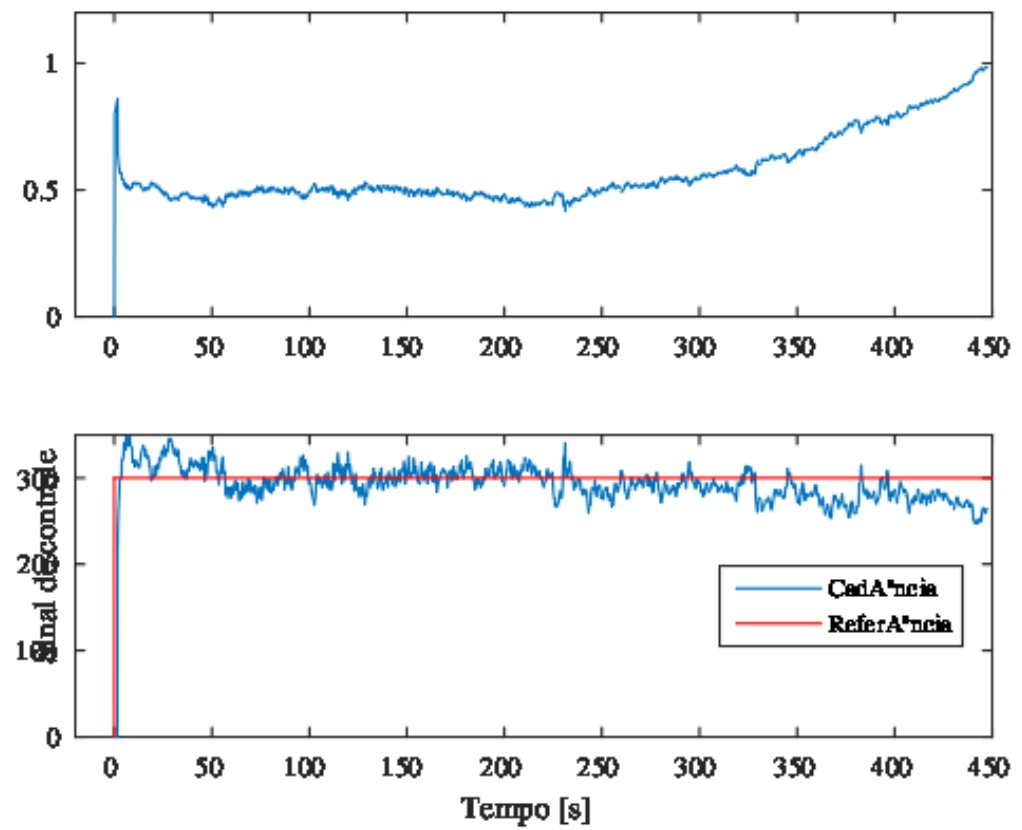

(b) Indivíduo B

Figura 4.8: Resultados do experimento com controlador em malha fechada 


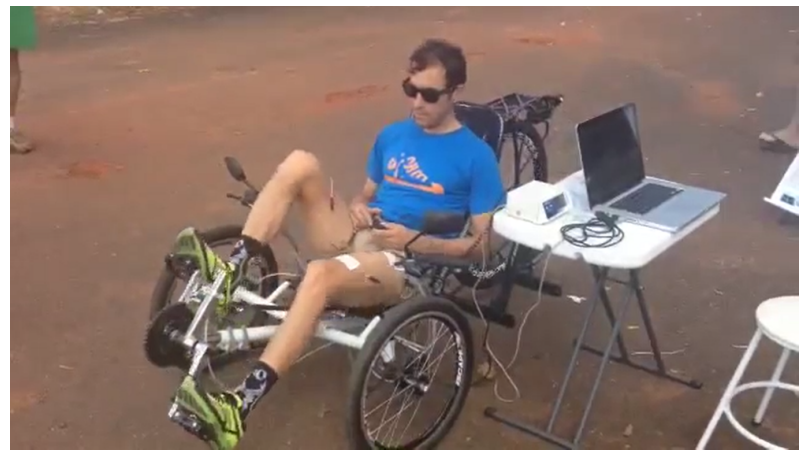

Figura 4.9: Voluntário testando o triciclo funcionando em malha fechada durante a primeira etapada Copa Brasil de Paraciclismo, em Brasília. Abril/2015.

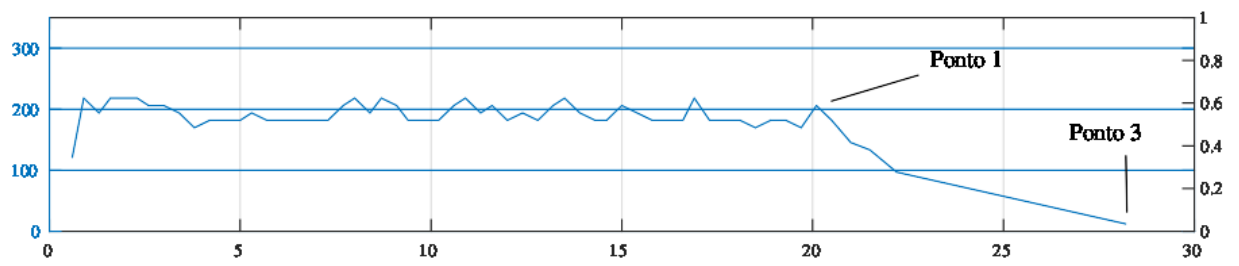

(a) Experimento em malha aberta. Indivíduo com moderado nível de atividade física.Teste 1. O eixo horizontal representa o tempo do teste em $s$.
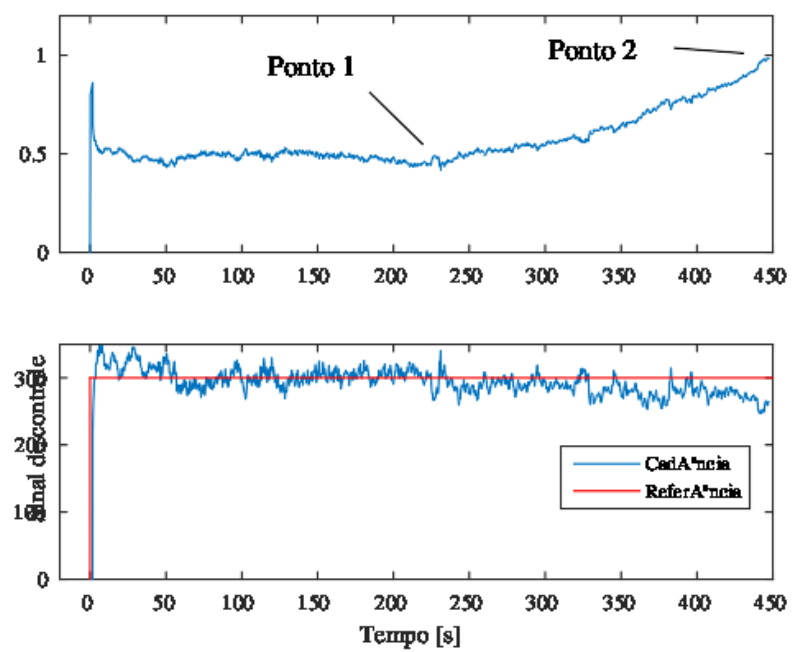

(b) Experimento em malha fechada. Indivíduo B.

Figura 4.10: Pontos de fadiga identificáveis de acordo com a definição na seção 3.1. 


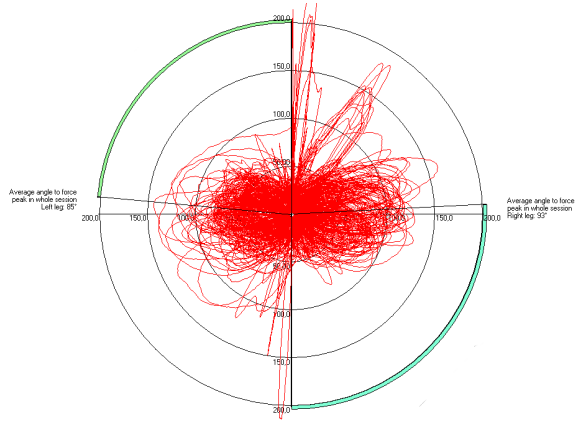

Figura 4.11: Todas as revoluções realizadas pelo indivíduo com estimulação elétrica sobrepostas

Tabela 4.2: Tempo total do primeiro e último teste com os indivíduos de nível de atividade física alto e moderado no experimento em malha aberta.

\begin{tabular}{|c|c|c|}
\hline \multirow{2}{*}{ Nível de atividade física } & \multicolumn{2}{|c|}{ Tempo total [s] } \\
\cline { 2 - 3 } & Primeiro teste & Último teste \\
\hline \hline Alta & 20 & 29 \\
\hline Moderada & 20 & 11 \\
\hline
\end{tabular}

Comparando-se os participantes do experimento, observou-se que, quanto maior o nível de atividade física do indivíduo, maior sua capacidade de manter uma atividade de pedalada mais suave e contínua, além de mais longa. De fato, o indivíduo de alto nível de atividade física teve um aumento no tempo total de exercício no último teste em comparação com o primeiro, possivelmente devido à configuração de eletrodos (que será discutido adiante), enquanto o indivíduo com moderado nível de atividade física demonstrou diminuição do tempo entre testes, como pode ser visto na comparação entre eles na tabela 4.2.

Uma possível interpretação é que isso acontece porque, quanto maior o nível de atividade física, mais sensíveis e responsivos são os músculos à estímulos neurais, sejam eles naturais ou artificiais. Em outras palavras, um mesmo estímulo pode ser capaz de recrutar mais fibras musculares em um indivíduo que mantém um alto nível de atividade física. O fato de o valor da intensidade de corrente ter sido inversamente proporcional ao nível de atividade física, conforme tabela 4.3, corrobora com essa hipótese. Outra possível explicação é que as fibras musculares são mais desenvolvidas em pessoas que mantém atividade física regular. Então, esses indivíduos conseguem exercer a mesma força que pessoas com menor nível de atividade física com um menor número de fibras musculares, exigindo um recrutamento menor de fibras e, consequentemente, um estímulo neural natural ou artificial menor. Além disso, o sinal neural de uma pessoa com maior nível de atividade física poderia ser diferente de outra com menor nível, fazendo com que um estímulo menor, natural ou artificial, seja capaz de recrutar um maior número de fibras musculares.

Tabela 4.3: Corrente calibrada para os indivíduos com diferente níveis de atividade física no experimento em malha aberta

\begin{tabular}{|c|c|}
\hline Nível de atividade física & Valor médio de corrente [mA] \\
\hline \hline Alta & 17 \\
\hline Moderada & 33 \\
\hline Baixa & 44 \\
\hline
\end{tabular}


Os indivíduo de baixo e moderado nível de atividade física realizaram testes onde a única variável modificada para comparação foi o posicionamento do usuário entre vertical e recumbente. Esses testes fora os 4 e 5 para o indivíduo com moderado nível de atividade física, e 7 e 8 para o indivíduo com baixo nível de atividade física. Em ambos os casos, foi possível perceber que a posição recumbente ofereceu um maior desafio, exigindo maiores correntes. Em particular, o indivíduo com baixo nível de atividade física sequer conseguiu pedalar na posição recumbente. Isso ocorre porque, na posição vertical, o indivíduo utiliza-se do peso do próprio corpo para gerar a força aplicada no pedal. Entretanto, no caso de um usuário com lesão medular, a posição recumbente é necessária. A falta de capacidade do indivíduo com nível de atividade física $1 \mathrm{em}$ pedalar na posição recumbente mostra que, se o usuário possuir uma musculatura de membros inferiores pouco desenvolvida, ele terá dificuldades nesse exercício.

A configuração de eletrodos número 3, com o padrão de estimulação 3, foi a única combinação capaz de gerar movimento completo em todos os indivíduos e posições. Com relação à configuração de eletrodos, dois canais em cada quadríceps fornecem mais corrente na estimulação e isso é favorável para gerar um movimento com mais torque. O canal no bíceps femoral não fornecia corrente suficiente para gerar flexão de joelho, mas os indivíduos relataram mais "estabilidade" dos membros inferiores durante o exercício quando esses canais eram ativados continuamente por todo o tempo. Essa percepção de estabilidade pode ser originada na maior rigidez causada no joelho devido à coativação do agonista (quadríceps) e antagonista (bíceps femoral)[74, 75].

Era esperado que, em todos os casos, os indivíduos alcançassem a fadiga cada vez mais rápido ao longo dos testes. Isso aconteceu com os indivíduos de nível de atividade física 1 e 2, mas não com o nível 3, conforme mencionado anteriormente e ilustrado na tabela 4.2. Nesse último caso ocorreu o contrário: ele pedalou mais tempo no último teste que ele participou. Isso pode estar relacionado ao melhores resultados atingidos com o padrão de estimulação 3. Por outro lado, mais uma vez o nível de atividade física superior pode ter contribuído para uma recuperação mais rápida entre os testes, diminuindo o efeito acumulativo da fadiga de uma coleta para a próxima.

O padrão de estimulação $3 *$ (teste número 6) foi aquele onde o método de calibração foi realizado em movimento, com a mínima corrente necessária para a manutenção deste, em contraste com os outros testes onde a calibração era feita com o membro inferior em repouso e a corrente era aumentada até que atingisse um valor capaz de movimentar a pedivela. Nesse teste, o tempo total sofreu pouca alteração com relação ao teste anterior do mesmo indivíduo. Isso poderia indicar que esse método diferente de calibração, que resultou em um valor menor de corrente (24-26mA, em contraste com os 30-34mA anteriores), evitou que a fadiga acumulada fizesse com que o tempo total fosse menor. Essa hipótese concorda com o fato de que a corrente calibrada foi menor dessa forma, pois não era necessário o torque inicial para vencer a inércia do cicloergômetro quando esse estava em repouso. Assim, um exercício com menor corrente, mesmo sendo capaz de manter a mesma cadência, deve retardar os efeitos da fadiga. Ainda, o relato do indivíduo nessa situação foi que ela resultou em um exercício mais confortável, o que é esperado devido à menor corrente. Esses resultados apontam para o potencial de melhoria com um controle de malha fechada, que tenha conhecimento da cadência e possa arrancar e depois ajustar a corrente para o menor valor possível.

A extensão dos membros inferiores não eram suficientes para gerar, durante a estimulação, uma rotação de $180^{\circ}$ da pedivela. Para que o semicírculo se completasse, o sistema dependia da inércia angular gerada pelo torque da extensão. Essa inércia angular fazia com que a pedivela continuasse em movimento nos momentos sem estimulação. Se esse movimento não ocorresse, a próxima extensão ocorria na posição incorreta e o movimento da pedivela era invertido. Isso acontecia quando os tempos de sincronia entre os membros inferiores não eram configurados corretamente, ou quando a fadiga atingia o ponto máximo naquele teste, fazendo com 


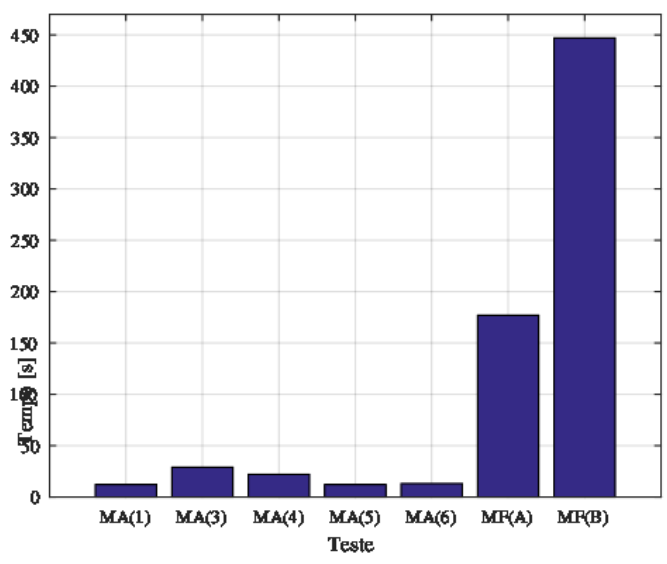

Figura 4.12: Comparação entre os tempos totais de experimentos em malha aberta e fechada. MA(n) significa o teste número "n" do experimento em malha aberta, e MF(X) é o teste em malha fechada com o indivíduo X.

que a extensão não fosse capaz de gerar esse momento angular. Entretanto, é possível realizar todo o movimento da pedalada sem depender da inércia do equipamento, desde que mais músculos estejam envolvidos. Em [72], o uso do tibial anterior e do gastrocnêmio medial é evidenciado com eletromiografia (EMG) em ciclismo, e [9] apresenta uma revisão de diversos trabalhos que estimularam, além desses músculos, também o glúteos máximo, sendo este o mais estudado após quadríceps e bíceps femorais.

\subsubsection{Malha Fechada}

\subsubsection{Análise de Fadiga}

Em comparação com o controlador em malha aberta, observa-se diretamente que todos os testes em malha fechada foram mais longos que em malha aberta. A figura 4.12 mostra que o indivíduo A dos experimentos em malha fechada pedalou por aproximadamente 6 vezes mais tempo que o melhor resultado em malha aberta. $\mathrm{O}$ teste com o indivíduo B foi ainda mais longo. Vale lembrar que esse resultado foi obtido no que seria a configuração de eletrodos 1 (um canal em cada quadríceps), padrão de estimulação 1 (estimulação apenas em quadríceps), e posição 2 (recumbente) dos testes em malha aberta, ou seja, nas condições que haviam sido classificadas como desfavoráveis. Essa diferença justifica-se na malha fechada de controle. Com o monitoramento da velocidade angular da pedivela, o controle de intensidade de corrente calcula a estimulação necessária para que essa velocidade atinja a referência. Quando a velocidade está abaixo da referência, a corrente é aumentada de acordo com o canal proporcional e integral, e diminuído da mesma forma se a velocidade for superior. Assim, o sistema busca não inserir nos nervos e músculos mais corrente do que o necessário, retardando a fadiga e aumentando o tempo total de exercício. O monitoramento da posição angular da pedivela permite ao controlador acionar o estimulador nos momentos apropriados, independente da velocidade angular, impedindo que o movimento saia de sincronismo, assim como ocorreu na malha aberta.

A cadência de referência nos testes em malha fechada foi sempre $300 \%$, e os experimentos sempre partiam da cadência $0^{\circ} / \mathrm{s}$. No indivíduo A, observa-se um pico do sinal de controle, que é responsável pela partida. Rapidamente a cadência de aproximadamente $250 \%$ é atingida. Após o pico inicial, o sinal de controle retorna à um valor próximo de 0,6 e depois começa a incrementar. Esse incremento deve-se à atuação do canal 
integrador, que aumenta gradativamente seu valor, buscando reduzir o erro. Observa-se um incremento, também, na cadência, que fica oscilando entre 250 e $300 \%$ boa parte do experimento. Como a referência é 300

$\%$, o sinal de controle continua incrementando até saturar em 1 . Percebe-se, então, que ainda havia erro no sistema, e que a cadência medida não atingiu a referência. De fato, a cadência média no período entre $t=50 \mathrm{~s}$ e $t=150 \mathrm{~s}$ foi de $284^{\circ} \mathrm{s}$. Mesmo assim, o sistema é capaz de manter a cadência em torno desse valor por cerca de $150 \mathrm{~s}$. Aproximadamente nesse momento, é possível perceber que a cadência começa a diminuir. Esse momento pode ser comparado com o segundo ponto de identificação de fadiga definido na seção 4.3.

O indivíduo B obteve um resultado com algumas diferenças com relação ao indivíduo A. Novamente ocorreu o pico inicial, mas neste caso a cadência sofreu um overshoot, atingindo o valor de $350^{\circ} / \mathrm{s}$. O controle então recua e vai ajustando a cadência até que, em cerca de $t=50 \mathrm{~s}$, ela se mantém em torno de $300^{\circ} / \mathrm{s}$. A cadência se mantém em torno desse valor até $\mathrm{t}=220 \mathrm{~s}$. De fato, nesse período, a média da cadência é $200^{\circ} / \mathrm{s}$. A partir desse momento, entretanto, percebe-se que o sinal de controle passa a incrementar, ao mesmo tempo que a cadência decresce lentamente. Isso ocorre porque o primeiro ponto de fadiga foi atingido, quando a mesma corrente não é mais suficiente para manter a cadência, e o controlador precisa compensar. Nesse caso, porém, o controlador estava com ganhos abaixo do ideal, pois sua resposta não foi suficiente para manter a cadência em $300^{\circ} / \mathrm{s}$, e essa iniciou uma rampa descendente. Essa rampa se prolongou até o fim do experimento, que ocorreu em $\mathrm{t}=450 \mathrm{~s}$, antes do controlador atingir a saturação, ou seja, antes de o segundo ponto identificável de fadiga ser atingido.

Com relação aos resultado do indivíduo A, é possível que a intensidade de corrente calibrada tenha sido abaixo da ideal e, por isso, mesmo saturado, o controlador não foi capaz de atingir a cadência de referência. Lembrando que a calibração é feita no limite de conforto do indivíduo, deve-se levar em consideração que o indivíduo A não tinha experiência prévia com eletroestimulação. Durante vários testes realizados neste trabalho, foi possível perceber que existe uma fase de adaptação de um indivíduo à estimulação. Tipicamente, quando o indivíduo é apresentado à sensação da estimulação, seu limiar de conforto é mais baixo, quando comparado com o mesmo limiar depois de sucessivas sessões. Portanto, pode-se supor que, se o indivíduo A tivesse mais familiaridade com a estimulação elétrica, a calibração resultaria em um valor de corrente maior e, assim, o controlador conseguiria atingir a cadência de referência. O indivíduo B possuía experiência de mais de 5 anos com eletroestimulação, e se sentia muito confortável, possibilitando que a corrente calibrada tivesse um valor maior, dando mais liberdade de atuação ao controlador. Vale lembrar que, apesar de o valor absoluto da intensidade de corrente calibrada para o indivíduo A foi maior que para o indivíduo B (30mA para o indivíduo A e $24 \mathrm{~mA}$ para o indivíduo B), os testes em malha aberta mostram que o valor da corrente necessária para gerar um movimento está relacionado ao nível de atividade física do usuário. Neste caso, o indivíduo A se declarou ocioso, enquanto o indivíduo B se declarou fisicamente ativo. Assim, era esperado que a intensidade de corrente calibrada para o indivíduo A fosse maior que para o indivíduo B, assim como ocorreu nos testes em malha aberta.

Nos testes em malha fechada, os indivíduos eram instruídos a interromperem o experimento, apertando o botão 2 do controle remoto que lhes era entregue, quando sentissem desconforto. Em ambos os casos foi possível ver a cadência em declínio quando o teste foi finalizado, mas em nenhum caso a cadência chegou a zero. Portanto, não foi possível registrar o terceiro ponto de fadiga descrito na seção 4.3.

Observa-se, pelas figuras 4.12, 4.8a, e 4.8b que o indivíduo B foi capaz de pedalar por mais tempo. Mais uma vez a diferença de nível de atividade física dos indivíduos parece estar correlacionada com o tempo de exercício antes de atingir a fadiga. O primeiro ponto de fadiga não foi registrado no indivíduo A, pois, como o controlador ficou saturado durante boa parte do teste, não foi possível identificar o ponto onde ele inicia a 
Tabela 4.4: Pontos de fadiga dos indivíduos A e B, conforme definidos na seção 3.1, no experimento em malha fechada.

\begin{tabular}{|c|c|c|c|}
\hline \multirow{2}{*}{ Indivíduo } & \multicolumn{3}{|c|}{ Pontos de fadiga [s] } \\
\cline { 2 - 4 } & 1 & 2 & 3 \\
\hline \hline A & - & 150 & $>180$ \\
\hline B & 240 & $>450$ & $>>450$ \\
\hline
\end{tabular}

compensação da fadiga. No indivíduo B não foi possível registrar com precisão o segundo ponto de fadiga, mas pode-se afirmar que, caso o teste continuasse, ele ocorreria depois de $t=450 \mathrm{~s}$. Portanto pode-se dizer que $o$ segundo ponto de fadiga ocorreu, no indivíduo A, em $\mathrm{t}=150 \mathrm{~s}$, e, no indivíduo $\mathrm{B}$, em $\mathrm{t}>450$ s. Esses tempos são resumidos na tabela 4.4 .

Como índice de desempenho e comparação com a literatura, foi avaliado o tempo máximo de exercício. Com as duas malhas de controle em funcionamento foram atingidos resultados muito superiores quando comparados com os testes em malha aberta. O melhor resultado atingido em malha aberta foi de cerca de $30 \mathrm{~s}$, enquanto em malha fechada foi de 450s, ou seja, quase 8 minutos. Em [58], três sujeitos com lesão medular foram submetidos à exercícios semelhantes aos deste trabalho. Após três meses de treinamento, dois deles conseguiam pedalar por 30-40 minutos, e, após um ano, por 1 hora. Esses números mostram o potencial do controle de membros inferiores com FES para ciclismo, e os resultados deste trabalho indicam que melhorias no sistema podem acarretar ainda mais ganho no desempenho.

Lembrando que uma das motivações deste trabalho é a competição Cybathlon, vale apontar que, nessa competição, a prova consistirá de um percurso de 1000 metros. Considerando um valor médio entre os indivíduos A e B de tempo de exercício, uma pessoa poderia pedalar por cerca de 315 segundos, ou pouco mais de 5 minutos. Considerando, agora, uma velocidade, baixa, de $15 \mathrm{Km} / \mathrm{h}$, o indivíduo precisaria de aproximadamente 240 segundos para terminar o percurso, deixando 75 segundos de folga. Naturalmente essa análise é muito simples e pouco relevante quando os indivíduos em questão são hígidos, porém são valores animadores o suficiente para prosseguir com o desenvolvimento do sistema.

\subsubsection{Análise do Controle de Cadência}

No caso do indivíduo B, figura $4.8 \mathrm{~b}$, pode-se perceber que o controlador obteve um bom resultado em regular a cadência. No caso do indivíduo A, conforme discutido, parece que a calibração da corrente ou os parâmetros do controlador PI poderiam ter sido melhor ajustados. Além dessas sugestões, pode-se supor que um degrau é um bom método de avaliação de controle em simulação, mas uma mudança de referência onde a primeira derivada atinge o valor infinito não representa um caso real. Mesmo quando um indivíduo hígido pretende exercer um movimento em explosão, partindo do repouso, ainda assim o movimento pode ser modelado por uma rampa, e não um degrau. Nesse contexto, possivelmente uma referência em rampa teria sido um teste mais apropriado para um sistema fisiológico e, possivelmente, teria um resultado diferente com o indivíduo A.

Outra técnica comumente utilizada com motores elétricos, e que poderia ser testada nos experimentos deste trabalho, consiste em identificar quando o sinal de controle está saturado e, mesmo assim, não é capaz de atingir a referência, como ocorreu com o indivíduo A. Identificada essa situação, o sistema pode relaxar a referência até o ponto de operação da máquina (ou do indivíduo, no caso) e, depois, aumentar gradativamente 
até o ponto originalmente pretendido. Em alguns casos essa técnica é capaz de elevar o desempenho até a referência original.

\subsubsection{Análise do Perfil Adaptativo e Atrasos envolvidos}

Para executar o movimento correto de ciclismo, cada músculo envolvido deve ser acionado no momento apropriado[72]. Por isso um perfil de ativação da cada músculo em função do ângulo da pedivela foi desenvolvido. Esse perfil abrange os quadríceps e define os ângulos em que eles devem ser estimulados, conforme descrito na seção 3.4.2. Entretanto existem atrasos no sistema que estão relacionados ao tempo de despolarização dos nervos, ativação das fibras musculares pelos nervos, e também ao próprio sistema desenvolvido, incluindo captura de dados dos sensores, processamento e ativação do estimulador. Quando a cadência é alterada, esses atrasos modificam os pontos onde a estimulação efetivamente atua nos músculos. Quando maior a cadência, maior essa defasagem. Seguindo o trabalho de [9], para compensar esse efeito, o monitoramento da velocidade angular da pedivela é utilizado para adiantar o perfil de ativação. Esse ajuste é feito continuamente até $300^{\circ} / \mathrm{s}$, onde a defasagem máxima é de $35^{\circ}$. Se não houvesse esse ajuste, possivelmente a atuação seria atrasada e o movimento sairia de sincronia, travando no final da extensão como ocorreu nos testes de malha aberta. Os resultados dos testes em malha fechada mostram que isso não aconteceu.

Como descrito, os atrasos do sistema desenvolvido devem ser levados em consideração para o ajuste dos momentos de ativação dos músculos. O sistema funciona de forma assíncrona, ou seja, os dados dos sensores são solicitados quando necessários. Depois disso eles são processados e o sinal de ativação é enviado ao estimulador. Depois o ciclo se repete. Não há controle de taxa de amostragem, ou frequência de funcionamento. É possível, porém, calcular a frequência com que o sistema está funcionando analisando-se os dados dos sensores. Analisando os tempos de cada medida no teste de malha fechada para o indivíduo A, temos um período médio entre medições de aproximadamente $62 \mathrm{~ms}$, com desvio padrão de $19 \mathrm{~ms}$, e uma frequência aproximada de $17 \mathrm{~Hz}$, com desvio padrão de $4 \mathrm{~Hz}$. Para o indivíduo B, esses números foram, aproximadamente, $80 \mathrm{~ms}$, com desvio padrão de $32 \mathrm{~ms}$, e $12,5 \mathrm{~Hz}$, com desvio padrão de $4 \mathrm{~Hz}$. A figura 4.13 apresenta os períodos e frequências de aquisição de dados dos indivíduos A e B, respectivamente.

A equação 4.1 permite calcular $f_{\omega}$, que representa quantos graus a pedivela gira entre medições. Considerandose a cadência de referência de $300^{\circ} / \mathrm{s}$, obtém-se $f_{\omega}=17,4^{\circ}$ para o indivíduo A e $f_{\omega}=21,7^{\circ}$ para o indivíduo B. Como essas valores não são divisores de $360^{\circ}$, em cada revolução as medições devem ocorrer em momentos diferentes. Quanto mais próximo do início da fase de ativação, mas ainda antes dela, maior será o atraso da atuação em decorrência do sistema desenvolvido. Por exemplo, se a ativação deve iniciar em $295^{\circ}$, e a medição for feita em $290^{\circ}$, o controlador identifica a posição angular como fora da região de atuação. A próxima medição, considerando uma cadência de $300^{\circ} / \mathrm{s}$ e o indivíduo $\mathrm{B}$, será na posição de, aproximadamente, $312^{\circ}$. Nesse momento o controlador identifica a posição angular como região de ativação e envia o sinal para o estimulador, com cerca de $17^{\circ}$ de atraso. Portanto a defasagem no perfil de ativação atua para compensar esses atrasos, além dos atrasos de origem fisiológica.

$$
f_{\omega}=\frac{r e f}{f}
$$

\subsubsection{Aspectos Gerais}

Ao longo de todos os experimentos realizados foi frequente o relato, por parte dos voluntários, de que a estimulação elétrica gera uma sensação de formigamento ou tremor. Na maioria das pessoas não há desconforto 


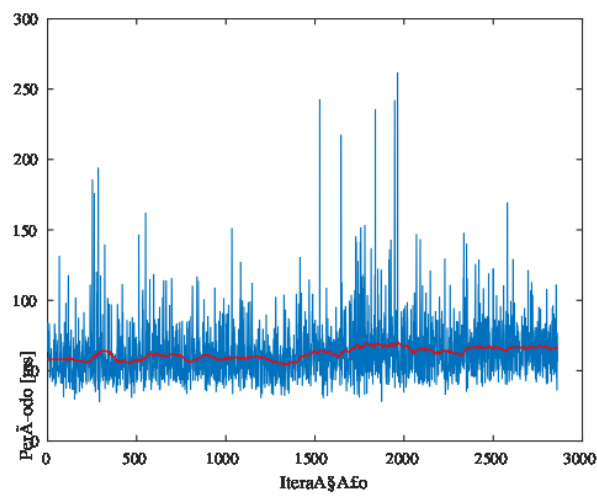

(a) Período de amostragem. Indivíduo A.

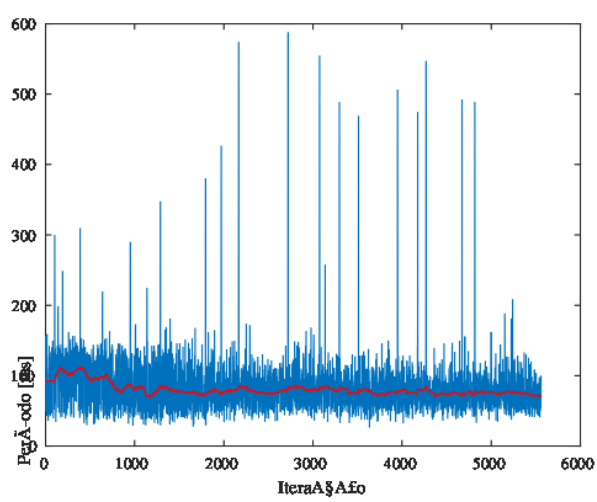

(c) Período de amostragem. Indivíduo B.

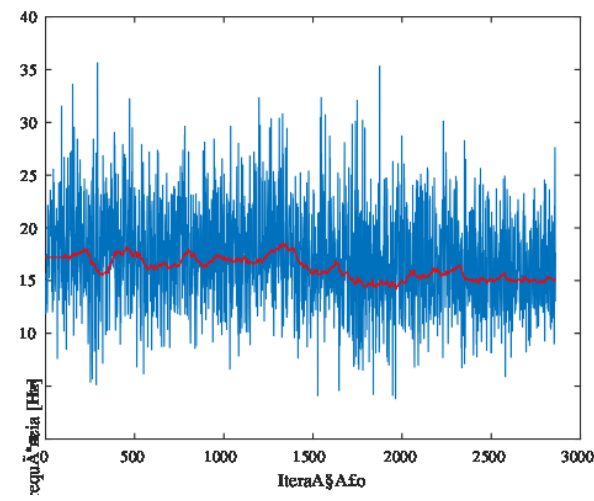

(b) Frequência. Indivíduo A.

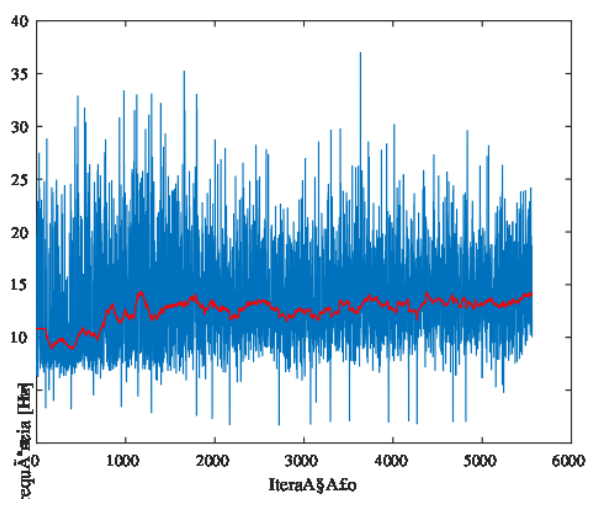

(d) Frequência. Indivíduo B.

Figura 4.13: Período e frequência de amostragem do sistema durante o experimento em malha fechada. Os dados em vermelho representam os dados em azul com um filtro de média de tamanho 100. 
até que a intensidade de corrente seja aumentada até um limiar de dor particular de cada um. Em casos raros a pessoa pode sentir desconforto e pedir para que a estimulação seja descontinuada, mesmo com correntes baixas. Nesses casos, quando perguntado se houve dor, os relatos mais comuns são que o que eles sentem não é dor, mas um "desconforto" com a sensação inesperada. Aparentemente, a forma com que o procedimento é apresentado pode desempenhar um papel significativo na primeira experiência que o indivíduo tem com FES. $\mathrm{Se}$, antes da primeira estimulação, for dada uma explicação sobre os aspectos de segurança e uma descrição da sensação, as pessoas tendem a se sentirem mais confortáveis no início. Após alguns minutos de estimulação e, principalmente, após duas ou três sessões, a maioria das pessoas já se sente totalmente confortável. Algumas pessoas chegam a relatar vontade de receber a estimulação mais vezes.

Durante o desenvolvimento deste trabalho, muitos testes foram realizados pelo mesmo voluntário. Por vezes, varias sessões eram praticadas por dia, vários dias consecutivos. Apesar de a percepção não ser clara, os resultados dos testes eram alterados quando isso acontecia. Houve uma situação, em específico, que o resultado esperado não era alcançado, mesmo após vários ajustes no sistema, até que o mesmo teste foi realizado em outra pessoa que não havia participado de nenhum teste antes. $\mathrm{O}$ sistema funcionou imediatamente. Isso pode indicar que repetidas sessões de estimulação podem gerar uma situação de fadiga que pode não ser claramente percebida pelo indivíduo, mas que influencia a resposta muscular à estimulação.

Todos os indivíduos participantes deste trabalho possuem habilidades motoras saudáveis e inalteradas. Por isso, para efeito dos testes, era sempre solicitado que eles relaxassem completamente, e não executassem nenhum movimento voluntário. Entretanto, houve relatos de que era muito difícil se manterem totalmente passivos. Além dos relatos, era possível observar outros músculos, que não os estimulados eletricamente, sendo contraídos, como os tibiais anteriores e gastrocnêmios. Esses eram usados de forma quase inconsciente para manter os pés fixos nos pedais. Isso seria muito diferente em alguém com lesão medular ou alguma outra deficiência motora. 


\section{CONCLUSÕES}

\subsection{CONSIDERAÇÕES FINAIS}

A lesão medular é uma condição severamente debilitante, capaz de causar perda de motricidade, redução de massa óssea, atrofia muscular, incontinência urinária e depressão, entre outros malefícios. Além da fisioterapia tradicional, outros métodos buscam a recuperação da saúde e da qualidade de vida dos pacientes. Este trabalho explorou a estimulação elétrica funcional (FES) dos membros inferiores em indivíduos com lesão medular dentro do contexto de ciclismo, com o objetivo de potencializar a plasticidade do sistema nervoso, bem como oferecer treinamento cardiovascular e muscular, e um meio de locomoção e lazer.

Para isso, foram feitos experimentos com controles em malha aberta e fechada, utilizando como base estratégias de controle adaptadas da literatura. O setup experimental incluiu a instrumentação de um triciclo com sensores sem fio, estimulador elétrico e unidade de controle. A principal métrica de avaliação foi o tempo total de exercício. Ao comparar os resultados dos experimentos em malha aberta e fechada, é clara a vantagem do controle em malha fechada. Com essa estratégia, os indivíduos foram capazes de pedalar entre 3 e 8 minutos, enquanto que em malha aberta nenhum teste chegou a 1 minuto. Entretanto, ao comparar com o estado da arte, é possível encontrar relatos de indivíduos com lesão medular que são capazes de pedalar por uma hora. Apesar da grande diferença entre esses relatos e os resultados deste trabalho, a comparação entre os desempenhos das estratégias de controle testadas indicam a existência de um grande potencial de melhoria no sistema.

Outro ponto importante é o treinamento de longo prazo. Os testes realizados neste trabalho foram com indivíduos hígidos e destreinados, apesar de alguns possuírem um alto nível de atividade física. Os relatos da literatura sempre descrevem meses de treinamento intensivo, o que não foi realizada neste trabalho.

Apesar de os resultados deste e de outros trabalhos serem animadores, alguns desafios ainda impedem a popularização dessa tecnologia, assim como o marcapasso ou o implante coclear. Portanto é necessário continuar buscando formas de tornar toda a terapia com FES mais prática, barata e atraente. Uma plataforma de ciclismo que, simultaneamente, contribua para a neurorreabilitação e proporcione uma maneira de se deslocar utilizando as próprias pernas pode ser um passo promissor nesse caminho

\subsection{TRABALHOS FUTUROS}

Com o controle e o triciclo funcionais, os trabalhos futuros devem se voltar para a continuidade da pesquisa com indivíduos com lesão medular. Primeiramente é necessário a obtenção da aprovação do projeto de pesquisa pelo Comitê de Ética em Pesquisa. Depois disso, treinamentos prévios com indivíduos devem ser feitos para desenvolver a musculatura de membros inferiores e contornar possíveis problemas com espasticidade[58]. Em seguida, a principal adaptação mecânica a ser feita é uma fixação do membro inferior ao pedal. Indivíduos hígidos são capazes de manter os pés nos pedais mesmo sem fixação, mas pessoas com lesão medular não. Por isso, se faz necessária essa fixação, bem como um suporte para suporte da tíbia, de forma que a articulação do tornozelo fique imobilizada, ou quase imobilizada, impedindo que a perna se mova lateralmente, o que poderia causar lesões ortopédicas. Após esses avanços, os mesmos experimentos realizados neste trabalho podem ser reproduzidos com a população alvo, e resultados de longo prazo podem ser avaliados e comparados com o 
estado da arte.

Além disso, uma série de melhorias são previstas, seja para pesquisa e desenvolvimento do dispositivo, quanto para sua utilização pelo usuário final:

- Experimentos com diferentes estratégias de controle, como controladores adaptativos, ou com fatores de aprendizado propícios para atividades cíclicas. Técnicas de controle adaptativas podem ser especialmente eficazes visto que o sistema em questão é variante no tempo, devido à fadiga neuromuscular.

- Um gerenciador de conexões e dados, capaz de modularizar software e hardware no sistema. A proposta atual é utilizar o Robotics Operational System (ROS) para gerenciar essas conexões e dispositivos. Além da modularidade que uma arquitetura assim fornece, cada elemento do sistema funciona independentemente dos outros. Uma das vantagens desse recurso é que a leitura dos valores dos sensores pode ocorrer em frequência diferente do controlador, fazendo com que a velocidade resultado do sistema como um todo aumente. De fato, uma estrutura assim foi testada após o fim de todos os experimentos, e frequências próximas de $50 \mathrm{~Hz}$ foram alcançadas. Vale lembrar que a frequência de estimulação utilizada é 50 $\mathrm{Hz}$, ou seja, o software não precisa ser executado mais rapidamente.

- Instalação de um sensor de força nos pedais. Atualmente as malhas de controle recebem sinais de posição e velocidade angular da pedivela, que podem ser controladas pela estimulação elétrica. Mudanças nos parâmetros da estimulação afetam a ativação dos músculos, o que pode alterar a força aplicada nos pedais. Essa alteração de força resulta em mudanças na posição e velocidade angular. Portanto a força nos pedais é uma medida mais direta da atuação da estimulação, e pode revelar melhores ajustes ao controlador. Outra medida ainda mais direta seria a leitura de eletromiografia (EMG) nos músculos estimulados. EMG em conjunto com FES é uma linha de pesquisa à parte e promissora[76], que pode permitir um controle preciso da ativação muscular por estimulação elétrica.

- Instalação de sensor de freio, de forma que, quando o usuário os acione, a estimulação seja interrompida ou atenuada.

- Instalação de sensor de velocidade e distância percorrida. Atualmente o sistema tem acesso apenas à valores referentes à pedivela. Com sensores na roda de tração será possível avaliar mais dados de desempenho, como velocidade máxima, velocidade média, e distância máxima percorrida. Além disso, será possível realizar cálculos de potência desenvolvida, considerando a carga aplicada. Nesse caso, um rolo de treinamento com carga mensurável precisaria ser utilizado.

- Instalação de sensor de marcha, para que o controle seja capaz de aplicar a estimulação apropriada para a carga definida pelo usuário. Considerando-se que o sistema atual já possui um sensor na pedivela, que gira junto da coroa, basta instalar outro sensor na roda de tração, que gira junto da catraca. Dessa forma a relação de velocidades será conhecida.

- Instalação de assistência elétrica para auxiliar o usuário em casos necessários, como uma subida íngreme, ou quando atingir a fadiga.

- Sistema de detecção de fadiga, capaz de perceber, em tempo real, todos os ponto de fadiga definidos na seção 4.3 .

- Interface de usuário que permita ao indivíduo alterar a velocidade de referência, interromper a estimulação, e ter acesso à informações como tempo de exercício, distância percorrida, velocidade instantânea e média, parâmetros de estimulação, e avisos de fadiga. 


\section{PUBLICAÇÕES}

Além desse documento, os experimentos realizado e experimentos obtidos neste trabalho foram publicados em dois congressos nacionais. O autor, durante seu tempo de mestrado, também se dedicou à outras pesquisas, sempre relacionadas à reabilitação do sistema nervoso, que geraram publicações, incluindo um capítulo de livro, uma submissão para uma revista, e um prêmio de melhor poster no Workshop Internacional de Engenharia Biomédica.

Título: Estudo Sobre o Uso de Estimulação Elétrica Funcional de membros inferiores em Ciclismo[4]

Autores: Lucas O. da Fonseca, Lucas L. de Oliveira, Mileny X. Oliveira, Miguel E. G. Paredes, Clarissa C. S. C. Paz, Paulo E. Silva, João L. Q. Durigan, Antônio P. L. Bó.

Publicado em: XXIV Congresso Brasileiro de Engenharia Biomédica ${ }^{1}$

Resumo/Abstract: This paper describes a study of Functional Electrical Stimulation applied to cycling. The proposed platform makes use of constant stimulation parameters, up to three pairs of electrodes, Hasomed RehaStim electrical stimulator and variables such as: system user (none with motor disabilities), electrodes positioning, stimulation pattern and user's position related to the bicycle. Best results were achieved when certain parameters were set, according to generated torque and pedaling smoothness; e.g. the most physically fit subject achieved more satisfying results with lower current intensities and the user's vertical stance contributed to a more movement favorable pedaling. Moreover, muscle fatigue felt by the subjects was analyzed.

Título: Experiments on Lower Limb FES Control for Cycling [5]

Autores: Antônio Padilha L. Bó, Lucas O. da Fonseca, Stephany R. Rodrigues, Ana Carolina C. de Sousa, Lucas L. Oliveira, George A.Brindeiro

Publicado em: XII Simpósio Brasileiro de Automação Inteligente ${ }^{2}$

Resumo/Abstract: Cycling aided by Functional Electrical Stimulation (FES) for individuals with neurological disorders, such as Spinal Cord Injury (SCI), has been shown to provide different clinical benefits. The technology is based on the coordinated stimulation of lower limbs muscles to produce cyclic leg movements. Although there are systems available today mostly in clinical settings, studies indicate that the performance of such systems with respect to efficiency, FES induced muscle fatigue and other aspects are still limited. Based on these premises, in this work we present an innovative FES aided tricycle for SCI subjects, as well as novel control algorithms that enable cycling cadence tracking and compensation of variable muscle response. Preliminary results on two neurologically intact subjects are presented. Analysis of the data has shown that the system is able to provide satisfactory performance, but additional techniques must be evaluated in order to further reduce the effect of muscle fatigue

Título: Challenges in Neurorehabilitation and Neural Engineering[77]

\footnotetext{
${ }^{1}$ http://www.cbeb.org.br/

${ }^{2}$ http://www.sbai2015.dca.ufrn.br/
} 
Autores: Martina Caramenti, Volker Bartenbach, Lorenza Gasperotti, Lucas Oliveira da Fonseca, Theodore W. Berger, José Luis Pons

Capítulo do livro: Emerging Therapies in Neurorehabilitation II

Resumo/Abstract: Great progress has been achieved in the last few years in Neurorehabilitation and Neural Engineering. Thanks to the parallel development of medical research, the chances to survive a neural injury are growing, so it is necessary to develop technologies that can be used both for rehabilitation and to improve daily activities and social life. New robotic and prosthetic devices and technologies such as Functional Electrical Stimulation, Brain-Computer Interfaces and Virtual Reality are slowly becoming part of clinical rehabilitation setting, but they are far from be- ing part of everyday life for the patients. As technology improves, expectations keep rising and new problems emerge: from cost reduction to the diffusion in the medical environment, from the enlargement of the number of patients who may benefit from these technologies to transferring rehabilitation to the patient's home.

Título: FES-induced co-activation of antagonist muscles for upper limb control and disturbance rejection

Autores: Antônio Padilha L. Bó, Lucas O.da Fonseca, Ana Carolina C. de Sousa

Submetido para: Medical Engineering \& Physics

Resumo/Abstract: Great progress has been achieved in the last few years in Neurorehabilitation and Neural Engineering. Thanks to the parallel development of medical research, the chances to survive a neural injury are growing, so it is necessary to develop technologies that can be used both for rehabilitation and to improve daily activities and social life. New robotic and prosthetic devices and technologies such as Functional Electrical Stimulation, Brain-Computer Interfaces and Virtual Reality are slowly becoming part of clinical rehabilitation setting, but they are far from be- ing part of everyday life for the patients. As technology improves, expectations keep rising and new problems emerge: from cost reduction to the diffusion in the medical environment, from the enlargement of the number of patients who may benefit from these technologies to transferring rehabilitation to the patient's home.

Título: Desenvolvimento de um Sistema de Reabilitação de Movimentos e Exercícios Musculares Utilizando Estímulos Elétricos Funcionais (FES) e Jogos Eletrônicos

Autores: Lucas O.da Fonseca

Apresentado em: Workshop Internacional em Engenharia Biomédica

Resumo/Abstract: Lesões no Sistema Nervoso Central (SNC), sejam elas resultado de doenças, síndromes ou acidentes, podem causar deficiências motoras temporárias ou permanentes. Mais especificamente, um Acidente Vascular Encefálico (AVE) é caracterizado por um bloqueio, e possível rompimento, de um ou mais vasos sanguíneos no cérebro que pode causar danos aos tecidos próximos por falta de oxigenação. AVEs geralmente resultam em hemiplegia ou paralisia parcial dos movimentos. Existem terapias para a reabilitação desses movimentos. A maioria baseia-se em exercícios repetitivos que visam fortalecer a musculatura e restaurar o controle voluntário sobre os movimentos. Estimulação Elétrica Funcional, ou, do inglês, Functional Electrical Stimulation (FES), tem efeitos comprovadamente benéficos no processo de reabilitação, pois auxilia na indução da plasticidade do SNC, que consiste em sua habilidade de se adaptar a novas situações. Um dos maiores desafios na reabilitação pós AVE, seja utilizando FES ou não, é a dificuldade do paciente de engajar-se em 
exercícios repetitivos e frequentemente dolorosos durante todo o período da terapia. Nos últimos anos o uso de elementos de jogos para incentivar e motivar esses pacientes têm ganhado muita atenção, e alguns estudos indicam que é possível utilizar esses elementos para aumentar o engajamento na terapia. Este trabalho propõe um sistema de reabilitação pós AVE baseado na sinergia entre FES e jogos sérios. Dessa forma, os jogos poderão interagir com o paciente não apenas com interfaces sensoriais, mas também ativamente causando contrações musculares por meio de um controle de malha fechada com o objetivo de motivá-lo e/ou aumentar a eficácia do processo de reabilitação neural 


\section{Referências Bibliográficas}

[1] V. Dietz and K. Fouad, "Restoration of sensorimotor functions after spinal cord injury.," Brain: a journal of neurology, vol. 137, pp. 654-67, mar 2014.

[2] D. Popovic and T. Sinkjaer, Control of Movement for the Physically Disabled. London: Springer London, 2000.

[3] Y. Technology, “3-Space Sensor Suite Manual,” 2013.

[4] L. O. da Fonseca, L. L. Oliveira, M. X. Oliveira, M. E. G. Paredes, C. C. S. C. Paz, P. E. Silva, J. L. Q. Durigan, and A. P. L. Bó, "Estudo Sobre o Uso de Estimulação Elétrica Funcional de membros inferiores em Ciclismo," in Congresso Brasileiro de Engenharia Biomédica, 2014.

[5] A. P. L. Bó, L. O. da Fonseca, S. R. Rodrigues, A. C. C. de Sousa, L. L. Oliveira, and G. A. Brindeiro, "EXPERIMENTS ON LOWER LIMB FES CONTROL FOR CYCLING," in Simpósio Brasileiro de Automação Inteligente, vol. 1, (Natal, Brasil), 2015.

[6] R. Lent, Cem bilhões de neurônios: conceitos fundamentais de neurociência. São Paulo: Atheneu, 2 ed., 2004.

[7] S. Sabharwal and MD, Essentials of Spinal Cord Medicine. Demos Medical Publishing, 2013.

[8] G. Asín Prieto, A. Ilzarbe Andrés, A. Venkatakrishnan, W. Q. Malik, V. Dietz, and W. Z. Rymer, "Rehabilitation Technologies for Spinal Injury," in Emerging Therapies in Neurorehabilitation II, ch. 3, pp. 65-85, 2016.

[9] K. J. Hunt, Control Systems for Function Restoration, Exercise, Fitness and Health in Spinal Cord Injury. $\mathrm{PhD}$ thesis, 2005.

[10] H. Krebs, N. Hogan, M. Aisen, and B. Volpe, "Robot-aided neurorehabilitation," IEEE Transactions on Rehabilitation Engineering, vol. 6, no. 1, pp. 75-87, 1998.

[11] D. Reinkensmeyer, D. Aoyagi, J. Emken, J. Galvez, W. Ichinose, G. Kerdanyan, J. Nessler, S. Maneekobkunwong, B. Timoszyk, K. Vallance, R. Weber, R. de Leon, J. Bobrow, S. Harkema, J. Wynne, and V. Edgerton, "Robotic gait training: toward more natural movements and optimal training algorithms.," Conference proceedings : ... Annual International Conference of the IEEE Engineering in Medicine and Biology Society. IEEE Engineering in Medicine and Biology Society. Conference, vol. 7, pp. 4818-4821, 2004.

[12] J. L. Pons, R. Raya, and J. González, eds., Emerging Therapies in Neurorehabilitation II, vol. 10 of Biosystems \& Biorobotics. Cham: Springer International Publishing, 2016.

[13] R. T. Frood, "The use of treadmill training to recover locomotor ability in patients with spinal cord injury," Bioscience Horizons, vol. 4, pp. 108-117, feb 2011.

[14] A. Frotzler, S. Coupaud, C. Perret, T. H. Kakebeeke, K. J. Hunt, and P. Eser, "Effect of detraining on bone and muscle tissue in subjects with chronic spinal cord injury after a period of electrically-stimulated cycling: a small cohort study.," Journal of rehabilitation medicine, vol. 41, pp. 282-5, mar 2009. 
[15] J. C. Baldi, R. D. Jackson, R. Moraille, and W. J. Mysiw, "Muscle atrophy is prevented in patients with acute spinal cord injury using functional electrical stimulation.," Spinal cord, vol. 36, pp. 463-9, jul 1998.

[16] J. M. MacPherson, "How flexible are muscles synergies?" in Motor control. Concept and issues. (F. Humphrey, ed.), Chichester: John Wiley and Sons Ltd, 1991.

[17] Cajal and S. Ramon, "Sur l'origine et les ramifications des fibres nerveuses de la moelle embryoniaire," Anat Anx, vol. 5, pp. 85-95, 111-119, 1890.

[18] F. TELLO, "La influencia del neurotropismo en la regeneracion de los centros nerviosos," Trab Lab Invest Biol Univ Madrid, vol. 9, pp. 123-159, 1911.

[19] P. Caroni and M. E. Schwab, "Two membrane protein fractions from rat central myelin with inhibitory properties for neurite growth and fibroblast spreading.", The Journal of cell biology, vol. 106, pp. 1281-8, apr 1988.

[20] S. David and A. J. Aguayo, "Axonal regeneration after crush injury of rat central nervous system fibres innervating peripheral nerve grafts," Journal of Neurocytology, vol. 14, pp. 1-12, feb 1985.

[21] H. Cheng, Y. Cao, and L. Olson, "Spinal cord repair in adult paraplegic rats: partial restoration of hind limb function.," Science (New York, N.Y.), vol. 273, pp. 510-3, jul 1996.

[22] H. Cheng, M. Fraidakis, B. Blombäck, P. Lapchak, B. Hoffer, and L. Olson, "Characterization of a fibrin glue-GDNF slow-release preparation.," Cell transplantation, vol. 7, pp. 53-61, jan 1998.

[23] L. Olson, H. Cheng, R. H. Zetterström, L. Solomin, L. Jansson, L. Giménez-Llort, B. J. Hoffer, and T. Perlmann, "On CNS repair and protection strategies: novel approaches with implications for spinal cord injury and Parkinson's disease.," Brain research. Brain research reviews, vol. 26, pp. 302-5, may 1998.

[24] S. Hamid and R. Hayek, "Role of electrical stimulation for rehabilitation and regeneration after spinal cord injury: an overview.," European spine journal : official publication of the European Spine Society, the European Spinal Deformity Society, and the European Section of the Cervical Spine Research Society, vol. 17, pp. 1256-69, sep 2008.

[25] P. Tabakow, W. Jarmundowicz, B. Czapiga, W. Fortuna, R. Miedzybrodzki, M. Czyz, J. Huber, D. Szarek, S. Okurowski, P. Szewczyk, A. Gorski, and G. Raisman, "Transplantation of autologous olfactory ensheathing cells in complete human spinal cord injury.," Cell transplantation, vol. 22, pp. 1591-612, jan 2013.

[26] M. R. Dimitrijević, "Head injuries and restorative neurology.," Scandinavian journal of rehabilitation medicine. Supplement, vol. 17, pp. 9-13, jan 1988.

[27] D. E. Farina, W. E. Jensen, and A. E. Metin, Introduction to Neural Engineering for Motor Rehabilitation. 2013.

[28] K. T. Ragnarsson, "Functional electrical stimulation after spinal cord injury: current use, therapeutic effects and future directions.," Spinal cord, vol. 46, pp. 255-74, apr 2008.

[29] P. Taylor, J. Esnouf, and J. Hobby, "The functional impact of the Freehand System on tetraplegic hand function. Clinical Results," Spinal Cord, 2002. 
[30] R. Rupp and G. Müller-Putz, "Bci-controlled grasp neuroprosthesis in high spinal cord injury," Converging Clinical and Engineering Research on Neurorehabilitation. Springer Berlin Heidelberg., pp. 12531258, 2013.

[31] A. Kreilinger, V. Kaiser, and M. Rohm, "BCI and FES training of a spinal cord injured end-user to control a neuroprosthesis," Biomedical Engineering/Biomedizinische Technik, 2013.

[32] M. Rohm, M. Schneiders, and C. Müller, "Hybrid brain-computer interfaces and hybrid neuroprostheses for restoration of upper limb functions in individuals with high-level spinal cord injury," Artificial intelligence in medicine, no. 59.2, pp. 133-142, 2013.

[33] P. Lim and A. Tow, "Recovery and regeneration after spinal cord injury: a review and summary of recent literature," ANNALS-ACADEMY OF MEDICINE SINGAPORE, no. 36.1, p. 49, 2007.

[34] A. J. Del-Ama, A. Gil-Agudo, J. L. Pons, and J. C. Moreno, "Hybrid FES-robot cooperative control of ambulatory gait rehabilitation exoskeleton.," Journal of neuroengineering and rehabilitation, vol. 11, p. 27, jan 2014.

[35] S. Jezernik and G. Colombo, "Robotic orthosis lokomat: A rehabilitation and research tool," Neuromodulation: Technology at the neural interface, no. 6.2, pp. 108-115, 2003.

[36] J. Arle, J. Shils, and W. Malik, "Localized stimulation and recording in the spinal cord with microelectrode arrays," Engineering in Medicine and Biology Society (EMBC), 2012 Annual International Conference of the IEEE, 2012.

[37] R. Saigal, "Intraspinal microstimulation generates functional movements after spinal-cord injury," Neural Systems and Rehabilitation Engineering, IEEE Transactions, no. 12.4, pp. 430-440, 2004.

[38] V. Mushahwar, D. Collins, and A. Prochazka, "Spinal cord microstimulation generates functional limb movements in chronically implanted cats," Experimental neurology, no. 163.2, pp. 422-429, 2000.

[39] Y. Stauffer and Y. Allemand, "The WalkTrainer-a new generation of walking reeducation device combining orthoses and muscle stimulation," Neural Systems and Rehabilitation Engineering, IEEE Transactions, no. 17.1, pp. 38-45, 2009.

[40] E. Urendes, G. A. Prieto, M. Gómez, R. Ceres, and J. Pons, “An integrated lower limb exoskeleton and body weight support system: design and implementation," International Workshop on Wearable Robotics, 2014.

[41] M. Aach, O. Cruciger, and M. Sczesny-Kaiser, "Voluntary driven exoskeleton as a new tool for rehabilitation in chronic spinal cord injury: a pilot study," The Spine Journal, no. 14.12, pp. 2847-2853, 2014.

[42] A. Hicks and K. Ginis, "Treadmill training after spinal cord injury: it's not just about the walking," Journal of rehabilitation research and development, no. 45.2, p. 241, 2008.

[43] D. B. McCreery, W. F. Agnew, T. G. H. Yuen, and L. a. Bullara, "Relationship between stimulus amplitude, stimulus frequency and neural damage during electrical stimulation of sciatic nerve of cat," Medical and Biological Engineering and Computing, vol. 33, pp. 426-429, may 1995.

[44] J. D. Bronzino, The Biomedical Engineering Handbook 1. 1999.

[45] G. Naples and J. Mortimer, "A spiral nerve cuff electrode for peripheral nerve stimulation," Biomedical Engineering, IEEE Transactions, no. 35.11, pp. 905-916, 1988. 
[46] D. Popovic and T. Gordon, "Properties of implanted electrodes for functional electrical stimulation," Annals of biomedical engineering, no. 19.3, pp. 303-316., 1991.

[47] L.-W. Chou and S. A. Binder-Macleod, "The effects of stimulation frequency and fatigue on the forceintensity relationship for human skeletal muscle.," Clinical neurophysiology : official journal of the International Federation of Clinical Neurophysiology, vol. 118, pp. 1387-96, jun 2007.

[48] R. Murray and M. Dwairy, "Evidence Based Review,"

[49] R. Berkelmans, “FES cycling,” Journal of Automatic Control, no. 18.2, pp. 73-76, 2008.

[50] J. J. Laskin, E. A. Ashley, L. M. Olenik, R. Burnham, D. C. Cumming, R. D. Steadward, and G. D. Wheeler, "Electrical stimulation assisted rowing exercise in spinal cord injured people. A pilot study.," Paraplegia, vol. 31, pp. 534-41, aug 1993.

[51] G. D. Wheeler, B. Andrews, R. Lederer, R. Davoodi, K. Natho, C. Weiss, J. Jeon, Y. Bhambhani, and R. D. Steadward, "Functional electric stimulation assisted rowing: Increasing cardiovascular fitness through functional electric stimulation rowing training in persons with spinal cord injury," Archives of Physical Medicine and Rehabilitation, vol. 83, pp. 1093-1099, aug 2002.

[52] A. Frotzler and S. Coupaud, "Effect of detraining on bone and muscle tissue in subjects with chronic spinal cord injury after a period of electrically-stimulated cycling: a small cohort study," Journal of rehabilitation medicine, no. 41.4, pp. 282-285, 2009.

[53] H. Gerrits and A. D. Haan, "Contractile properties of the quadriceps muscle in individuals with spinal cord injury," Muscle \& nerve, no. 22.9, pp. 1249-1256, 1999.

[54] G. Deley, J. Denuziller, N. Babault, and J. Taylor, "Effects of electrical stimulation pattern on quadriceps isometric force and fatigue in individuals with spinal cord injury," Muscle \& nerve, 2015.

[55] C.-W. Peng, "Review: Clinical Benefits of Functional Electrical Stimulation Cycling Exercise for Subjects with Central Neurological Impairments," Journal of Medical and Biological Engineering, vol. 31, no. 1, p. 1, 2011.

[56] T. Watanabe and Y. Karasawa, "A test of controlling different muscles in FES cycling with cycling wheelchair Profhand," Bioinformatics and Biomedical Engineering (iCBBE), IEEE, 2010 4th International Conference on, 2010.

[57] S. C. Abdulla, O. Sayidmarie, and M. O. Tokhi, "Functional electrical stimulation-based cycling assisted by flywheel and electrical clutch mechanism: A feasibility simulation study," Robotics and Autonomous Systems, vol. 62, no. 2, pp. 188-199, 2014.

[58] K. J. Hunt, T. Schauer, N. Negård, W. Steward, and M. H. Fraser, "A Pilot Study of Lower-limb FES Cycling in Paraplegia University of Glasgow," in 7th Annual Conference International Functional Electrical Stimulation Society, pp. 2-4, 2002.

[59] P.-F. L. P.-F. Li, Z.-G. H. Z.-G. Hou, F. Z. F. Zhang, Y.-X. C. Y.-X. Chen, X.-L. X. X.-L. Xie, M. T. M. Tan, and H.-B. W. H.-B. Wang, "Adaptive Neural Network Control of FES Cycling," Bioinformatics and Biomedical Engineering (iCBBE), IEEE, 2010 4th International Conference on, 2010.

[60] P.-f. Li, Z.-g. Hou, F. Zhang, M. Tan, H.-b. Wang, Y. Hong, and J.-w. Zhang, "An FES Cycling Control System Based on CPG," in Engineering in Medicine and Biology Society, 2009. EMBC 2009. Annual International Conference of the IEEE, 2009. 
[61] M. J. Bellman, T. H. Cheng, R. J. Downey, and W. E. Dixon, "Cadence Control of Stationary Cycling Induced by Switched Functional Electrical Stimulation Control," American Control Conference, no. 1161260, pp. 4802-4809, 2014.

[62] S. Khosravani, N. Lahimgarzadeh, and A. Maleki, "Developing a stimulator and an interface for FEScycling rehabilitation system," Biomedical Engineering (ICBME), 2011 18th Iranian Conference of, no. December, pp. 175-180, 2011.

[63] S. C. Abdulla and M. O. Tokhi, "Optimization of indoor FES-cycling exercise assisted by a flywheel mechanism using genetic algorithm," 2014 IEEE International Symposium on Intelligent Control (ISIC), pp. 1867-1871, 2014.

[64] R. J. Downey, E. Ambrosini, S. Ferrante, A. Pedrocchi, W. E. Dixon, and G. Ferrigno, "Asynchronous stimulation with an electrode array reduces muscle fatigue during FES cycling," Proceedings of the International Functional Electrical Stimulation Society, Banff, Alberta, Canada, pp. 154-157, 2012.

[65] T. Watanabe, T. Murakami, and Y. Handa, "Preliminary tests of a prototype FES control system for cycling wheelchair rehabilitation.," Rehabilitation Robotics (ICORR), 2013 IEEE International Conference on. IEEE, 2013.

[66] A. Ascensão, J. Magalhães, J. Oliveira, J. Duarte, and J. Soares, "Fisiologia da fadiga muscular. Delimitação conceptual, modelos de estudo e mecanismos de fadiga de origem central e periférica," Revista Portuguesa de Ciências do Desporto, vol. 3, no. 1, pp. 108-123, 2003.

[67] D. King-Hele, "Erasmus Darwin's Improved Design for Steering Carriages-And Cars," Notes and Records of the Royal Society of London, vol. 56, no. 1, pp. 41-62, 2002.

[68] T. Schauer, N.-o. Negaard, and C. Behling, "RehaStim TM Stimulation Device Description and Protocol," 2009.

[69] Y. Technology, "3-Space Sensor Wireless 2.4GHz - Miniature Wireless Attitude \& Heading Reference System User's Manual,” 2011.

[70] E. Upton and G. Halfacree, "Raspberry Pi Manual do Usuário," 2013.

[71] C. D. M. HERLANDSON, Trabalho de graduação desenvolvimento de sistemas de controle para aplicação em fes. $\mathrm{PhD}$ thesis, 2013.

[72] A. D. Lopes, S. R. Alouche, and N. Hakansson, "ELECTROMYOGRAPHY DURING PEDALING ON UPRIGHT AND RECUMBENT ERGOMETER," The International Journal of Sports Physical Therapy, vol. 9, no. 1, pp. 76-81, 2014.

[73] F. H. Netter, Anatomia Humana. Rio de Janeiro: Elsevier, 5a ed., 2011.

[74] A. P. L. Bó, P. Poignet, D. Zhang, and W. T. Ang, "FES-controlled co-contraction strategies for pathological tremor compensation," in 2009 IEEE/RSJ International Conference on Intelligent Robots and Systems, IROS 2009, pp. 1633-1638, IEEE, oct 2009.

[75] A. P. L. Bó, Compensation active de tremblements pathologiques des membres supérieurs via la stimulation électrique fonctionnelle. $\mathrm{PhD}$ thesis, 2010. 
[76] A. L. Cologni, T. Seel, M. G. Madaschi, F. Previdi, C. Werner, and T. Schauer, "Automatic Adjustment of Electromyography-Based FES Control," in IFESS 2013-18th International Functional Electrical Stimulation Society Conference: Bridging Mind and Body.

[77] M. Caramenti, V. Bartenbach, L. Gasperotti, L. Oliveira da Fonseca, T. W. Berger, and J. L. Pons, "Challenges in Neurorehabilitation and Neural Engineering," in Emerging Therapies in Neurorehabilitation II (J. L. Pons, R. Raya, and J. González, eds.), vol. 10 of Biosystems \& Biorobotics, ch. 1, pp. 1-27, Cham: Springer International Publishing, 2016. 


\section{Parte I}

\section{Apêndices}




\section{Risk Management File}

Device name:

\section{EMA Trike}

Document version number:

Version 1.0

\section{Created by}

Name and address of manufacturer:

EMA Project

Laboratória de Robótica e Automação - LARA

Campus Darcy Ribeiro

Universidade de Brasília

Brasília / DF

Brazil

ZIP code: $70910-900$

\section{Responsibility and Approval}

Place and date:

Brasília, 01.05.2015

\section{Name of responsible person:}

Antônio Padilha Lanari Bó

Signature: 


\section{ExîHzürich}

CYBATHLON

\section{Table of Contents}

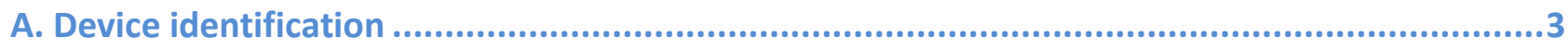

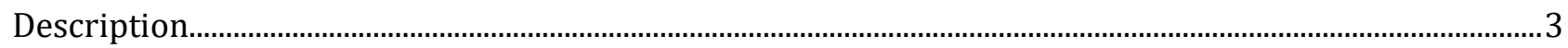

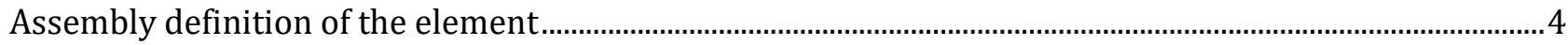

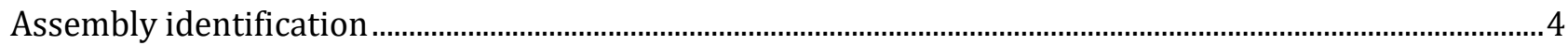

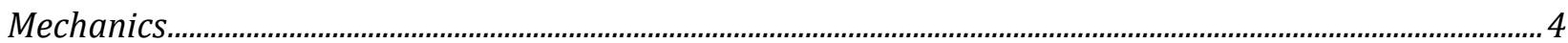

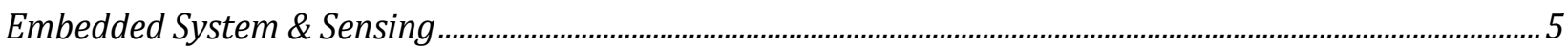

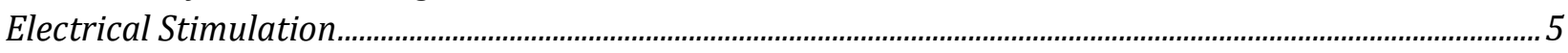

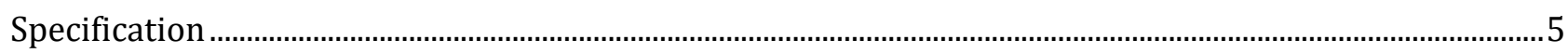

Trike

Handlebars (9)

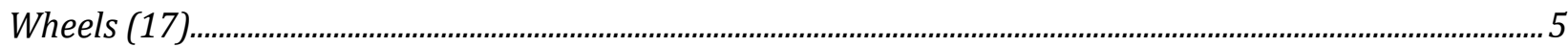

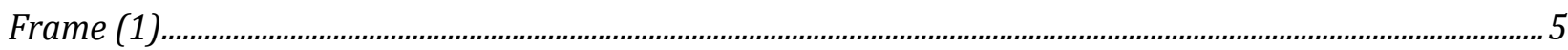

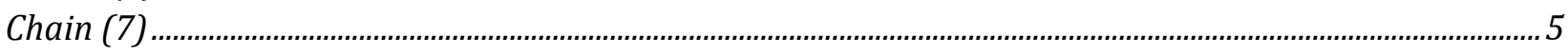

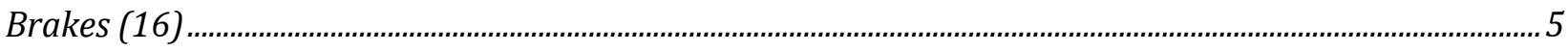

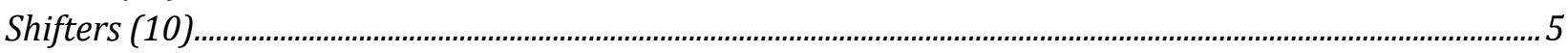

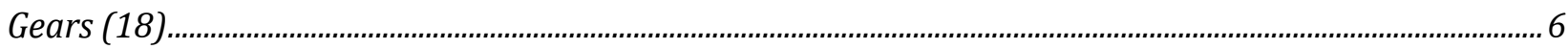

Seat (6)

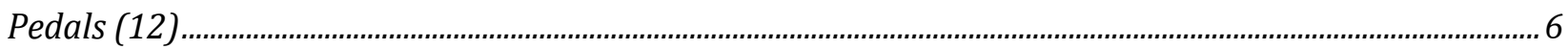

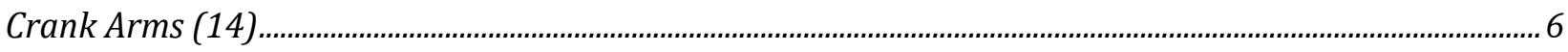

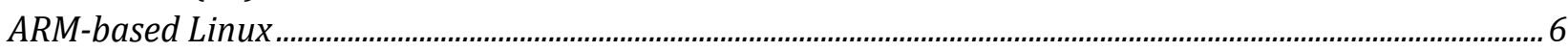

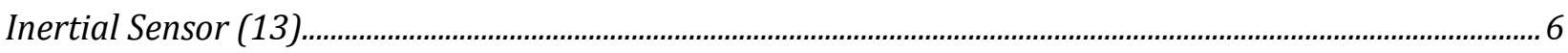

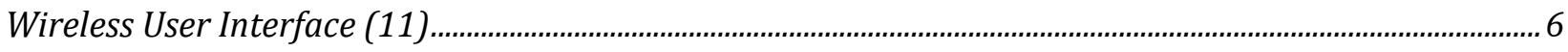

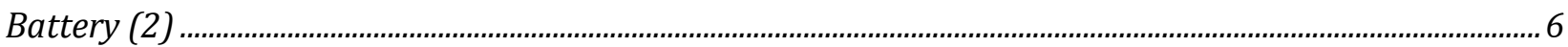

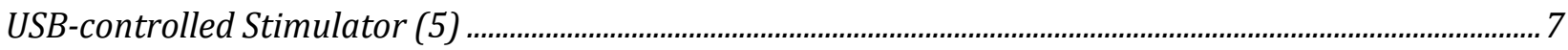

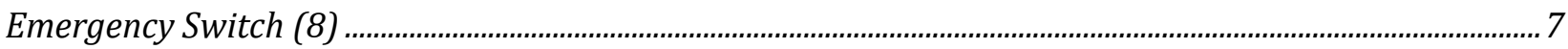

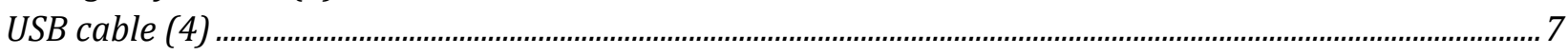

Surface Electrodes and cables .........................................................................................................................................

Power Supply

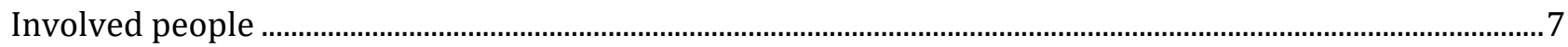

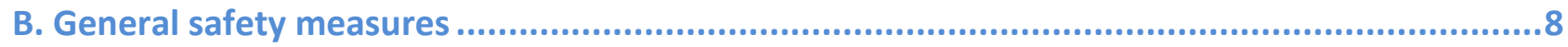

C. Specific risks and failures, detection and preventing measures .................................. 8

Critical Risk Priority Number.......................................................................................................................

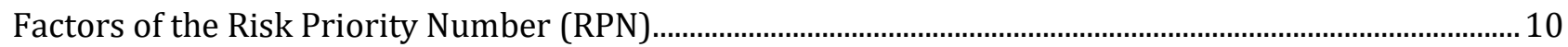

$S-$ Severity

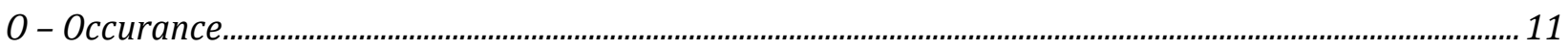

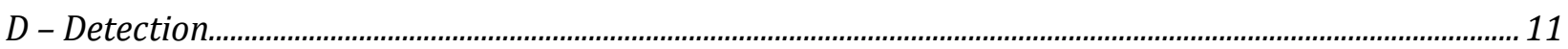

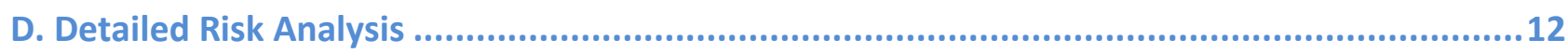

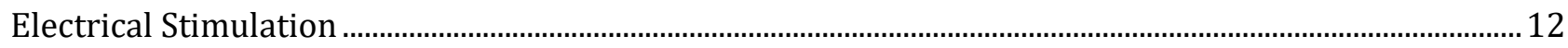

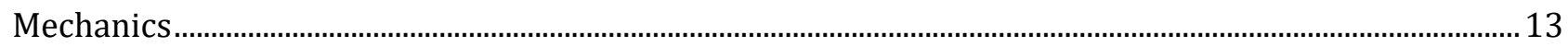

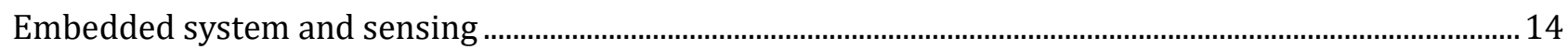




\section{EHzürich}

C YBATHLON

\section{A. Device identification}

\section{Description}

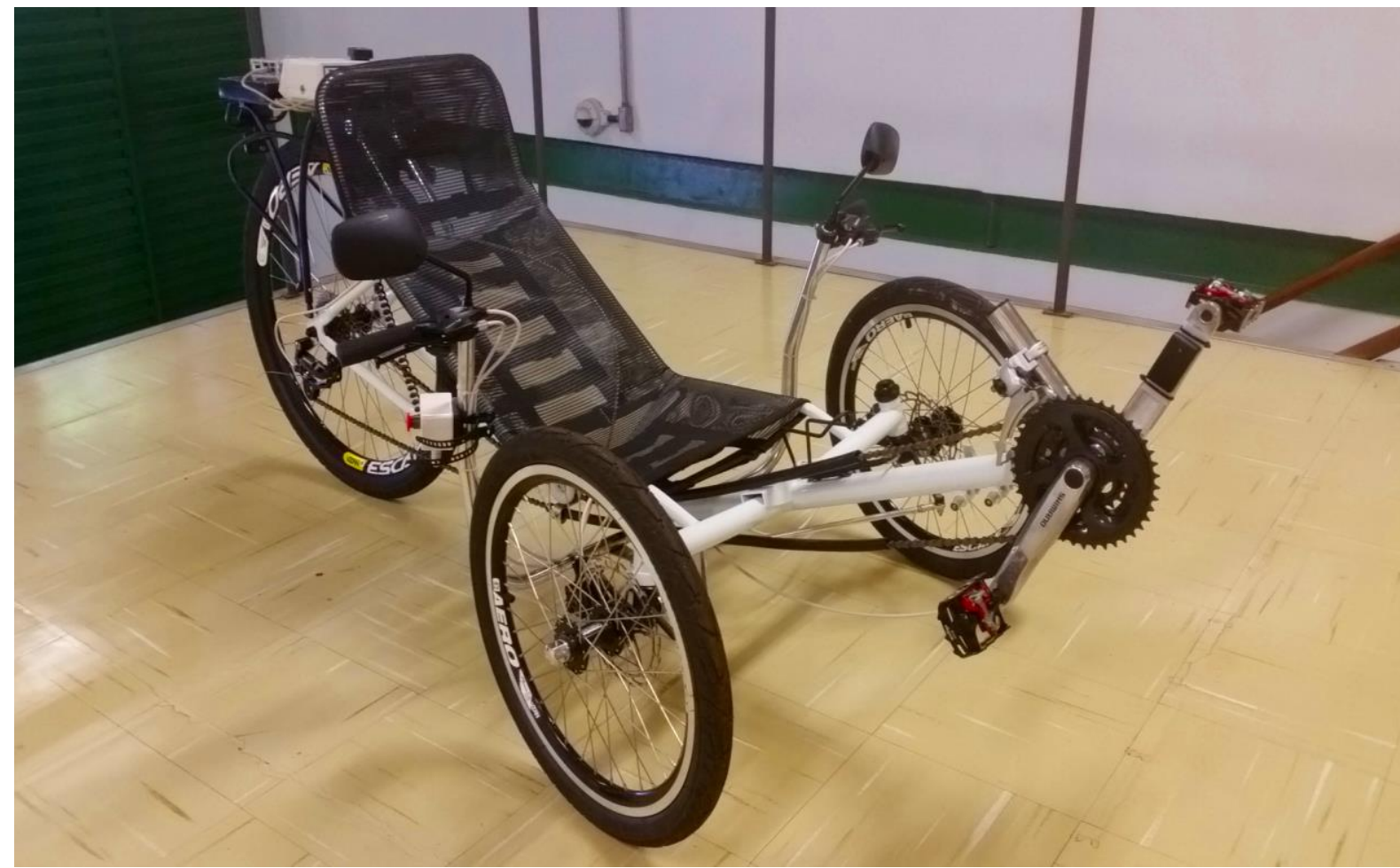

The EMA Trike is a three-wheeled vehicle with no electromechanical actuators. It is powered by human lower limbs in a cycling motion the same way as a bicycle.

This device is intended to be used by a spinal cord injured pilot. Therefore, there is an electrical stimulator embedded that can act on the pilot's lower limbs and provoke the cycling motion.

There are sensors that are used in a closed-loop control system that are responsible for the cycling motion. 
ETḦzürich

C YB ATHLON

AMPIONERIEFOF

Assembly definition of the element

\begin{tabular}{|c|c|c|}
\hline $\begin{array}{l}\text { Mechanics } \\
\text { Handlebars } \\
\text { Wheels } \\
\text { Frame } \\
\text { Chain } \\
\text { Brakes } \\
\text { Shifters } \\
\text { Gears } \\
\text { Seat } \\
\text { Pedal } \\
\text { Crank arm }\end{array}$ & $\begin{array}{l} \\
\begin{array}{l}\text { Embedded system \& } \\
\text { sensing }\end{array} \\
\text { Inertial sensor } \\
\text { ARM-based Linux } \\
\text { Wireless user interface } \\
\text { Battery }\end{array}$ & $\begin{array}{l}\text { Electrical stimulation } \\
\text { USB-controlled stimulator } \\
\text { Emergency switch } \\
\text { USB cable } \\
\text { Surface electrodes \& cables } \\
\text { Power supply }\end{array}$ \\
\hline
\end{tabular}

\section{Assembly identification}

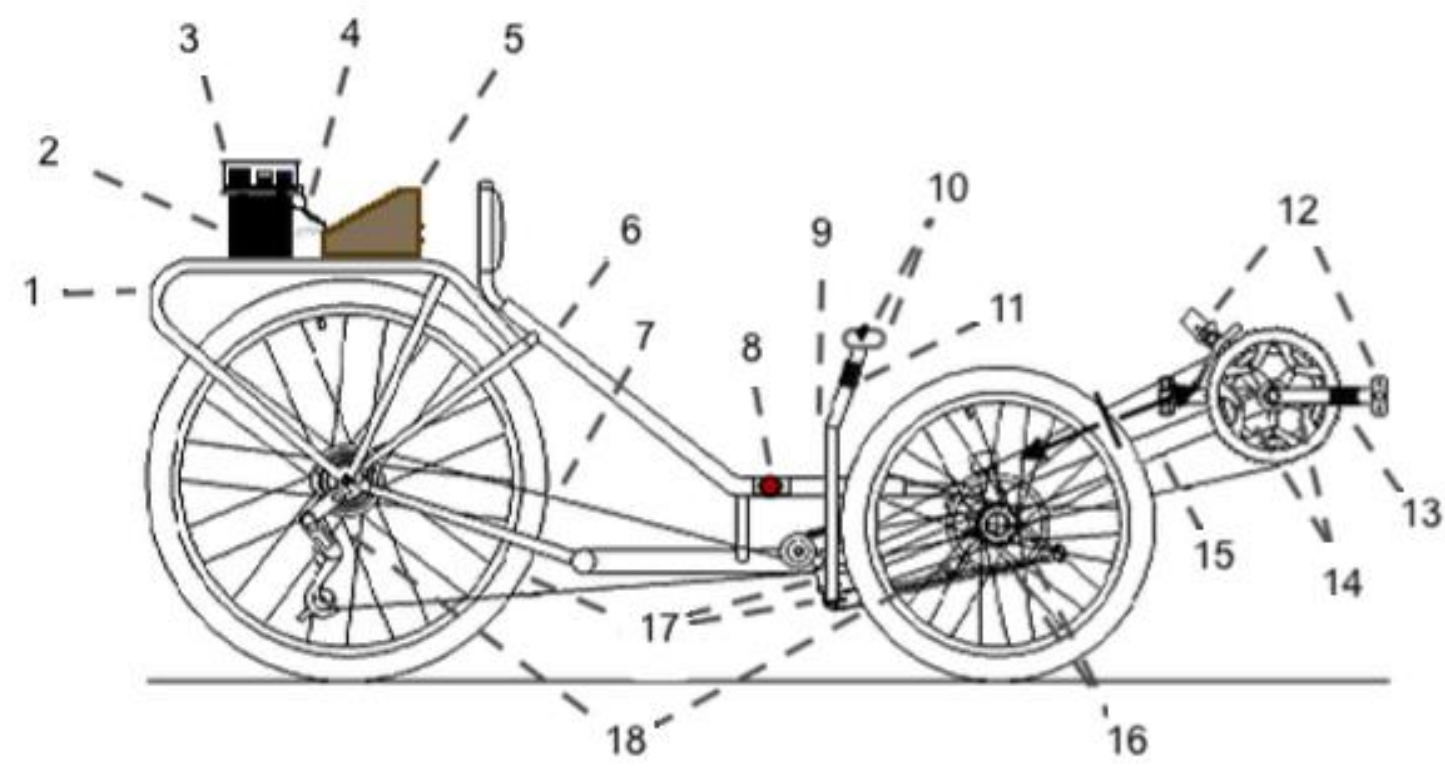

\section{Mechanics}

A standard tricycle with three wheels (17), one at the front and two at the back, propelled by pedals (12).

There is an extendable boom (15) for pilots with different heights. 
EIḦzürich

CYBATHLON

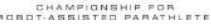

\section{Embedded System \& Sensing}

An embedded system (3) that controls the electrical stimulation device in order to timely activate the appropriate muscles for pedaling.

\section{Electrical Stimulation}

A device (5) that generates an electrical stimulation at the muscles through surface electrodes.

\section{Specification}

\section{Trike}

An $18 \mathrm{~kg}$ aluminum tricycle, measuring $900 \mathrm{~mm} \times 750 \mathrm{~mm} \times 1980 \mathrm{~mm}$ with a $1040 \mathrm{~mm}$ wheelbase. This is a slightly modified version of a trike commercialized by HP3 Trikes, which is based in Rio de Janeiro, RJ, Brazil.

\section{Handlebars (9)}

The handlebars employ a modified Ackermann steering geometry, also being adjustable in length and inclination.

\section{Wheels (17)}

There are two aluminum wheels with Levorin tires in the front (20"x1.75) and one in the rear (26"x1.9).

\section{Frame (1)}

The structure of the tricycle is made of carbon steel tubes with automotive painting. Its structure has been designed using Finite Element Modeling (FEM) analysis, guaranteeing improved safety against structural failure.

\section{Chain (7)}

The chain is a Shimano HG Index with a guiding and protection system, which uses a pulley fixed to the frame by two pulley $6082 \mathrm{RS}$ bearings, and protective hoses also fixed for the chain.

\section{Brakes (16)}

There are two independent $160 \mathrm{~mm}$ mechanical disk brakes, one on each front wheel, that may be activated by the pilot to stop or reduce speed.

\section{Shifters (10)}

Front shifter Shimano Rapid Fire 3V and rear shifter Shimano Rapid Fire 8V, are used to change the position of the chain at the cassette pinions and the chainrings. 


\section{Gears (18)}

There are 8 cassette pinions and 3 chainrings, so there are 24 possible speeds.

\section{Seat (6)}

The seat has an inclination angle and is covered with a soft tissue to improve comfort to the pilot.

\section{Pedals (12)}

The Pedal Wellgo WPD 998, has a clip on one side of each pedal so a cycling shoe can be attached to it.

\section{Crank Arms (14)}

It connects the pedal to the crankset, MTB aluminium $170 \mathrm{~mm}$.

\section{ARM-based Linux}

The Raspberry Pi 1 Model B+ (3) is responsible for the control system, it acquires the sensors data and sends commands to the stimulator (5). The device is powered by a $5 \mathrm{~V}$ micro USB supply (2) and it can power up to $1 \mathrm{~A}$ to other devices connected to it. Debian Weezy Linux is the Operational System used.

\section{Inertial Sensor (13)}

The YEI 3-space-sensor uses triaxial gyroscope, accelerometer and compass sensors to determine orientation to a reference. In this case one is used to determine the angular position and angular speed of the pedal relative to its rotation axis. The data is transmitted through wireless signal to the controller which can access the sensor via an open communication protocol and send command with configuration parameters and data acquisition. The sensor is $60 \times 35 \times 15$ $\mathrm{mm}, 28$ grams, has two input buttons, communication with USB virtual COM port or 2.4Ghz Wireless and a rechargeable LiPO Battery and a supply voltage of $+5 \mathrm{~V}$ USB. The temperature range is $-40^{\circ} \mathrm{C}$ to $85^{\circ} \mathrm{C}$ for a good performance.

A dongle is responsible for the wireless communication. It is a USB 2.0 Wireless $2.4 \mathrm{GHz}$ DSSS adapter, with dimensions $65 \times 22.7 \times 15 \mathrm{~mm}$. It support up to 15 wireless sensor units.

\section{Wireless User Interface (11)}

A second sensor, also YEI 3-space-sensor, is used as start/stop button, with the two input buttons available, to the stimulation when the user decides.

\section{Battery (2)}

The control unit is powered using a lithium polymer battery with a capacity of $1450 \mathrm{mAh}$ and $11.1 \mathrm{~V}$ of nominal voltage. 


\section{USB-controlled Stimulator (5)}

The RehaStim is a portable device $(130 \mathrm{~mm} \times 150 \mathrm{~mm} \times 7 \mathrm{~mm}$ and $5 \mathrm{~kg})$ that generates impulses. The method of line current insulation is a SANYO, NiMh and C $=2700 \mathrm{mAh}$. It is suggested to be used within a range from $0^{\circ} \mathrm{C}$ to $40^{\circ} \mathrm{C}$ temperature. The device may be controlled with using a touch sensitive LCD or with USB/RS232 communication. There are 8 stimulation channels, with $2 \mathrm{~mA}$ to $130 \mathrm{~mA}$ current output incremented in steps of $2 \mathrm{~mA}$ and a biphasic waveform type. The duration of the stimulation impulses varies from $20-500 \mu$ s incremented in steps of $10 \mu \mathrm{s}$, and the frequency range is 10 to $50 \mathrm{~Hz}$ in steps of $5 \mathrm{~Hz}$.

\section{Emergency Switch (8)}

The button allows the user to terminate the stimulation at any time if necessary. It shuts off the stimulatior completely and immediately.

\section{USB cable (4)}

It communicates the stimulator to a computer, which can be used to send commands with the proper protocol and, therefore, control the device functioning. It can also be used to update the device software.

\section{Surface Electrodes and cables}

The surface electrodes must be applied above the relevant muscles. When the impulse is applied, the muscle will contract. The cables connect the surface electrodes to the stimulator. Each cable has two channels, and each channel separates in two electrodes.

\section{Power Supply}

The power supply currently employed in the project is produced by Cincon Electronics CO., LTD. Model TR30M090. Rated to $110-220 \mathrm{VAC}, 50-60 \mathrm{~Hz}, 150 \mathrm{~W}$ maximum input and a 9V, 3A output supply that charges the internal battery.

\section{Involved people}

The system design resulted from contributions of engineers and undergraduate students in engineering from different institutions, mostly the University of Brasília. From the University of Brasilia:

- Lucas Oliveira da Fonseca - grad student

- Stephany Ribeiro Rodrigues - undergrad student

- Lucas de Levy Oliveira - undergrad student

- George Andrew Brindeiro - grad student

- Antônio Padilha Lanari Bo - professor

- Ana Carolina Cardoso de Sousa - grad student

- Miguel Eduardo Gutierrez Paredes - grad student

From HP3 Trikes:

- Arthur Melo. Mechanical engineer with experience on oil heavy industry, mostly Petrobras, Mr. Melo is the main responsible for the mechanical design of HP3 Trike. 


\section{Exitzzürich \\ C YBATHLON \\ . \\ B. General safety measures}

The EMA trike must not be used if wet. Even though the EMA trike can withstand small bumps, it is intended to be used on mostly smooth surfaces.

The pilot must always wear seat belt and helmet and have the remote control unit correctly attached and by hand. Make sure the trike is at an appropriate size for the pilot adjusting the seat, if necessary. Attach both feet on the pedals ensuring a secure rotation.

Before the ride, check if all three tires are properly calibrated and the brakes are working properly. Make sure the chain is in good condition and if it does not accumulate rust, dirt, or other debris. Both stimulator and control devices batteries must be completely charged for operation. All cables must be securely fixed, and the emergency button must be checked. Use new electrodes, with good adhesiveness properties, and bandages to further fixate them.

After all safety measures were checked, at the start of operation, the left pedal must be on the upward position and the system may be turned on.

\section{Specific risks and failures, detection and preventing measures}

Each risk/failure should be listed in the "Detailed Risk Analysis" below. Describe the failure and possible resulting effects, rate the probability of its occurrence, the severity, and the probability to detect the failure. Describe preventing measures and rate the failure again.

The format of this risk/failure table has been adapted from:

http://www.npd-solutions.com/fmea.html,

http://www.harpcosystems.com/articles/Design-FMEA-Ratings-Part1/,

http://www.harpcosystems.com/articles/Design-FMEA-Ratings-Part2/,

http://www.harpcosystems.com/articles/Design-FMEA-Ratings-Part3/

Examples of possible hazards are listed below (based on ISO 14971):

\begin{tabular}{|c|c|c|c|}
\hline $\begin{array}{l}\text { Examples of energy } \\
\text { hazards }\end{array}$ & $\begin{array}{l}\text { Examples of biological and chemical } \\
\text { hazards }\end{array}$ & $\begin{array}{l}\text { Examples of } \\
\text { operational } \\
\text { hazards }\end{array}$ & $\begin{array}{l}\text { Examples of information } \\
\text { hazards }\end{array}$ \\
\hline $\begin{array}{l}\text { Electromagnetic } \\
\text { energy } \\
\text { Line voltage } \\
\text { Leakage current } \\
>\text { enclosure } \\
\quad \text { leakage current } \\
>\text { earth leakage } \\
\quad \text { current } \\
>\text { patient leakage } \\
\quad \text { current } \\
\text { Electric fields }\end{array}$ & $\begin{array}{l}\text { Biological } \\
\text { Bacteria } \\
\text { Viruses } \\
\text { Other agents (e.g. prions) } \\
\text { Re- or cross-infection } \\
\text { Chemical } \\
\text { Exposure of airway, tissues, } \\
\text { environment or property, e.g. to foreign } \\
\text { materials: }\end{array}$ & $\begin{array}{l}\text { Function } \\
\text { Incorrect or } \\
\text { inappropriate } \\
\text { output or } \\
\text { functionality } \\
\text { Incorrect } \\
\text { measurement } \\
\text { Erroneous data } \\
\text { transfer } \\
\text { Loss or }\end{array}$ & $\begin{array}{l}\text { Labelling } \\
\text { Incomplete instructions for } \\
\text { use } \\
\text { Inadequate description of } \\
\text { performance characteristics } \\
\text { Inadequate specification of } \\
\text { intended use } \\
\text { Inadequate disclosure of } \\
\text { limitations }\end{array}$ \\
\hline
\end{tabular}




\section{EHzürich}

C YB ATHLON

CHAMPONBMEF FOE

\begin{tabular}{|c|c|c|c|}
\hline $\begin{array}{l}\text { Magnetic fields } \\
\text { Radiation energy } \\
\text { lonizing radiation } \\
\text { Non-ionizing } \\
\text { radiation } \\
\text { Thermal energy } \\
\text { High temperature } \\
\text { Low temperature } \\
\text { Mechanical energy } \\
\text { Gravity } \\
\text { > falling } \\
\text { > suspended } \\
\text { masses } \\
\text { Vibration } \\
\text { Stored energy } \\
\text { Moving parts } \\
\text { Torsion, shear and } \\
\text { tensile } \\
\text { Force } \\
\text { Moving and } \\
\text { positioning of pilot } \\
\text { Acoustic energy } \\
\text { > ultrasonic energy } \\
\text { > infrasound } \\
\text { energy } \\
\text { > sound }\end{array}$ & $\begin{array}{l}>\text { acids or alkalis } \\
>\text { residues } \\
>\text { contaminates } \\
>\text { additives or processing aids } \\
>\text { cleaning, disinfecting or testing } \\
\quad \text { agents } \\
>\text { degradation products } \\
>\text { medical gasses } \\
>\text { anaesthetic products } \\
\text { Biocompatibility } \\
\text { Toxicity of chemical constituents, e.g.: } \\
>\text { allergenicity/irritancy } \\
>\text { pyrogenicity }\end{array}$ & $\begin{array}{l}\text { deterioration of } \\
\text { function } \\
\text { Use error } \\
\text { Attentional failure } \\
\text { Memory failure } \\
\text { Rule-based failure } \\
\text { Knowledge-based } \\
\text { failure } \\
\text { Routine violation }\end{array}$ & $\begin{array}{l}\text { Operating instructions } \\
\text { Inadequate specification of } \\
\text { accessories to be used with } \\
\text { the device } \\
\text { Inadequate specification of } \\
\text { pre-use checks } \\
\text { Over-complicated operating } \\
\text { Instructions } \\
\text { Warnings } \\
\text { of side effects } \\
\text { of hazards likely with re-use } \\
\text { of single-use medical devices } \\
\text { Specification of service } \\
\text { and maintenance }\end{array}$ \\
\hline
\end{tabular}




\section{Critical Risk Priority Number}

During the risk analysis, each risk or failure is analyzed and rated with respect to its severity (S), probability of occurrence $(\mathrm{O})$, and detection rate (D). The rating for each of the three aspects ranges from 1 (low security risk/failure, low probability of occurrence, high detection probability) to 10 (severe injuries or death, high probability of occurrence, no/low probability for detection). The product out of these three ratings is called Risk Priority Number (RPN). In case, the RPN is greater than a critical threshold, preventing measures are required in order to reach a final RPN below or equal to the critical threshold by means of reasonable and justifiable security measures.

Define a critical threshold in this section here - we recommend a critical RPN threshold of $\mathbf{7 5}$.

In case, the risk is greater than the critical threshold the risk must clearly be mentioned in the "declaration of agreement" signed by the pilot and involved staff.

According to the organization's recommendation, and discussions within the team, a Risk Priority Number, RPN = 75 seems to be a good measure regarding safety.

\section{Factors of the Risk Priority Number (RPN)}

Find below a recommendation how to rate occurrence, severity, and detection. The "Risk Priority Number before" is a mathematical product of the numerical Severity- (S), Occurrence- (O), and Detection-Ratings (D) obtained before applying any preventing measures to reduce the likelihood for dangerous incidents, thus: $\mathbf{R P N}$ before $=(\mathbf{S 1}) \mathbf{x}(\mathbf{O} 1) \mathbf{x}$ (D1). This "RPN before" should be set to prioritize items that require additional quality planning or action.

The "RPN after" is a mathematical product of the numerical Severity- (S), Occurrence- (O), and Detection-Ratings (D) obtained after applying the preventing measures to reduce the likelihood for dangerous incidents, i.e. RPN after $=(\mathbf{S} 2) \mathbf{x}$ (O2) x (D2). The "RPN after" has to be equal or below the predefined threshold in order to guarantee safe use of the part/element/device.

Preventing measures are mechanisms that prevent the cause of the failure mode from occurring or that detect the failure and stop the application before an incident can happen. It could also reduce the severity by e.g. designing softer and rounder edges. Preventing measures could include specific inspection, testing or quality assurance procedures; selection of other components or materials; de-rating; limiting environmental stresses or operating ranges; redesign of the item to avoid the failure mode; monitoring mechanisms; performing preventative maintenance; or inclusion of back-up systems or redundancy.

\section{S - Severity}

\begin{tabular}{|c|l|l|l|}
\hline $\begin{array}{l}\text { Rating } \\
\text { S }\end{array}$ & Criteria: Severity of effect & Consequence & Treatment \\
\hline 10 & Death & - & - \\
\hline 9 & Quadriplegia & $\begin{array}{l}\text { Life-long medical care } \\
\text { necessary / coma / } \\
\text { permanent damage }\end{array}$ & Hospital stay \\
\hline 8 & $\begin{array}{l}\text { Amputations, paraplegia, blindness, } \\
\text { deafness, traumatic brain injury (severe), } \\
\text { fourth-degree burns }\end{array}$ & $\begin{array}{l}\text { Life-long medical care } \\
\text { necessary / coma / } \\
\text { permanent damage }\end{array}$ & Hospital stay \\
\hline 7 & $\begin{array}{l}\text { Complex fractures, open fracture, inner } \\
\text { injuries, traumatic brain injury (severe), third- } \\
\text { degree burns }\end{array}$ & Permanent damage possible & Hospital stay \\
\hline 6 & Gash, fractures, torn muscles, articular & Permanent damage possible & Hospital stay \\
\hline
\end{tabular}




\section{EIHzürich}

C YBATHLON

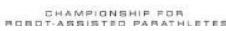

\begin{tabular}{|c|l|l|l|}
\hline & $\begin{array}{l}\text { cartilage injury, traumatic brain injury } \\
\text { (moderate), second-degree burns }\end{array}$ & Reversible injury & $\begin{array}{l}\text { Hospital stay or } \\
\text { ambulant } \\
\text { treatment }\end{array}$ \\
\hline 5 & $\begin{array}{l}\text { Gash, fractures, torn muscles, articular } \\
\text { cartilage injury, traumatic brain injury (mild), } \\
\text { second-degree burns }\end{array}$ & $\begin{array}{l}\text { Ambulant } \\
\text { treatment or self- } \\
\text { treatment }\end{array}$ \\
\hline 4 & $\begin{array}{l}\text { Severe cuts, severe scratches, severe } \\
\text { contusions, strains, first-degree burns }\end{array}$ & Reversible injury & Self-treatment \\
\hline 3 & $\begin{array}{l}\text { Minor cuts, minor scratches, minor } \\
\text { contusions, stiff muscles, tension, blisters, } \\
\text { excoriations, sickness, first-degree burns }\end{array}$ & $\begin{array}{l}\text { Discomfort during application } \\
\text { up to three days after } \\
\text { application }\end{array}$ & - \\
\hline 2 & Slight sickness, pressure marks & Discomfort & - \\
\hline 1 & No harm & - & \\
\hline
\end{tabular}

\section{O-Occurance}

\begin{tabular}{|c|l|}
\hline Rating $\mathbf{0}$ & Criteria: Probability of occurrence \\
\hline 10 & Occurs or may occur very likely during every use of the session \\
\hline 9 & Occurs or may occur likely during every use of the session \\
\hline 8 & Occurs in 1 of 5 sessions (less than once a day) \\
\hline 7 & Occurs in 1 of 10 sessions (less than once a day) \\
\hline 6 & Occurs in 1 of 50 sessions (less than once half a month) \\
\hline 5 & Occurs in 1 of 100 sessions (less than once a month) \\
\hline 4 & Occurs in 1 of 500 sessions (less than once half a year) \\
\hline 3 & Occurs in 1 of 1000 sessions (less than once per year) \\
\hline 2 & Occurrence very unlikely \\
\hline 1 & Occurrence nearly impossible \\
\hline
\end{tabular}

\section{D - Detection}

\begin{tabular}{|c|l|}
\hline Rating D & Criteria: Likelihood of detection by design control \\
\hline 10 & No chance of detection \\
\hline 9 & Very remote chance of detection \\
\hline 8 & Remote chance of detection \\
\hline 7 & Very low chance of detection by indirect methods (hardware or software) \\
\hline 6 & Low chance of detection by indirect methods (hardware or software) \\
\hline 5 & Moderate chance of detection by indirect methods (hardware or software) \\
\hline 4 & High chance of detection by indirect methods (hardware or software) \\
\hline 3 & High chance of detection by direct or indirect methods (hardware/software) \\
\hline 2 & Direct and indirect detection: Hardware or software \\
\hline 1 & Direct detection: Hardware or safe software (category 4, performance level e) \\
\hline
\end{tabular}




\title{
D. Detailed Risk Analysis
}

\author{
Electrical Stimulation
}

\begin{tabular}{|c|c|c|c|c|c|c|c|c|c|c|}
\hline Assembly & Failure \& Effect & S1 & 01 & D1 & $\begin{array}{c}\text { RPN } \\
\text { before }\end{array}$ & Preventing measures & $\mathrm{S} 2$ & $\mathrm{O} 2$ & D2 & $\begin{array}{l}\text { RPN } \\
\text { after }\end{array}$ \\
\hline Stimulator & $\begin{array}{l}\text { Stimulator achieves a } \\
\text { higher current value or } \\
\text { a wider pulse than } \\
\text { expected, which could } \\
\text { cause a serious skin } \\
\text { chemical burn or an } \\
\text { unwanted movement } \\
\text { that could lead to } \\
\text { falling. }\end{array}$ & 5 & 2 & 10 & 100 & $\begin{array}{l}\text { The stimulator has a } \\
\text { safety system that uses } \\
\text { an electrical test pulse } \\
\text { prior to the main pulse } \\
\text { that is used to evaluate if } \\
\text { the impedance } \\
\text { decreased dramatically, } \\
\text { which would cause the } \\
\text { higher current. If that is } \\
\text { the case, the main pulse } \\
\text { is not sent. }\end{array}$ & 5 & 2 & 3 & 30 \\
\hline \multirow[t]{2}{*}{ Electrodes } & $\begin{array}{l}\text { The electrodes could } \\
\text { partially come out. } \\
\text { That would cause the } \\
\text { current to get higher } \\
\text { and could cause a } \\
\text { serious skin chemical } \\
\text { burn or an unwanted } \\
\text { movement that could } \\
\text { lead to falling. }\end{array}$ & 5 & 8 & 7 & 280 & $\begin{array}{l}\text { Besides the stimulator } \\
\text { safety measures } \\
\text { described above, the } \\
\text { electrodes will be brand } \\
\text { new, which means a } \\
\text { high adhesiveness. Also, } \\
\text { bandage-like constraints } \\
\text { will be used to keep the } \\
\text { electrodes in place. }\end{array}$ & 5 & 3 & 1 & 15 \\
\hline & $\begin{array}{l}\text { The electrodes could } \\
\text { totally come out. That } \\
\text { would cause the } \\
\text { stimulation to cease } \\
\text { on that muscle, which } \\
\text { could lead to an } \\
\text { unbalanced cycling } \\
\text { and possibly a crash. }\end{array}$ & 5 & 8 & 6 & 240 & $\begin{array}{l}\text { The stimulator safety } \\
\text { system and the } \\
\text { constraints described } \\
\text { above will decrease this } \\
\text { risk }\end{array}$ & 5 & 3 & 1 & 15 \\
\hline $\begin{array}{l}\text { Electrodes } \\
\text { Cables }\end{array}$ & $\begin{array}{l}\text { The cables could get } \\
\text { tangled on a wheel or } \\
\text { the chain. That could } \\
\text { disconnect the cables } \\
\text { or stuck the chain, } \\
\text { which, in hard } \\
\text { circumstances, could } \\
\text { result in falling. }\end{array}$ & 5 & 6 & 5 & 150 & $\begin{array}{l}\text { The stimulator safety } \\
\text { system would avoid any } \\
\text { damage from the } \\
\text { disconnected cables. } \\
\text { But, to avoid this risk, } \\
\text { the cables will be fixed, } \\
\text { and not loose. }\end{array}$ & 5 & 3 & 1 & 15 \\
\hline $\begin{array}{l}\text { Stop } \\
\text { Emergency } \\
\text { button }\end{array}$ & $\begin{array}{l}\text { The button could } \\
\text { break or not work. } \\
\text { That would make the } \\
\text { pilot unable to shut off } \\
\text { the system. }\end{array}$ & 5 & 1 & 10 & 50 & & & & & \\
\hline
\end{tabular}




\section{EHzürich}

C YB ATHLON

\begin{tabular}{|l|l|l|l|l|l|l|l|l|l|l|}
\hline USB Cable & $\begin{array}{l}\text { The cable could be } \\
\text { disconnected or } \\
\text { tangled on a wheel or } \\
\text { the chain. In hard } \\
\text { circumstances, it could } \\
\text { result in falling. }\end{array}$ & 5 & 6 & 10 & 300 & $\begin{array}{l}\text { The stimulator safety } \\
\text { system and the cables } \\
\text { fixation will decrease this } \\
\text { risk. }\end{array}$ & 5 & 3 & 3 & 45 \\
\hline $\begin{array}{l}\text { Power } \\
\text { supply }\end{array}$ & $\begin{array}{l}\text { The battery runs out } \\
\text { and the stimulation } \\
\text { stops. That would } \\
\text { make the pilot unable } \\
\text { to keep cycling. }\end{array}$ & 1 & 4 & 1 & 4 & & & & & \\
\hline
\end{tabular}

\section{Mechanics}

\begin{tabular}{|c|c|c|c|c|c|c|c|c|c|c|}
\hline Assembly & Failure \& Effect & S1 & 01 & D1 & $\begin{array}{l}\text { RPN } \\
\text { before }\end{array}$ & $\begin{array}{l}\text { Preventing } \\
\text { measures }\end{array}$ & $\mathrm{S} 2$ & $\mathrm{O} 2$ & D2 & $\begin{array}{l}\text { RPN } \\
\text { after }\end{array}$ \\
\hline $\begin{array}{l}\text { Handle } \\
\text { bar }\end{array}$ & $\begin{array}{l}\text { The handlebar breaks during } \\
\text { operation causing loss of } \\
\text { maneuverability and a possible } \\
\text { crash. }\end{array}$ & 5 & 2 & 4 & 40 & & & & & \\
\hline $\begin{array}{l}\text { Wheels \& } \\
\text { Tires }\end{array}$ & $\begin{array}{l}\text { Tire blowout during high velocity or } \\
\text { while driving in a curve leads to a } \\
\text { fall. }\end{array}$ & 5 & 3 & 4 & 60 & & & & & \\
\hline & Tire loses pressure. & 1 & 5 & 6 & 30 & & & & & \\
\hline Frame & $\begin{array}{l}\text { The frame breaks during operation } \\
\text { leading to a fall. }\end{array}$ & 5 & 2 & 4 & 40 & & & & & \\
\hline Chain & $\begin{array}{l}\text { The chain breaks, stopping the } \\
\text { cycling suddenly. It could hit the } \\
\text { pilot and possibly hurt him/her. }\end{array}$ & 3 & 2 & 4 & 24 & & & & & \\
\hline Brakes & The brakes fail causing a crash. & 5 & 3 & 4 & 60 & & & & & \\
\hline $\begin{array}{l}\text { Chain } \\
\text { Rings }\end{array}$ & $\begin{array}{l}\text { The chain breaks, stopping the } \\
\text { cycling suddenly. It could hit the } \\
\text { pilot. }\end{array}$ & 3 & 2 & 4 & 24 & & & & & \\
\hline Gears & $\begin{array}{l}\text { The gears fail, forcing the pilot to } \\
\text { reduce the velocity and } \\
\text { compromising his/her performance } \\
\text { during competition. }\end{array}$ & 1 & 5 & 4 & 20 & & & & & \\
\hline Seat & $\begin{array}{l}\text { The seat breaks during operation, } \\
\text { forcing the pilot to quit the } \\
\text { competition, and possibly harming } \\
\text { he/she with scratches. }\end{array}$ & 4 & 2 & 4 & 32 & & & & & \\
\hline Pedal clip & $\begin{array}{l}\text { The pedal clip breaks during } \\
\text { operation forcing the pilot to quit } \\
\text { the competition. }\end{array}$ & 2 & 2 & 4 & 16 & & & & & \\
\hline
\end{tabular}




\section{EIHzürich}

CYBATHLON

\section{Embedded system and sensing}

\begin{tabular}{|c|c|c|c|c|c|c|c|c|c|c|}
\hline Assembly & Failure \& Effect & S1 & 01 & D1 & $\begin{array}{c}\text { RPN } \\
\text { before }\end{array}$ & Preventing measures & $\mathrm{S} 2$ & $\mathrm{O} 2$ & D2 & $\begin{array}{l}\text { RPN } \\
\text { after }\end{array}$ \\
\hline \multirow[t]{2}{*}{$\begin{array}{l}\text { Inertial } \\
\text { sensor }\end{array}$} & $\begin{array}{l}\text { The sensor could stop } \\
\text { sending data, either } \\
\text { because the internal } \\
\text { battery runs out or some } \\
\text { other reason, which could } \\
\text { cause the system to send } \\
\text { incorrect stimulation } \\
\text { commands and, in hard } \\
\text { circumstances, lead to } \\
\text { falling. }\end{array}$ & 5 & 3 & 5 & 75 & $\begin{array}{l}\text { The software expects } \\
\text { the data from the } \\
\text { inertial sensor. In case } \\
\text { the data does not } \\
\text { come, it stops the } \\
\text { stimulation. }\end{array}$ & 5 & 2 & 3 & 30 \\
\hline & $\begin{array}{l}\text { The sensor could send } \\
\text { incorrect data. It could } \\
\text { cause the system to send } \\
\text { incorrect stimulation } \\
\text { commands and, in hard } \\
\text { circumstances, lead to } \\
\text { falling. }\end{array}$ & 5 & 7 & 5 & 175 & $\begin{array}{l}\text { The systems only starts } \\
\text { if the inertial sensor is } \\
\text { correctly calibrated. } \\
\text { That way, it is unlikely } \\
\text { that the sensor will } \\
\text { send incorrect data. }\end{array}$ & 5 & 3 & 2 & 30 \\
\hline $\begin{array}{l}\text { ARM- } \\
\text { based } \\
\text { linux }\end{array}$ & $\begin{array}{l}\text { The linux could crash in a } \\
\text { way that the stimulation } \\
\text { is still running. In some } \\
\text { circumstances, it could } \\
\text { lead to a crash. }\end{array}$ & 5 & 3 & 5 & 45 & & & & & \\
\hline $\begin{array}{l}\text { Wireless } \\
\text { user } \\
\text { interface }\end{array}$ & $\begin{array}{l}\text { The wireless user } \\
\text { interface could stop } \\
\text { working or not send the } \\
\text { correct data. In some } \\
\text { circumstances, it could } \\
\text { lead to a crash. }\end{array}$ & 5 & 3 & 5 & 45 & & & & & \\
\hline Battery & $\begin{array}{l}\text { The battery could run out } \\
\text { and shut off the system in } \\
\text { a way that the stimulator } \\
\text { keeps on. In some } \\
\text { circumstances, it could } \\
\text { lead to a crash. }\end{array}$ & 5 & 5 & 5 & 125 & $\begin{array}{l}\text { There is a "system turn } \\
\text { on checklist" which } \\
\text { includes checking the } \\
\text { battery levels. The } \\
\text { system must only be } \\
\text { turned on if there is } \\
\text { enought battery for the } \\
\text { session. Also, the } \\
\text { system checks the } \\
\text { battery regularly. If it is } \\
\text { low, it shuts everything } \\
\text { down safely. }\end{array}$ & 5 & 3 & 3 & 45 \\
\hline
\end{tabular}


Parte II

Anexos 


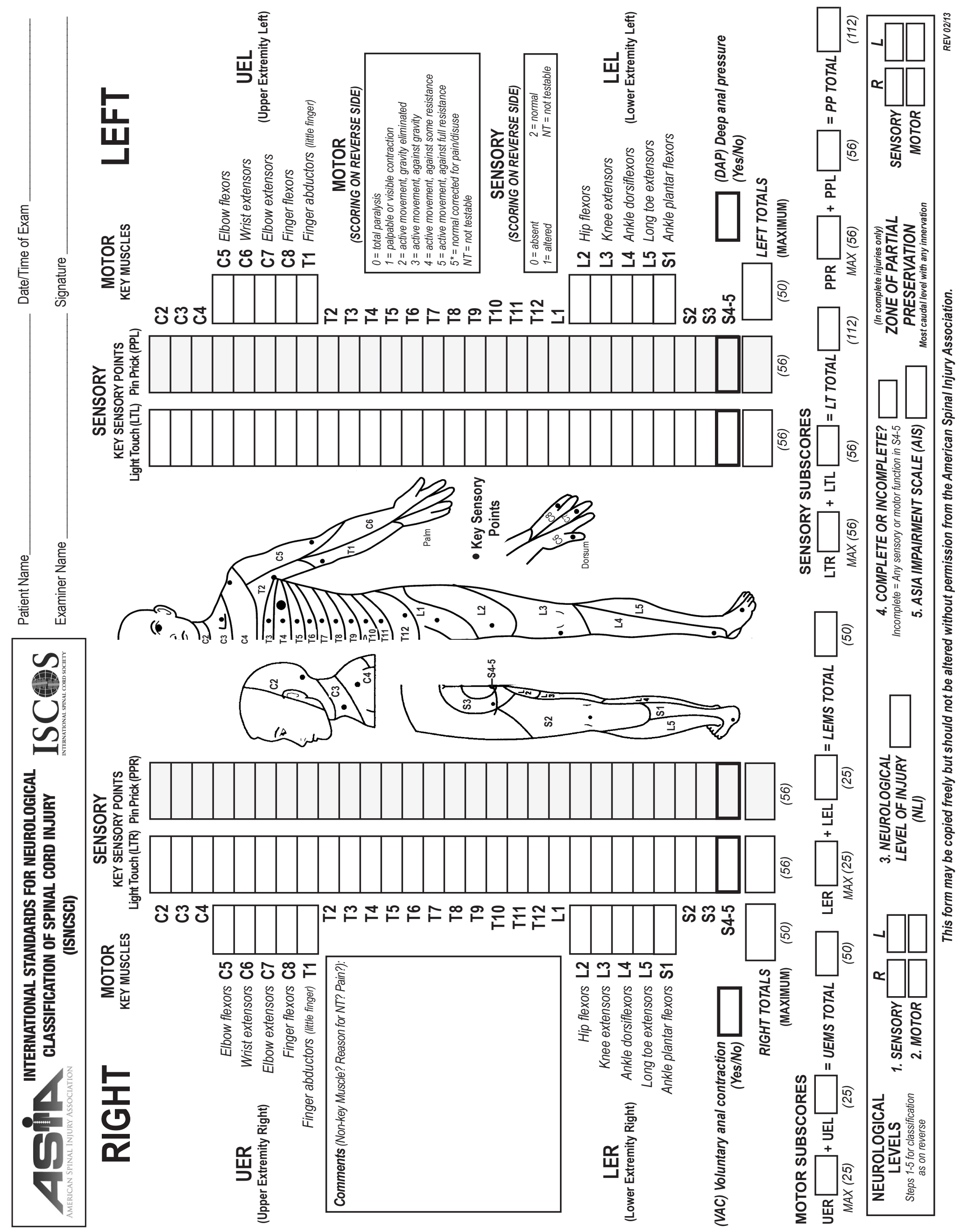



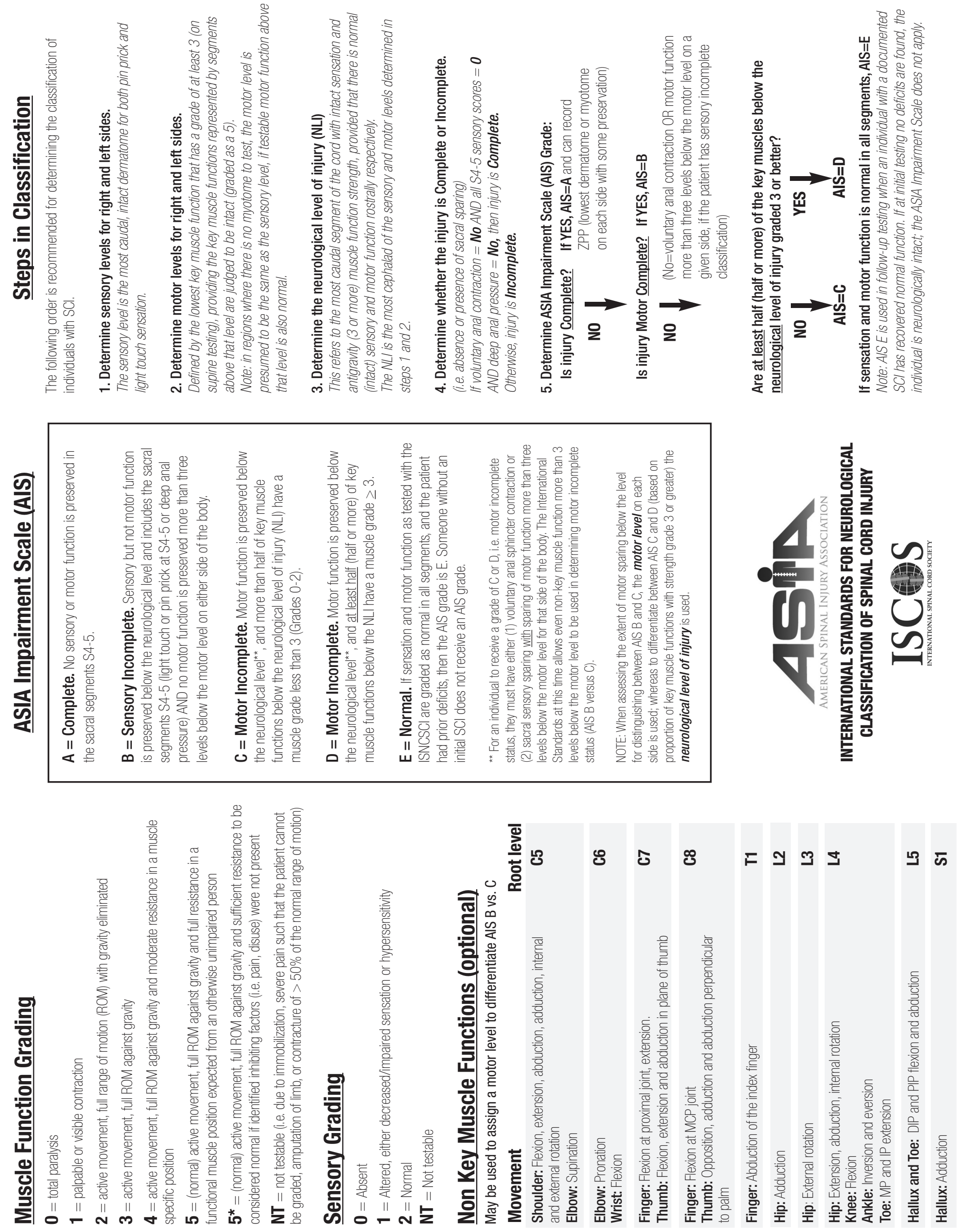